\title{
The inside story: \\ Early Childhood Practitioners' Perceptions of \\ Teaching Science
}

Kayte Edwards

2009

A thesis presented in partial fulfilment of the requirements for the degree of

Masters of Education

at Victoria University of Wellington,

New Zealand. 



\begin{abstract}
This thesis investigates early childhood teachers' perspectives of how they support children's scientific learning, and how they felt about the way they supported that learning, within one childcare centre setting. Using a qualitative case study approach the views of the six participants teaching at the research site were gathered during initial individual interviews. Participants were then asked to document situations where they noticed and recognised children engaged in scientific learning. In a second interview participants talked about the documentation they had gathered and what responses they had to what they had seen, if any. The interview data and participant documentation was then coded and collated into a matrix form in order to use the initial findings as the basis for a focus group discussion involving all participants. The transcript of the focus group discussion was then added to the initial findings and subsequently considered in light of Rogoff's (2003) three analytical foci (the personal, interpersonal and cultural-institutional). This enabled a broad spectrum of ideas to emerge and served to highlight several teaching strategies.
\end{abstract}

Three key findings emerged from the data. The first, a unique contribution of this study, highlights specific teaching strategies relating to the interdependent nature of team teaching relationships. The dialogue that developed between participants during the research emerged as a significant teaching support. The way the participants drew on each other's expertise, knowledge, experiences, and physical support was noticeable and often contributed to an individual participant's learning and increased confidence. On an individual level, the second finding concerned how capable and competent the individual participants felt about their support of children's scientific learning was related to their view of what 'science' is, and the role they thought the teacher should play in science education. This emphasises the importance of teachers having subject knowledge and a solid understanding of the nature of science (NOS). Furthermore, in this study the complexity of increasing the effectiveness of the support that early childhood teachers provide for children's scientific learning was revealed as the third finding. The influence of participants' confidence in and attitudes toward supporting children's scientific learning is further complicated when considering them in relation to the role of the teacher's understanding of NOS. Both of these factors have implications for the difference in teachers' available knowledge, skills and resources, and their inclination to use them. 
This thesis argues that there is no one solution to encouraging teachers to engage in more effective scientific learning support. However, reflective practice can enable teachers to develop their understanding of what science is and a pedagogy that will support the children's scientific learning, as well as increasing their confidence in and willingness to expand their scientific subject knowledge base. In addition, it also contends that collective teaching strategies are a significant factor in early childhood teachers' abilities to notice, recognise and respond to children engaged in scientific learning and as such need further consideration in teacher education, policy making decisions, and future research. 


\section{Acknowledgements}

The time it has taken me to undertake and complete this research has been a time of holistic learning, encompassing all aspects of my life. Not only have I learnt more about how early childhood teachers support young children's scientific learning but I have also learnt more about myself, my supports and my strengths.

First I wish to thank all those involved in the research - the participants who bravely shared their ideas and ideals, as well as the other staff, management, parents, and children at the research site - as without their trust and involvement this research thesis would not have been possible. I wish to also warmly thank Dr. Judith Loveridge, my supervisor, for her patience, competence and guidance on this research journey. Thank you also to the School of Early Childhood Education, and the School of Educational Policy and Implementation in the Faculty of Education at Victoria University of Wellington who facilitated grants and time to complete this project. Likewise, thanks to Susan Kaiser for her editing expertise and the staff at the WJ Scott Library at Victoria University. My heartfelt thanks also to the early childhood lecturing community at Victoria University whose research conversations, empathy, continued encouragement and support carried me on.

I wish to deeply thank my family - my parents, siblings and progeny - for not only their support of my single-mindedness but also their enduring belief in my academic capabilities. Likewise, thanks very much to my friends with whom we shared our research journeys, especially Margaret Wilkie; also Alan Witham who shared his knowledge of the English language. And finally I sincerely thank my wonderful companion HarrisParis Monaghan who sustained, believed and bemused me through the troubled times that accompanied this research.

Go in search of your gift.

The more you understand yourself, the more you will understand the world.

(Coelho, 2007, p. 19) 


\section{Table of Contents}

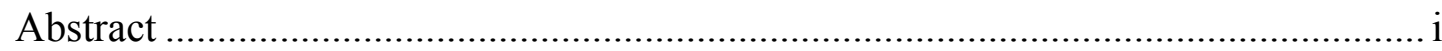

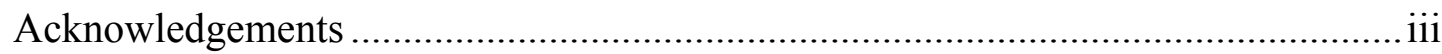

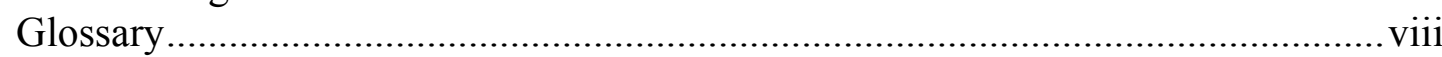

Chapter One: Introduction to Thesis ..............................................................1

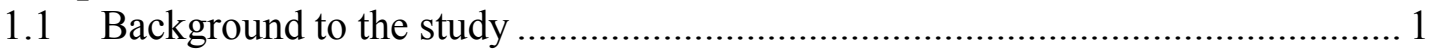

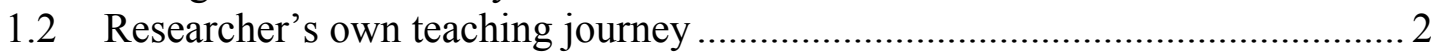

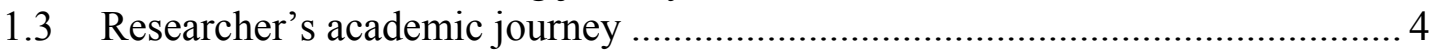

1.4 The inside story: Early childhood practitioners' perceptions of teaching science... 5

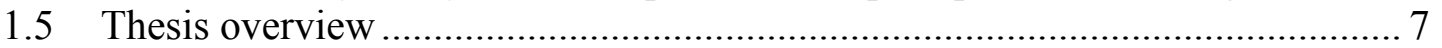

Chapter Two: Literature Review.................................................................. 8

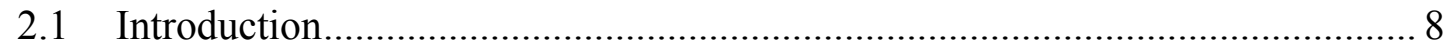

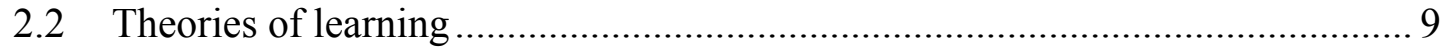

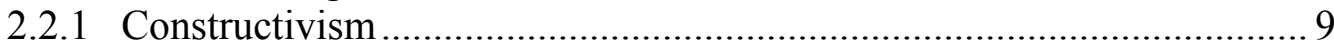

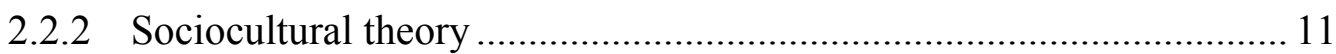

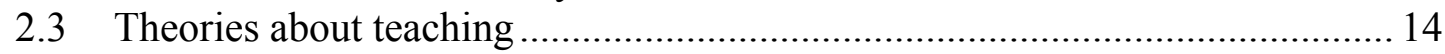

2.3.1 Pedagogical Content Knowledge (PCK) .......................................... 14

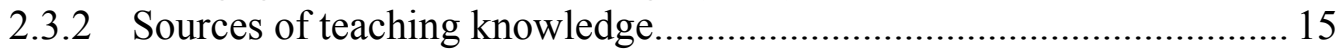

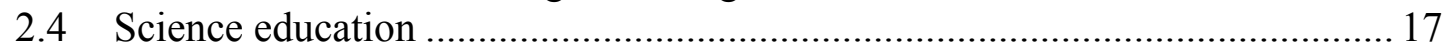

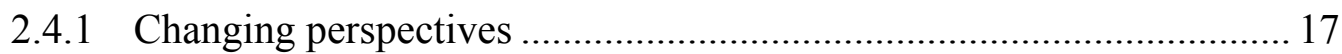

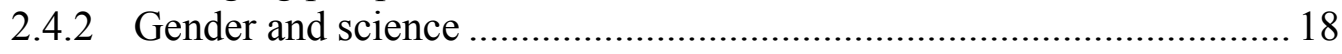

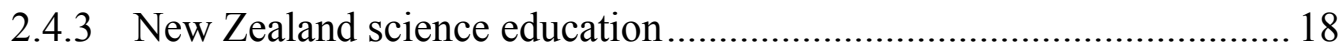

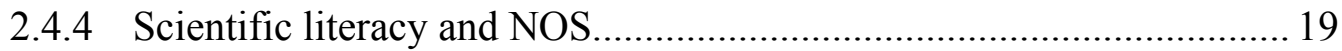

2.4.5 Teachers' scientific subject knowledge .......................................... 21

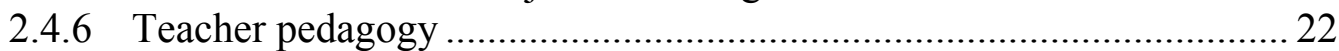

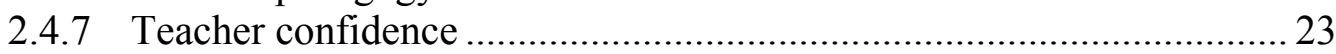

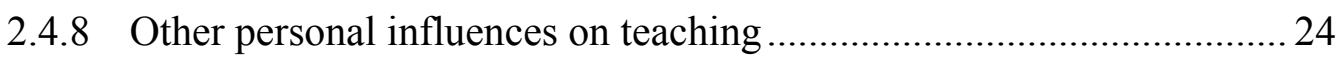

2.4.9 Individual teacher beliefs and team teaching .................................... 25

2.5 The New Zealand early childhood educational context................................ 26

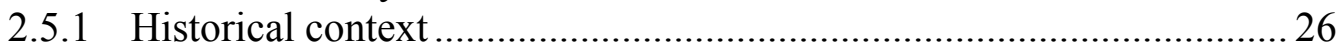

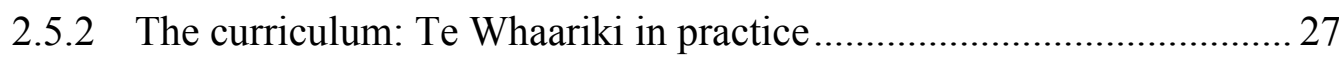

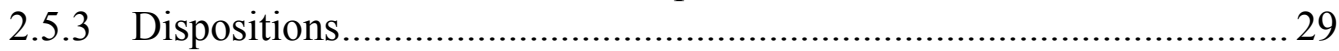

2.5.4 Te Whaariki and science .................................................................... 29

2.5.5 NZ Early childhood science education research ............................... 30

2.6 Rationale for research focus ........................................................................... 33

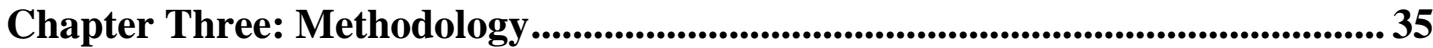

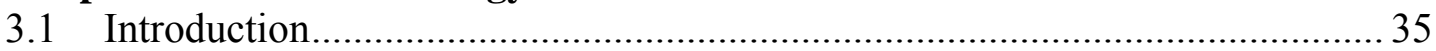

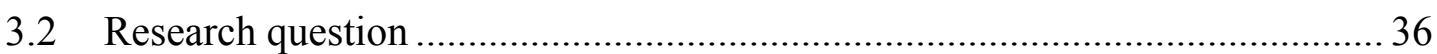

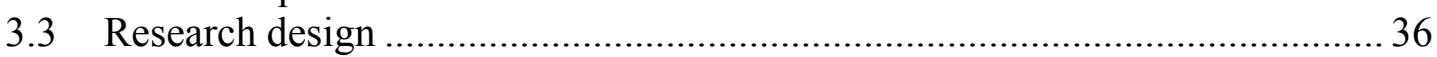

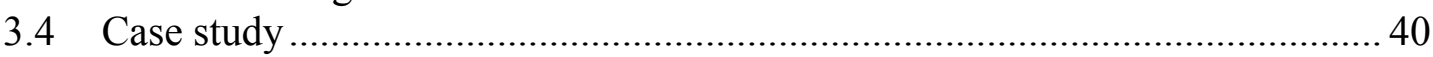

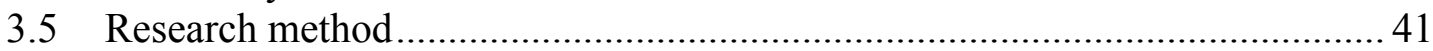

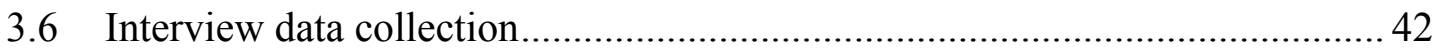

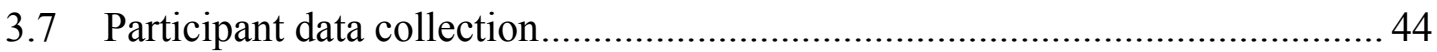

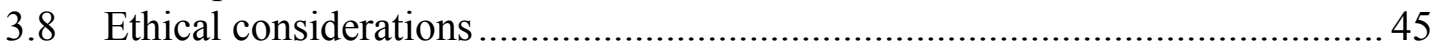

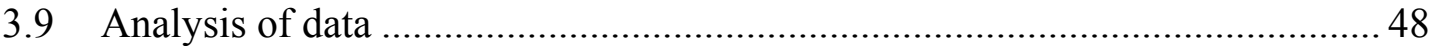

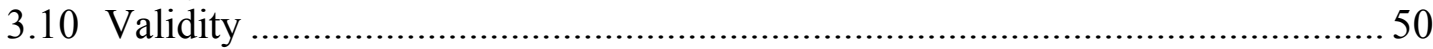

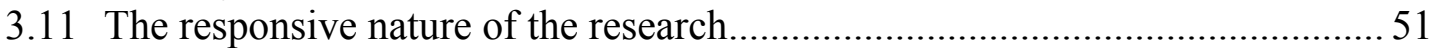

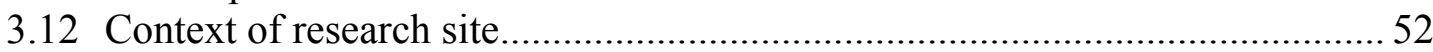




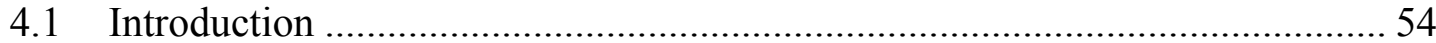

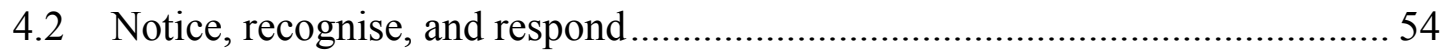

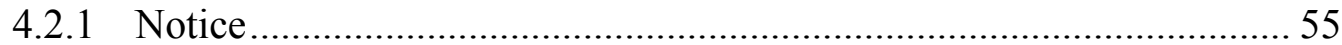

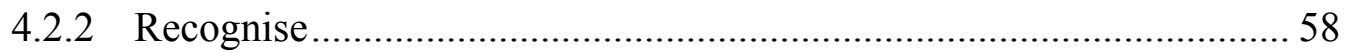

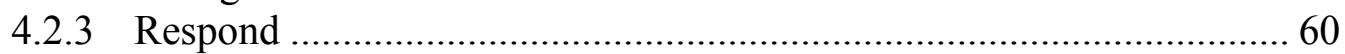

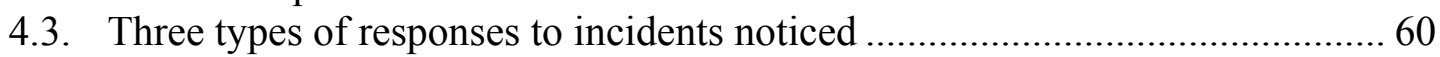

4.3.1 Supporting the child's increasing knowledge base............................. 61

4.3.2 Supporting the child's developing understanding and ability to use

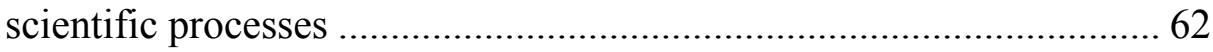

4.3.3 Supporting the child's scientific learning dispositions ........................ 63

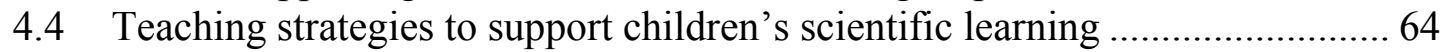

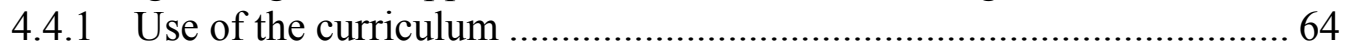

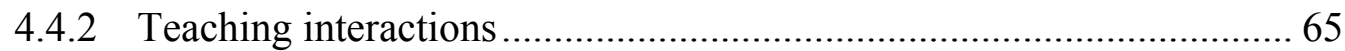

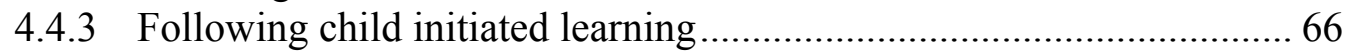

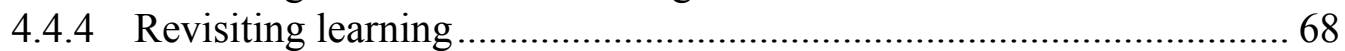

4.4.5 Planned responses: Daily activities and long-term responses .............. 70

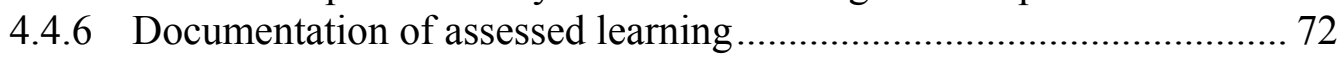

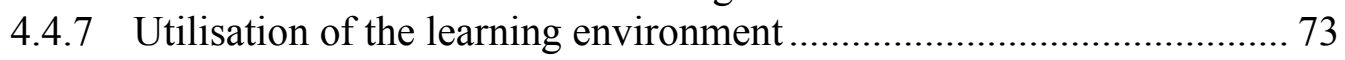

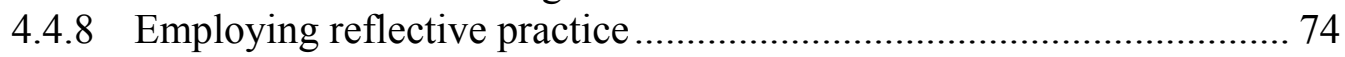

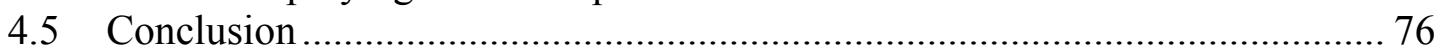

Chapter Five: Feelings about supporting young children's scientific learning....... 77

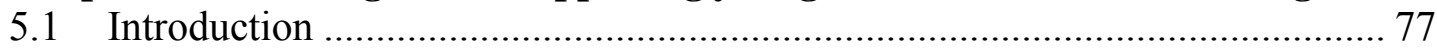

5.2 Confidence in, and attitudes toward, supporting children's scientific learning..... 77

5.2.1 Attitudes toward scientific content knowledge.................................. 79

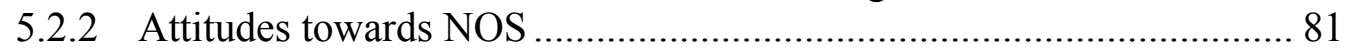

5.2.3 Attitudes to learning opportunities ................................................... 84

5.3 Day-to-day realities: Barriers and enablers in supporting children's

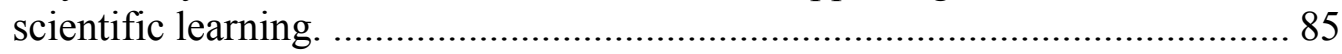

5.3.1 Teaching infants, toddlers and young children in one setting ............. 86

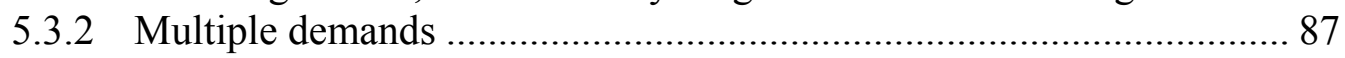

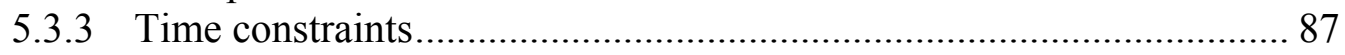

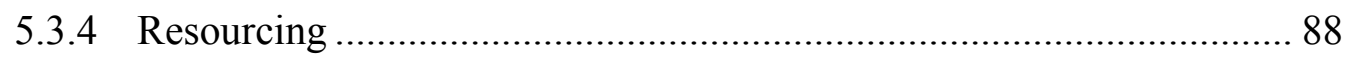

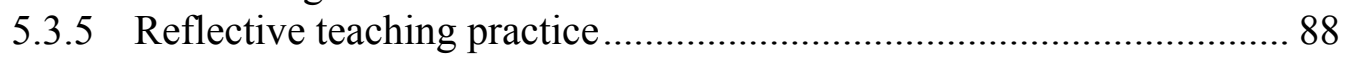

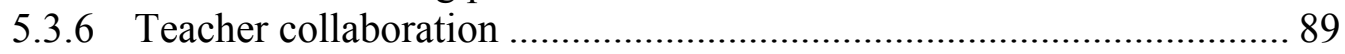

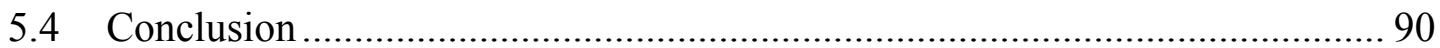

\section{Chapter Six: Taking personal, interpersonal and cultural-institutional} foci of analysis.................................................................................... 92

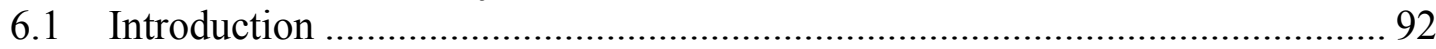



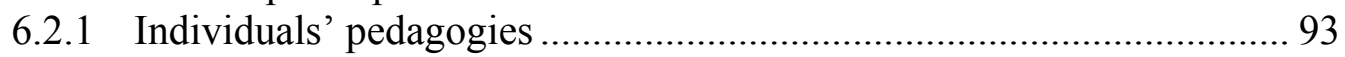

6.2.2 Individuals' understandings of NOS ................................................ 97

6.2.3 The influence of individuals' perceptions of their subject knowledge ..... 98

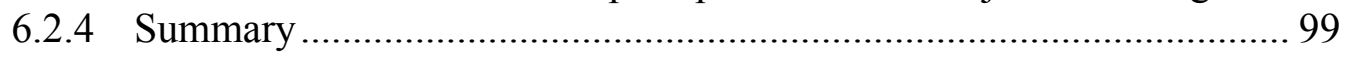

6.3 The interrelationships between participants ................................................. 101

6.3.1 Debate, reflection and development of teaching ideas ...................... 101

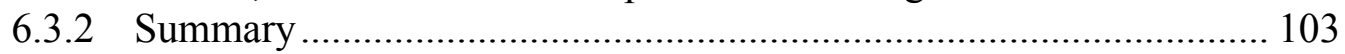

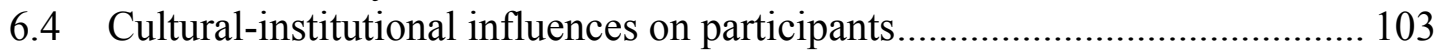

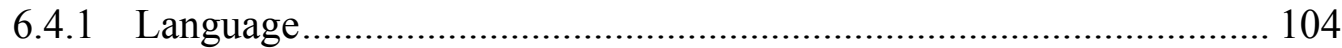

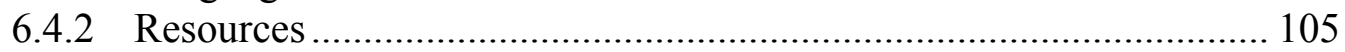

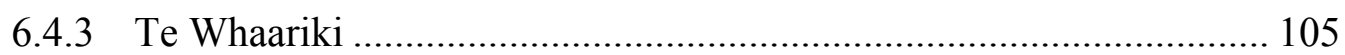




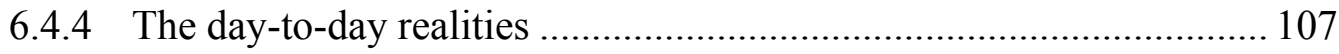

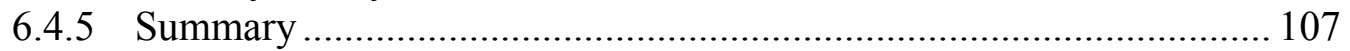

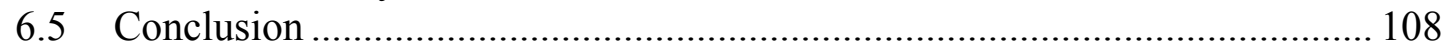

Chapter Seven: Conclusion ........................................................................... 110

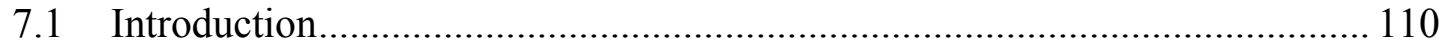

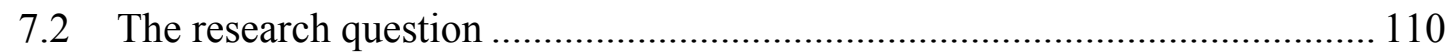

7.3 Key research findings and implications....................................................... 111

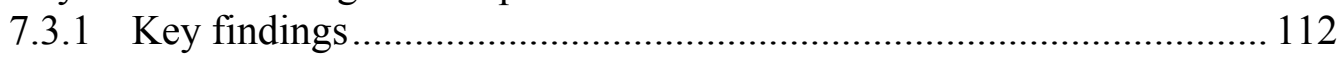

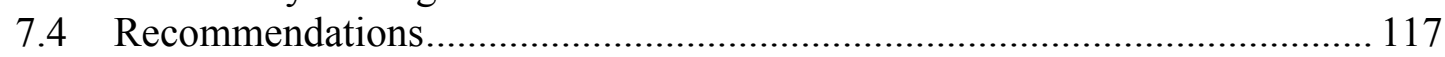

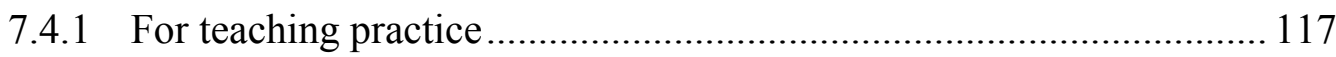

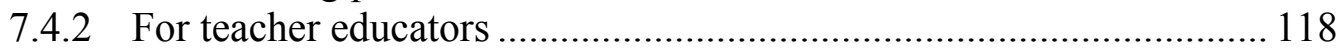

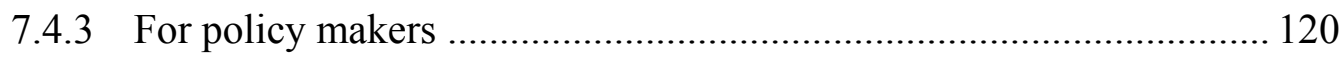

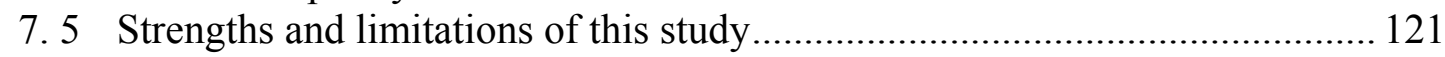

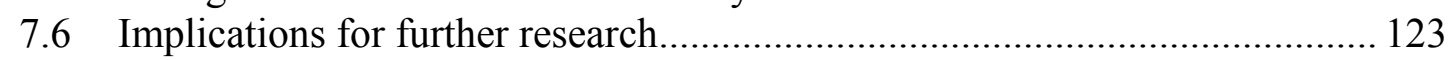

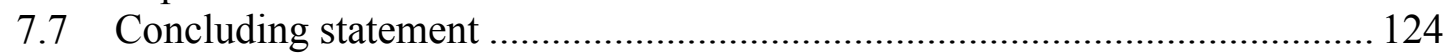

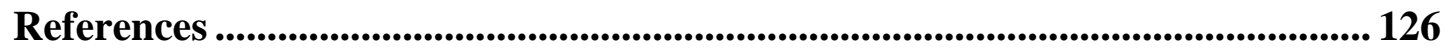

\section{Appendices}

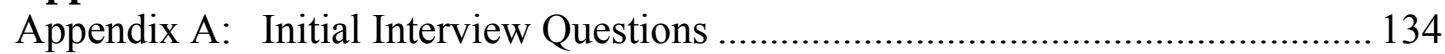

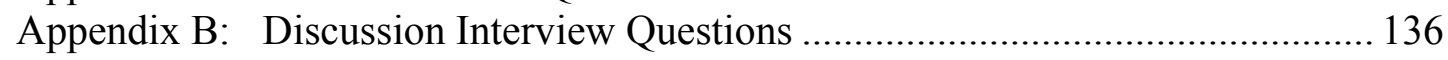

Appendix C: Focus Group PowerPoint (minus the pictures) ............................... 137

Appendix D: Analysis of Incidents Noticed by Participants.................................. 142

Appendix E: Analysis of Photographic Data Collected by Participants................ 143

Appendix F: Management Information Sheet .................................................. 145

Appendix G: Management Consent Form....................................................... 147

Appendix H: Participant Information Sheet...................................................... 149

Appendix I: Teacher Participant Consent and Request Forms ............................ 151

Appendix J: Participant Focus Group Information Sheet ..................................... 153

Appendix K： Participant Consent and Request Forms - Focus Group Only .............. 154

Appendix L: Parent Information Sheet ................................................................. 156

Appendix M: Parent Consent and Request Forms .............................................. 158

Appendix N: Photo Dissemination Permission ..................................................... 160

Appendix O: Analysis of Participants' Teaching Strategies ................................. 161

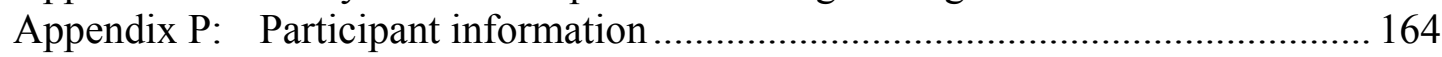

Appendix Q: The story of viscosity: A narrative ................................................ 168

Appendix R: The sandpit story: A narrative ...................................................... 170

Appendix S: Participant Teaching Strategies Comparison..................................... 172 


\section{List of Tables}

Table 1: Demographic aspects of incidents observed and data sources..................... 56

Table 2: Participant descriptions of their teaching interaction with children ............ 66

Table 3 Participant quotes relating to following children's interests in a

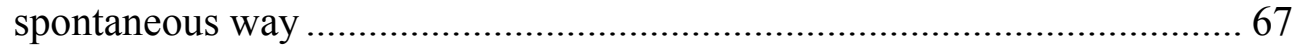

Table 4: Changes in participants' confidence level pre-study and post-study ............... 78

Table 5: Participant answers to: "What do you think early childhood science is?"

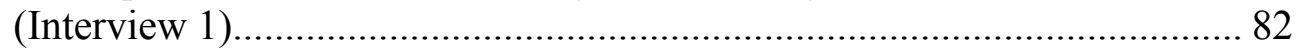

Table 6: Participant comment on their own scientific learning ................................ 84

Table 7: Comparisons of participants' preferred teaching strategies........................ 95

\section{List of Figures and Photographs}

Figure 3.1: Diagram of research methods ...................................................... 42

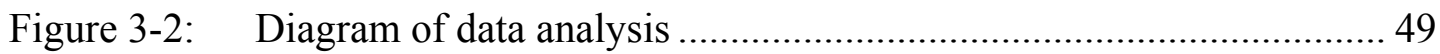

Photograph 1 Young child making castles............................................................ 57

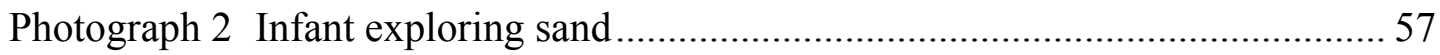

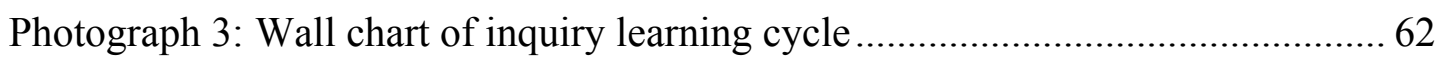

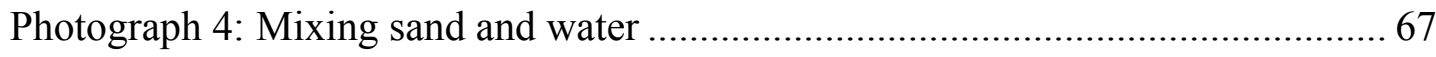

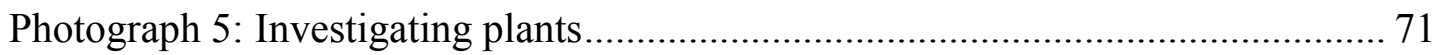

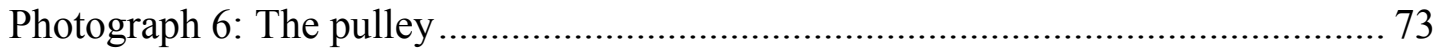

Photograph 7: Children helping to clean the fish tank .............................................. 73

Photograph 8: Young child exploring balancing with friends ................................ 74 


\section{Glossary}

\section{NOS - the Nature of Science}

For the purposes of this thesis the five most common tenets of NOS proposed by Adb-ElKhalick, Bell \& Lederman (1998, cited in Heap, 2006) have been used. While they are listed separately it is important to remember these ideas are also interrelated.

1. Science is not static and cannot claim absolute truths because it is subject to change with new evidence.

2. Science comes from observations of the world around us from which interpretations are made.

3. Science is not an orderly accumulation of knowledge and requires imagination and creativity to explain the things observed. This idea challenges the misconception that the scientific method is the only way to do science as there is no single method.

4. Scientists can interpret the same data sets differently so it is not possible to make truly objective observations and interpretations without any bias from the observer. This is because of a difference between scientists' prior knowledge, background, experiences, and theoretical beliefs.

5. Scientific knowledge is produced within a larger society and culture. It is influenced by politics, economy, power structures, religion and philosophy.

PCK Pedagogical Content Knowledge

\section{Tangata whenua}

(noun) local people, hosts, indigenous people of the land - people born of the whenua, i.e. of the placenta and of the land where the people's ancestors have lived and where their placenta are buried. (Moorfield, 2005)

TCS The Correspondence School

\section{Whaanau}

(noun) extended family, family group, a familiar term of address to a number of people. (Te Kākano Textbook (Ed. 2). (Moorfield, 2005) 


\section{Chapter One: \\ Introduction to Thesis}

\subsection{Background to the study}

Young children may be regarded as 'natural scientists' - curious, experimental, explorative, and persistent in their desire to understand the world they observe around them (Backshall, 2000). Yet past research has identified that early childhood teachers' ability to support children's scientific interests is questionable. Concerns raised in the past (Fensham, 1991) are still relevant now (Fleer, 2001). Through researching teacher practice, a variety of factors influencing teachers' reticence to engage in supporting children's scientific interests have been identified. These are primarily the individual teacher's confidence in, and attitudes to, teaching science (Fleer, 2001; Garbett, 2003; Hedges, 2002; Kallery \& Psillos, 2001), teachers having insufficient (Alexander, 2000; Hedges, 2002) or inconsistent use of their scientific subject knowledge (Hedges, 2002), and teachers' lack of understanding of the Nature of Science (known as NOS) (Alexander, 2000; Garbett, 2003; Heap, 2006; Lederman, 1992). To gain a deeper understanding of this issue the research for this thesis proposes to focus solely on the teacher's perspective of how they support a child's scientific learning in one setting. Consequently a qualitative, interpretivist case study methodology has been adopted to encapsulate the possible broad spectrum of ideas the teacher participants may have, rather than the researcher taking a specific focus on one factor. In adopting a flexible data gathering approach it is anticipated that the depth and breadth of information gathered will illuminate how the teachers feel about influences already identified, with the possibility of identifying additional influences.

The early childhood curriculum, Te Whaariki, which guides teacher practice within the New Zealand setting takes a holistic approach that integrates the learning goals related to science throughout the document. In not taking a subject-based approach the knowledge, skills and attitudes that are promoted are diverse and are intended to link to the child's other learning experiences. The curriculum primarily reflects sociocultural theory (Cullen, 2001; Edwards, 2003; Kilderry, 2004; Nuttall, 2004; Robbins, 2003) and encourages teachers to support children's development of "their working theories for making sense of the natural, social, physical, and material 
worlds" (Ministry of Education, 1996, p. 82). The teacher's role is seen as one of supporting children's understanding of the world, rather than imparting the teacher's own culturally specific understandings (Snively \& Corsiglia, 2001). Government documents such as Kei Tua o te Pae (Ministry of Education, 2004) encourage teachers to 'notice' children interested in scientific ideas, 'recognise' the scientific concepts and processes they are investigating, and 'respond' in order to support their own understanding of the world they live in (Cowie, 2000, cited in Ministry of Education, 2004, booklet 1). Children leading their learning can be a significant problem for generalist teachers (Bibby, 1999) as it requires teachers to engage in supporting all the interests the child has, not just those that the teacher knows more about. Unfortunately, if teachers are not noticing children engaged in scientific learning they are unable to support the child's increased understanding of the phenomena under investigation, that is, they are unable to recognise and respond.

\subsection{Researcher's own teaching journey}

Having been an early childhood teacher for many years, the proposed research reflects my experiences and pedagogy as a practitioner as well as a researcher. The awareness I developed and barriers I personally faced in encouraging children and student teachers' scientific learning are evident in the desire to gain a breadth of understanding from the teacher's point of view, enabling an articulation of the 'teacher's voice' to add to that of the researcher's voice, previously documented.

Like other teachers at the time, the school education and subsequent teacher training I received in the 1960s and 1970s was greatly influenced by the theories of Jean Piaget (Higgins \& McDonald, 2008). My student teacher notes define science teaching as "nothing more than a particular way of going about helping children understand why objects in their worlds are, what they are, and why they behave as they do" (personal communication, tutorial notes, 1975). The teacher's role was largely one of resourcing a "rich environment" and asking "thought provoking questions" which supported the "discovery method" (personal communication, tutorial notes, 1975) of science learning. The teacher was encouraged to allow the children to discover for themselves in order to learn. 
By the year 2000 I had become an experienced teacher having worked in kindergartens and child care centres throughout New Zealand as well as briefly in Australia. I considered myself well informed of the shifts that had occurred in early childhood education during the last twenty-five years of teaching with the advent of a new early childhood curriculum, Te Whaariki (Ministry of Education, 1996), and subsequent government documents. At this time $\mathrm{I}$ was working at The Correspondence School (TCS) with parents of 3-5 year-olds delivering a distance early childhood model of education to children in isolated situations. Using a variety of communication styles the parents and I would exchange information on resources and activity ideas I sent, and how the child had responded to them. Having a strong philosophy of working in partnership with parents I was surprised to realise how much I had led the learning agenda in previous teaching situations. Sending out a suggested programme of activities for parents to carry out with their children was initially challenging as it required a higher degree of articulation about my teaching beliefs and practices than had been previously necessary. As parents implemented the programme in line with their experiences, beliefs and practices I often found their subsequent replies also equally as challenging.

While working with families in the Taumarunui area one winter a series of storms resulted in several long power cuts and the parents - all mothers - wrote to me requesting help answering children's questions. I duly sent out the TCS electricity resource pack encouraging them to get the child to make the light go on in the circuit kit. The return postings were favourable but indicated most of the mothers had not engaged in the experiment. Instead many had encouraged their husbands to become involved. They were also commenting that they felt they were still unable to respond to their children's questions about power cuts. I quickly organised a school day, packed my bags and set out for rural Taumarunui. After a day of investigating and talking about circuit boards and torches I found that while the parents had as much, or more, understanding of the electricity than me, they were still not confident in supporting their children's interest in the topic.

As I returned to Wellington I reflected on my own understanding of the electrical phenomena. Still seeing electricity as flowing much like a tap I realised I had a lot to learn and that my previous understanding of the concept was at the root of my inability to support the understandings of the children, and parents, I was working 
with. This experience initiated a renewed interest in understanding electricity and other scientific phenomena, awakening my awareness of the everyday nature of science. Somehow science had become decontextualised and I had come to see others' explanations of phenomena as more worthy than my own. On reflection I also realised that while I had little more scientific knowledge than before, I was now beginning to use it to make sense of the world around me as well as increasingly encouraging children to do the same.

\subsection{Researcher's academic journey}

Having started reading about teaching, learning, and science I have eventually become a researcher and teacher educator specialising in supporting children's scientific learning. I am increasingly aware of the lack of scientific subject knowledge and unusual understandings student teachers have of scientific concepts. I am also increasingly aware that institutional parameters are a significant constraint in addressing these issues. How to best support student teachers to encourage children's scientific learning is a significant and hotly debated issue. While there appears to be a call for increased emphasis on scientific subject knowledge during teacher training (Garbett, 2003; Haynes, 2000; Kallery \& Psillos, 2001), I believe this alone will not prove a solution and may reinforce naive views of NOS that see science as a set body of facts to learn. Advice on how to educate teachers is abundant (Ginsburg \& Golbeck, 2004; Yoon \& Onchwari, 2006) and while considerable New Zealand research centres on teacher training programme possibilities (Garbett, 2003; Haynes, 2000), there appears to be no evidence of the effectiveness of these once the teacher is in the field.

Overseas research points to teachers working in a more prescribed, traditional manner where they lack subject knowledge (Alexander, 2000). This presents a serious concern given New Zealand's socioculturally led preferred pedagogy, which encourages the teacher to support the child's learning as opposed to executing a series of pre-planned activities. Recent New Zealand researchers have questioned teachers' understanding of the sociocultural theories underpinning Te Whaariki (Brennan, 2007; Hedges, 2002; Jordan, 2003; Nuttall, 2002) and have pointed out the importance of teachers' specific subject knowledge when they teach this way (Hedges \& Cullen, 2003). Increasingly teachers nationally and internationally are encouraged to engage in further professional development learning and integrate it 
into their own teaching situation in a reflective manner (Cochran-Smith \& Lytle, 1999). However, I believe science remains an unattractive topic for teachers to focus their reflection on due to the strong influence of teachers' beliefs and attitudes, many of which are formed during their own schooling experiences (Bandura, as cited in Hedges \& Cullen, 2003; Pajares, 1992).

Until Helen Hedges' study in 2002, New Zealand research on teachers' attitudes to science was scarce. Her thesis investigated the beliefs about subject knowledge held by teachers, parents and children in one kindergarten setting. She examined the ways in which children's subject knowledge was extended and enriched, and how beliefs influenced curriculum and pedagogy. Hedges' data showed that subject knowledge can add depth and substance to children's learning. While subject knowledge was evident during planned teaching interactions, Hedges found that it was "underemphasised in the majority of spontaneous interactions" (Hedges, 2002, p. 146), which accounted for most of the time the children were at the centre.

\subsection{The inside story: Early childhood practitioners' perceptions of teaching science}

The proposed research project hopes to build on Hedges' (2002) work seeking to explore, in greater breadth and depth, teachers' perceptions of science and how they believe they support children's scientific learning. My previous experience as an early childhood educator and research participant is reflected in the paradigm and methodology chosen. With an understanding that personal changes in my perception of science increased my ability to support children's scientific interests, I believe a greater understanding of other teachers' perceptions may lead to a greater awareness of how teachers might be encouraged to revisit and revise their awareness, interest and knowledge development in this area.

Along with other current New Zealand early childhood researchers (Brennan, 2007; Hedges, 2002; Jordan, 2003), I have adopted a sociocultural theoretical base which has influenced the approach, methodology, and type of questions asked in the study, as well as the way data are interpreted and represented. In adopting a qualitative, interpretivist case study approach I wished to gain a greater understanding of the complex and interrelated factors influencing early childhood teachers' perceptions of 
their teaching practices in regard to scientific learning. The proposed research strives to represent the views of one group of teachers in a holistic manner within one context and was designed to possibly empower the participants and be responsive to the context of the research site. Contextualised within the New Zealand early childhood community the researcher and participants share a common understanding of New Zealand early childhood concepts and terminology.

The specific question chosen for this research was: What are professionally trained early childhood teachers' understandings of, and feelings about, the way they support young children's learning in science? Eight sub-questions were developed to give further definition to the inquiry. These looked at what the research participants' views of science were, what they felt had informed their views, how they thought they supported children's scientific interests, and how they felt about that support, as well as the influences on their teaching they thought supported or hindered them in this role.

Data was gathered by individual participants as well as the researcher conducting individual and group interviews with participants. After an initial individual interview each participant gathered observational data, mainly photographic, for three days in a sequential manner over a five-week period. Each participant then had a second interview about the data they had collected before the data were analysed using a coding and matrix system. These initial findings then formed the basis for the group focus interview, the transcript of which in turn became new data. All data were then analysed further and finally considered in light of Rogoff's (2003) three foci of analysis to consider personal, interpersonal and cultural-institutional aspects. During the data gathering period a science teaching discourse developed amongst the participants who noted that their general awareness of science learning occurring within the centre environment was heightened. On an individual level the increased awareness led to teachers evaluating and developing their own personal teaching strategies and beliefs about supporting children's scientific investigations and some of these were documented in the focus group interview. In light of this it is hoped that the articulation of teachers' views in this study will also provoke reflection in the wider early childhood education community and possible changes in present teaching practice. 


\subsection{Thesis overview}

In this chapter I have introduced the topic, research question and the rationale for these choices. In the next chapter, the literature review, I present the theoretical basis for the study looking at constructivist and sociocultural theories of teaching and learning. Literature more specific to science education is then considered bringing in research on the influences of teachers' knowledge base and teaching pedagogy. The New Zealand early childhood context is then explored looking specifically at the curriculum, Te Whaariki, and issues that recent New Zealand early childhood researchers have identified in regard to teachers' support of children's scientific learning. Chapter Three presents information on the qualitative, interpretivist case study methodology employed. It also describes the methods used in gathering, collating and analysing the data.

The research findings are presented in the fourth and fifth chapters. Chapter Four looks at the participants' views of how they teach, while Chapter Five focuses on how they feel about their teaching. Chapter Six discusses the findings in light of three analytical foci, as proposed by Rogoff (2003). Each focus involves looking at the findings in different ways and, while inter-related, these have been used to help collate the broad range of responses from participants. The different foci also enable the data to be examined in regard to the individual teachers, the teaching team as a whole, and finally institutional or community factors. Finally, Chapter Seven presents the main findings and a discussion of the implications and recommendations. The chapter concludes with a discussion of the strengths and weaknesses of this study and the implications for further research. 


\section{Chapter Two: \\ Literature Review}

\subsection{Introduction}

Children's understanding of the world they live in is constantly developing. From the moment of birth the desire to understand what is observed provides motivation to engage in experiences that eventually lead to a greater understanding of scientific concepts. The degree to which New Zealand early childhood teachers are able to support children's scientific understandings has been questioned in previous literature (Cullen, 1996). Continued New Zealand and international research has identified substantial barriers (Fleer, 2001; Garbett, 2003; Heap, 2006; Hedges, 2002; Kallery \& Psillos, 2001; Russo \& Rennie, 2003). However, there is little known about how the teachers view the issue. This chapter seeks to explore the literature on teaching and learning about science in the early years of a child's life. It starts by broadly looking at aspects of constructivism and sociocultural theories of learning. Research on the influences of teacher attitudes and perceptions of teaching practice are then considered along with research on the effects of teachers' subject knowledge on teaching practice. Lastly, aspects of New Zealand early childhood teaching are examined and recent research is considered to contextualise the study.

Australians Fleer and Robbins (2003) comment on the limited number of science education researchers with backgrounds in early childhood being "clearly evident in both the literature and through their absence at international science conferences" (p. 2). As a consequence, literature in the area of early childhood science is minimal (de Kock, 2005; Garbett \& Yourn, 2002; Heap, 2006; Hedges, 2002; Hedges \& Cullen, 2003). Due to this the literature reviewed in this chapter also looks at aspects of junior primary science education. However, it is important to note that most early childhood teachers in New Zealand will teach in a collaborative team unlike teachers in the primary school sector. An international research perspective is also included although the definition of 'early childhood teaching' varies internationally. USA and Australia include children up to the age of 6 or 7, and along with England they exclude children under the age of 3 . In New Zealand, early childhood education covers children from birth to 5 or 6 years of age. It should also be noted that the literature reviewed here reflects a western cultural perspective due to research 
coming from the UK, USA, Canada, Australia and New Zealand. As a consequence, the cultural assumptions made by past researchers are evident (Fleer, 1997) and situate the proposed research within a western paradigm.

The literature for this review has been sourced in a variety of ways. An initial library search of science related books and journals revealed very little specific information. However, the references the authors had drawn upon gave excellent pointers to where more literature might be located. Conversations with fellow researchers also resulted in information relevant to acquiring recent literature on the research topic. A series of web searches was also conducted, using a variety of key words for searching, as well as search engines (Google, Scholar, Alta Vista). This produced a variety of material some of which was not academic, requiring a moderating process of the literature gathered. The last source of literature was an audit of recent early childhood theses completed in New Zealand. This identified research specifically located within the New Zealand early childhood context.

\section{$2.2 \quad$ Theories of learning}

\subsubsection{Constructivism}

The dominant theoretical concept relating to learning science is constructivism. It provides a "basis for understanding how people incorporate new knowledge into existing knowledge and then make sense of that knowledge" (Ferguson, 2007, p.28). There are a variety of forms of constructivism, each seeing the influence of the social context, role of language and balance of power to varying degrees. Personal constructivism places a greater emphasis on the individual rather than other aspects and has been critiqued for ignoring "the socially and historically situated nature of knowledge" (Bell, 2005, p. 43). As Lorsbach and Tobin (1993) point out, while the learning process is an individual act, "the inner voices of persons can be supplemented by discussion with others" (p. 3), such as peers or teachers. In this way social constructivism places a greater emphasis on the social and cultural aspects of learning. However, the effectiveness of a social constructivist approach depends on the teacher having an adequate scientific subject knowledge base to recognise prior learning and misconceptions (Harlen, 1999). 
While a personal constructivist approach was initially more dominant in educational discourses, more social-constructivist ideas have gradually been adopted. Now critical constructivists are challenging others to consider the wider societal influences of culture and power (McNaughton, 2004). For critical constructivists, meanings are constructed within a culture over which the child has little control. This can distort, limit and even exclude the meaning of things "due to the conditions under which the meaning takes place" (p. 46).

British academic Traianou's (2006) literature review on primary science education looks at research recommendations in regard to teachers lacking subject knowledge. She classifies the research as taking a "small range" (p. 282) constructivist stance of viewing knowledge as a commodity that teachers use, or having a focus on "big ideas" (p. 832) emphasising the role of social interaction and more knowledgeable others in acquiring scientific concepts. Both these approaches, she points out, assume there is a universal body of scientific knowledge for teachers to acquire "essentially decontextualised and able to be applied across situations" (p. 834; original emphasis). Whether increasing teachers' knowledge of specific facts, where a teacher is seen as a passive receiver of knowledge, or developing teachers' broader conceptual understanding and "procedural knowledge" (p. 833), which sees the teacher as capable of learning "under guidance of another more knowledgeable person" (p. 834), there is an assumption that teachers' increased subject knowledge will also increase the effectiveness of their teaching.

Instead Traianou prefers a sociocultural approach to knowledge and understanding which sees the adequacy of teachers' subject knowledge as more complex, incorporating their ability to use the cultural tools of science such as language. In this way, Traianou contends, researching how teachers use their knowledge is a greater indicator of what knowledge the teacher holds. Her own research highlighted that 'teachers' science subject knowledge develops over time in contingent ways" (p. 838). She recommends teachers have opportunities to become engaged with complex scientific ideas, as well as time to reflect on how they might be employed in teaching. In this way a teacher's understanding of scientific concepts is intertwined with their understanding of pedagogy. The research described in this dissertation has a sociocultural approach to constructivism and seeks to understand how teachers think they use their knowledge in supporting children's scientific learning. 


\subsubsection{Sociocultural theory}

Sociocultural theory currently provides the dominant theoretical base driving New Zealand early childhood teaching practice (Brennan, 2007; Cullen, 1996; Jordan, 2003). Deriving from Lev Vygotsky's work, seen by some as the "forefather of sociocultural approaches" (Anning \& Edwards, 2006, p. 56), it has its origins in the writings of Karl Marx. The sociocultural approach to learning sees individuals as inseparable from the context in which they are located and the activities they are engaged in (Rogoff, 2003); thus learning and development are seen to be shaped by the cultural values and practices that surround the child. There are a variety of sociocultural theories that offer different interpretations and emphasise different aspects of the theory (Higgins \& MacDonald, 2008). A commonality is seeing a model of the mind "that is primarily, but not entirely, a decoding, sense making mind, which engages with and is shaped by the world" (Edwards, 2001, p. 170). In interpreting and ascribing meanings to events and objects the mind is mediated by a variety of factors, some as obvious as conversations and texts while some are more subtle such as "socio-historical expectations of particular settings and which allow particular ways of being in the world" (Edwards, 2001, p. 170).

Vygotsky (1987, cited in Fleer, 2008) saw concept formation on two levels, the everyday and scientific. On the everyday, or "spontaneous" (Wells, 2008, p. 335) level, concepts are "learned as a result of interacting directly with the world" (Fleer, 2008 , p. 283) and embedded in the context in which they are learnt, reducing their ability to be used in other situations. However, they also form the foundations for learning scientific concepts, which in turn are strengthened by the child's understanding of everyday concepts. When the everyday concepts and the scientific concepts are brought together in children's learning, they "begin to link concepts in relation to knowledge outside their practical experiences" (p. 290). Fleer found in her study of Australian pre-schoolers that "without focussed teacher-child interactions at the scientific level, only everyday concepts could develop" (p. 294). This is of significance if there is a reliance on the resources and the environment to enhance learning rather than the teacher's role. Fleer points out the importance of language in providing children with the "vocabulary to describe the concepts emerging from the investigations" (p. 294) and provide models for its use. She highlights the way playful contexts can help young children "bring together their everyday concepts with scientific concepts" (p. 299). 
The role of the adult in supporting children's learning occurs in what Vygotsky called the Zone of Proximal Development (Rogoff, 2003) and occurs as children interact with more skilled partners using the tools provided by their culture for thinking. A variety of preferred teaching strategies are used to "provide the appropriate teaching assistance at the right time to move children forward in their learning" (Hedges, 2000, p. 20). Some such as co-constructing meanings with children are more empowering and encourage the child's higher order thinking (Jordan, 2004) while others such as scaffolding and guided participation provide differing degrees of teacher assistance for a period of time (Hedges, 2000). However, all support the child's integration of their prior knowledge and present experiences to develop a greater understanding of the concept. The next section explores sociocultural theory, looking further at some specific theoretical concepts that are of particular relevance to the research proposed in this thesis.

\subsubsection{The personal, interpersonal and cultural-institutional foci of analysis}

Barbara Rogoff is one of several theorists who have built on Vygotsky's initial work. She emphasises that learning is a process of "people's changing participation in the sociocultural activities of their communities" (Rogoff, 2003, p. 52; original emphasis). While still taking a holistic and integrated approach, Rogoff poses a "transformation of participation perspective" (p. 52) to learning that sees the personal, interpersonal and cultural aspects of human activity as "different analytical views of ongoing, mutually constituted processes" (p. 52). That is, while one aspect may be focused on, the other aspects should also be kept in mind as "they cannot exist in isolation" (p. 97). Although this theory was initially proposed with regard to children, it is just as relevant for any learner, teachers included (Manning \& Loveridge, 2009). In light of this, Rogoff's ideas are used in this study to describe the complexity of early childhood teaching by taking three planes - the personal, interpersonal and cultural-institutional - as a focus of analysis on the data findings.

The personal plane focuses on the individual learner and the way they incorporate knowledge, transferring their understanding of the activities they are involved in. Social influences are considered in the interpersonal plane which focuses on "the mutual involvement, communication and coordination" (Robbins, 2003, p. 97) between the learner and others as they participate in cultural activities. In this way the roles of peers, parents and teachers are considered. The interactions with the 
learner may be in formal situations, but they also include other "forms of participation in culturally guided activities through the use of particular tools and involvement with cultural institutions" (Rogoff, 2003, p. 284) such as the child care centre in this case study. This links to the third cultural-institutional plane, which examines cultural tools, and dominant views and practices of the community and institutions within it. In bringing in a focus on the cultural-institutional plane it becomes more evident that the goals and visions held by one group of people may not be those held by another group. As Rogoff points out, "each community's valued skills constitute the local goals of development" (1990, p. 12) and the societal practices that support children's development are tied to those values and skills. The choices of what activities or societal practices children have access to, and the use of language to bridge understandings between the child and others, are the two

processes by which children are guided in learning (Rogoff, 2003). In this way the skills a child may attain in one culture might not be deemed appropriate in another as they are related to the child's opportunities to observe and participate in social practices where they are able to practise those skills (Rogoff, 2003).

\subsubsection{Cultural tools/artefacts}

Culture is not static, neither are cultural tools or the ways in which they are used. From birth children use a multitude of cultural tools that they adapt for their own purposes, thus inheriting and transforming them "by successive generations" (Rogoff, 2003, p. 51). "Learning takes place in an activity in which the tool serves a recognisable purpose and assistance is available from more skilled participants in the activity" (Wells, 2008, p. 347). Cultural tools refer to both material tools, such as the physical objects used in everyday life, as well as psychological tools, such as language, symbols, systems and processes. In this way scientific concepts are also cultural artefacts "proposed, revised and improved over many generations by the community of professional scientists" (Wells, 2008, p. 346). Wells sees the scientific concepts as powerful tools that individuals learn to use for particular purposes. These are not only the physical paraphernalia and language associated with science, but also the scientific concepts themselves and the process by which they were derived. The role of the teacher is seen as guiding children to be competent users of the cultural tools, or artefacts, of their society (Anning \& Edwards, 2006). As such this requires the teacher to also be competent in the use of these tools. 


\subsubsection{Communities of practice}

In seeing learning as a social endeavour, several researchers have also explored collaborative learning situations. Focussing on learning through interactions within a group, Wenger (2000, as cited in Macklin, 2007) coined the term 'communities of practice' to describe groups of people who share a concern or a passion about a practice, learning more and gaining expertise by interacting on an ongoing basis. Here knowledge is seen as socially constructed through discussion, debate and discourse within the group. Communities of practice are distinguished by having varying levels of expertise and a movement of its members from novice to expert (Macklin, 2007). As not everyone is expected to be an expert in everything but is expected to take an active role, there are times when the novice in one situation is the expert in another: "As the members of the community move in and out of various roles, they begin to develop their own interests in pursuit of the common goal, thus taking on their identity in the group" (Macklin, 2007, p. 207).

New Zealand early childhood teachers typically, though not necessarily, work in teams and as such often operate within communities of practice (Cullen, 2001; Jordan, 2003). The philosophical statement of each early childhood setting should reflect the nature of that learning community as it is constructed by the individual learning identities of the teachers employed and the community in which they teach. As Jordan (2003) says, "our participation in a community shapes our identity at the same time as we are shaping the community" (p. 27). While not the focus of this study, it is anticipated that the influence of the interactions between the teacher participants in the same teaching team will be evident in the research data.

\subsection{Theories about teaching}

\subsubsection{Pedagogical Content Knowledge (PCK)}

Teaching is acknowledged as a "complex activity that requires a myriad of knowledge, skills and capabilities" (Hedges, 2000, p. 16). What these are, how they are acquired, and to what degree an effective teacher requires them has been a subject of research for many years with several ideas about 'knowing more' and 'teaching better' being proposed. Perhaps the most well known is Shulman's (1986) work, proposing categories of knowledge required for teaching. While identifying several areas of knowledge required for effective teaching, Shulman focused mainly on the category he 
termed Pedagogical Content Knowledge (PCK). He defined this as "the blending of content and pedagogy to an understanding of how particular topics, problems or issues are organised, represented and adapted to the diverse interests and abilities of learners, and presented as instruction" (Shulman, 1986, p. 8). That is, PCK is a form of knowledge that connects what the teacher understands about a subject to their teaching ability and knowledge of the learner. PCK is also seen as "a continually changing construction of knowledge" (Miller, 2007) where teachers actively engage in continual learning. Miller's (2007) critique of PCK highlighted an assumption that specific subject knowledge can inform the teacher of "superior teaching methods for that subject" (p. 89), thus seeing specific teaching methods as more relevant to specific subjects. Yet considering the individual nature of the teacher and of the prior learning of the student it seems logical that teachers' teaching strategies will vary with each individual teaching situation as well as when teaching different subject matter. It should also be noted that these ideas relate to the individual teacher in isolation of the teaching environment. As teachers also work in teams, perhaps another type of knowledge to consider is that of the learning community's collective knowledge.

\subsubsection{Sources of teaching knowledge}

American teacher researchers Cochran-Smith and Lytle (1999) have synthesised previous research on the relationship between knowledge and teaching practice, and classified them into three perspectives. They see each perspective as creating different types of knowledge, although they have been critiqued as focusing more on who produces the knowledge rather than what types of knowledge are produced (Fenstermacher, 1994). Regardless of this, it appears that each perspective is reflected in the New Zealand context and worthy of consideration. The first perspective "knowledge-for-practice" sees teachers' knowledge as "produced primarily by university-based researchers and scholars in various disciplines" (Cochran-Smith \& Lytle, 1999, p. 255; original emphasis). This approach assumes that quality teaching is related to the ability to acquire, retain and retrieve knowledge. This approach requires a high degree of specific subject knowledge which can be a "serious issue for the generalist" (Bibby, 1999, p. 230) early childhood teacher who is required "to have sufficient knowledge across a number of fields" (Kallery \& Psillos, 2001, p. 177). This raises the question of how much general knowledge teachers need to effectively support children's scientific learning. Or perhaps there is never enough given Hedges' 
(2002) research findings that children's knowledge may be more comprehensive than teachers', "particularly when it is domain- or discipline-specific" (Hedges, 2004, p. 4).

The second perspective, "knowledge-in-practice" views teaching as "situated and constructed in response to the everyday life in schools and classrooms" (CochranSmith \& Lytle, 1999, p. 262; original emphasis). In this perspective teachers' knowledge is acquired as a result of reflection on their own teaching experiences and through interactions with more 'expert' teachers. In this way the knowledge base is created within the teaching profession through reflective practice. However, this can perpetuate existing teaching behaviours, both positive and negative. In the case of science it is possible that a reluctance to teach science in some teachers (Fensham, 1991; Fleer, 2001) is transmitted to other novice teachers. It appears that reflection is also a key element in this type of knowledge base and may be evident in the research findings as an indicator of knowledge-in-practice.

The last perspective, knowledge-of-practice, has been the focus of Cochran-Smith and Lytle's (1999) own research. It sees teachers as knowledge creators, not needing to just absorb existing knowledge from academics or experts but also creating their own. Those researchers taking this perspective see teaching as connected to a wider political and social agenda, expanding the view of what 'practice' means to encompass relationships with children, their families and the community. This leads to knowledge being socially constructed by teachers, children, parents, the community and academics with the end product of "a locally developed curriculum and more equitable social relations" (p. 274). This is congruent with sociocultural teaching approaches and sees the way early childhood teachers construct a curriculum of learning as influenced not only by the children's historical and cultural influences but also the teachers'. As it is the teacher who makes the curriculum choices, their ability to hear and follow the voice of the child requires reflection and self-awareness. In Cochran-Smith and Lytle's (1999) knowledge-of-practice teachers become the researchers of their own teaching, in conjunction with universities. In doing so they are encouraged to deliberate over "what is regarded as expert knowledge, examining underlying assumptions, and making the lives of families and communities part of the curriculum" (p. 277). This creates the possibility that participation in the proposed research will have teaching consequences for the participants and the learning community in which they teach. 
This section of the literature review has considered constructivist and sociocultural theories examining the wide theoretical paradigm underlying the research proposed for this thesis. Shulman's (1986) theory of PCK has also been introduced along with Cochran-Smith and Lytle's (1999) literature syntheses collated around teachers gaining "knowledge-for-practice", "knowledge-in-practice" and "knowledge-ofpractice" (p. 255-274). The next section focuses on general issues that have arisen in regard to science education and more specifically in regard to the New Zealand situation.

\subsection{Science education}

\subsubsection{Changing perspectives}

As the world has advanced in science and technology, so too has the way we have seen science education. Grobstein (2005) describes science now as "the ongoing creation, revision and recreation of stories" (p. 13). The move from a permanent view of knowledge to more fluid and ubiquitous descriptions has brought about changes in teaching practices. Science education is now seen to be more the alteration of children's prior conceptions rather than "giving explanations where none existed before" (Levitt, 2001, p. 3). This has presented some teachers with the challenge to adapt and change teaching practices which also means an examination and development of their own views of what science is. Past personal constructivist theories encouraged teachers to focus on "preparing children for scientific vocations and maintaining the status quo of authoritarian science" (Millar \& Osborne, 1998, as cited in Watters, Diezmann, Grieshaber \& Davis, 2001, p. 2). More recent social constructivist teaching practices have encouraged the teacher to scaffold children's learning (Watters et al., 2001) by acting as a facilitator. Now critical constructivist ideas, seeing the child as an agent of change and co-constructor, encourage teachers to centre on the development of investigative skills and related attitudes and values with more of an emphasis on developing "scientifically literate citizens" (Watters et. al., 2001. p. 2). Lemke (2001) sees this as positioning science education as "human social activities conducted within institutional and cultural frameworks" (p. 296) resulting in teaching variations based on a country's educational paradigm, the age of the child and the teacher's personal pedagogy. He sees this approach requiring teacher reflection on what kinds of "personal identity and cultural values" their "science teaching accepts, rejects or is compatible with" (p. 300). 


\subsubsection{Gender and science}

The consideration of personal identity is of particular relevance in relation to gender. Early childhood in New Zealand is a predominantly female profession (Farquar, Cablk, Buckingham, Butler \& Ballantyne, 2006). Past researchers who have looked into why girls do not engage with science studies, or take on employment in the field, have explored the nature and extent of the problem but "not produced a solution" (Gilbert \& Calvert, 2003, p. 861). Gilbert and Calvert looked into New Zealand women scientists' understandings of themselves and science. Their findings led them to question the "extent to which sexual difference pervades and frames Western thought” (p. 876). This, they say, needs to be explicitly acknowledged if assumptions around masculinity and 'rational' thought processes of science are to be challenged. In acknowledging the socially constructed nature of how 'science', 'masculinity' or 'femininity' might be conceived, they suggest that reflection on preconceived notions of 'femininity' and 'science' would encourage more women to become engaged with the topic. Once again it appears that reflection is seen as a key ingredient to teacher development. It is anticipated that data in this study will also indicate the ways in which teachers employ reflective practices in the support of children's scientific learning.

\subsubsection{New Zealand science education}

Most of the science education research in New Zealand has been in the compulsory education sector. The curriculum documents in this sector are clear that there are three kinds of learning outcomes that teachers should concurrently be encouraging children's development in. These are content or conceptual outcomes, procedural or skill-based outcomes, and NOS outcomes (Ministry of Education, 2007). In 2002 the New Zealand government commissioned a literature review to look into previous national and international research on effective primary school teaching practice/pedagogy. The review identified the interconnected nature of the many different variables identified in research and emphasised that raising science achievement levels in classes would not be achieved by addressing each variable in isolation. It stressed the significance of teachers' "beliefs about the nature and characteristics of scientific inquiry" (p. 231) in shaping the child's learning experiences. Jones \& Baker who were involved in the review later commented that tThe report recommended research into "teachers' beliefs and perceptions about the nature and characteristics of science and the purpose of science education" (Jones \& 
Baker, 2005, p. 141). The literature review itself concluded that science learning could be more effective and inclusive when:

- learners' existing ideas and beliefs were ascertained and linked to classroom experiences

- the teacher knew the science content and set learning at an appropriate level of challenge

- the purpose of the learning was made clear to the student

- $\quad$ students' conceptual knowledge, procedural knowledge and knowledge of NOS were developed together

- $\quad$ students were engaged in thinking about their own thinking

- teachers modelled and scaffold conversations and investigative skills

- $\quad$ and engaged in formative interactions to help students as they learnt (Hipkins et al., 2002).

It is anticipated that the early childhood teachers in the proposed research will use similar teaching strategies to support children's scientific learning although a comparison of their strategies will ascertain this.

\subsubsection{Scientific literacy and NOS}

The idea of developing scientifically literate citizens has been at the heart of science education for more than fifty years (Heap, 2006). It involves an understanding of "the theories, principles, concepts and processes of science, and an appreciation of the complex relationships between science, technology and society" (Abd-El-Khalick \& Boujaoude, 1997, cited in Heap, 2006, p. 10). While not necessarily scientists, scientifically literate citizens understand the everyday nature of science and are able to confidently engage in public debate and informed decision-making (Watters et. al., 2001). An important part of scientific literacy is having an understanding of NOS. The concept of NOS refers to "science as a way of knowing, or values and beliefs inherent to the development of scientific knowledge" (Akerson, Buzzelli \& Donnelly, 2007, p. 750). Hipkins, Barker and Bolstad (2005) noted that while there is no one unified view of NOS, there is a "level of generality regarding NOS ideas that are acceptable to school students" (p. 244). Heap (2006) points out this is "partly because it is a social construct and as such is neither universal nor stable" (p. 14). 
New Zealand researcher Heap (2006) looked at a cohort of early childhood and primary teachers enrolled in a Bachelor of Education course, examining their views of NOS before and after the course. She adopted Adb-El-Khalick, Bell \& Lederman's (1998, cited in Heap, 2006) definition of NOS, and used the five interrelated tenets of NOS they had proposed in her research. These have been adopted as a definition of NOS for the proposed research for this thesis. They are that the NOS is: tentative; empirical; inferential, imaginative and creative; subjective and theory laden; and finally socially and culturally embedded (p. 16) (see Glossary). Heap, in finding congruence with previous research, concluded that, "teachers' ideas are naive rather than consistent with contemporary understandings of NOS" (p.157). Heap argues these understandings are an important part of developing scientific literacy, something today's children need "in order for them to fully realise the benefits of and participate in an increasingly scientific society" (p. 171). However, as Monk and Dillon (2000) point out, while a teacher might have an understanding of NOS there is no guarantee this will be part of their teaching. Hipkins et al. (2005) suggest this is largely due to "educational traditions and day-to-day classroom realities" (p. 247). Heap's thesis is the only local literature on NOS and early childhood teachers, nationally and internationally. The concept of NOS does not appear to be reflected in the early childhood curriculum, Te Whaariki (Ministry of Education, 1996) although is very evident in the compulsory sector's New Zealand Curriculum Framework (NZCF) (Ministry of Education, 2007).

In 1992 an American researcher, Lederman, conducted an international literature review on NOS, and although the literature has developed significantly since then Lederman's work still provides context and raises some important points. Lederman proposes that research in this area had initially centred on students' understandings of NOS and ways to develop these. Researchers then turned to studying teachers' understandings of NOS. However, this approach assumed that teachers' views significantly influenced student views and while Munby (1976, cited in Lederman, 1992) linked the language teachers' use with students' developing understandings of NOS, Lederman predominantly cites research that considers other factors that influence teachers' classroom practice and impact on their understandings of NOS, such as "institutional and instructional constraints" (Lederman, 1992, p. 347). Although Lederman stresses that developing teachers' views of NOS is only one way to improve science education, none of the other influences mentioned are outside of 
the classroom context, such as parents' and peers' view of NOS, perhaps reflecting the age of this literature. However, Lederman's main proposal that "teachers cannot teach what they do not understand" (p. 351) still appears significant. In regard to NOS he proposes that teachers need to learn how to teach NOS as well as having their own developed notion of what it is. In considering this idea it becomes necessary to acknowledge that the participants' views of NOS in the proposed research for this thesis may be embedded and not easily articulated.

\subsubsection{Teachers' scientific subject knowledge}

Past research has highlighted the lack of scientific subject knowledge many early childhood teachers have, linking this to their ability to teach science (Fensham, 1991; Fleer, 2008; Hedges, 2002; Parker \& Heywood, 2000). Reasons for this have been connected to the limited opportunities the teachers have had to study science (Garbett, 2003), the teaching methods employed in those opportunities (Gilbert \& Calvert, 2003; Haynes, 2000) and the societal positioning of what science is seen as (Gilbert \& Calvert, 2003; Waters-Adams, 2006). Several inter-related factors influence the teacher's acquisition of knowledge (Fleer, 2008; Waters-Adams, 2006), some of which are quite subtle, such as the teacher's images of science and gender (Gilbert \& Calvert, 2002), or their view of the child's capabilities (Fleer, 2009). However, scientific knowledge is necessary if a teacher is to extend a child's scientific learning (Fleer, 2009; Hedges, 2002; Smorti, 2005). It enables the teacher to keep in mind "both the everyday practice where the concept is used/built and the core concept that is to be taught" (Fleer, 2009, p. 1074), making links between the everyday and scientific concepts.

In looking at student teachers' scientific knowledge Auckland teacher educator Garbett (2003) collated questionnaires from student teachers at the start of their study. She used a Likert scale to ascertain student teachers' views on their "confidence and competence in applying subject knowledge in early childhood settings" (p. 470), as well as a scientific knowledge test where the participants were asked to predict their score. Garbett found the teachers had better understandings in biology than other areas of science, as did Fensham, (1991) in Australia. She concluded that as well as the student teachers' subject knowledge being poor they were not aware of how "much they didn't know and how this might affect their ability to provide appropriate science experiences for young children" (p. 470). Appleton's (2006, cited in Fleer, 2009) research also found that teachers did not 
recognise the value of the subject knowledge gained through informal learning such as hobbies or interests. He argued that teachers' perceptions of science, PCK, and their scientific subject knowledge should be developed together, pointing out that "more science per se does not necessarily lead to an increased confidence, more science teaching, or better science teaching" (p. 1071).

How the knowledge is used by the teacher (Davis, 2003; Hipkins et. al., 2002; Shulman, 1986) and the teacher's ability to explain scientific concepts has also been of concern in past research (Watters et al., 2001). British researchers Parker and Heywood (2000), studying PCK and subject knowledge of British primary student teachers, recommended that teachers also learn about learning. They see science teaching as "not simply about knowing something", but also understanding, "having a coherent, causal explanation” (p. 89). They raise concerns regarding teachers' lack of personal scientific background, commenting that teachers "may themselves hold misconceptions of current scientific ideas" (p. 90), and warning that a lack of subject knowledge results in transmission teaching. This study seeks to explore how teachers feel about supporting children's scientific learning in regard to their own personal scientific backgrounds and beliefs about science.

\subsubsection{Teacher pedagogy}

If teachers' content knowledge is a crucial factor in quality science education then the knowledge base that is valued, the type of knowledge it is, and the degree to which it has been adopted by individual teachers becomes very important. Australian researcher Fleer's (2009) recent research examines teachers' "philosophical beliefs and assumptions about the young learner, and the corresponding pedagogies that are developed" (p. 1070). She found that teacher beliefs about how children learn are an important variable. Her study identified two philosophical stances, one that relied on the provision of materials to generate learning opportunities for the children with minimal teacher interaction, and another that built on children's scientific learning through either discourse or experimentation. This latter perspective valued the child's viewpoint and took into account their motives and goals. It also employed "teacher talk, which helped children to move beyond their everyday concepts" (Fleer, 2009, p. 1084). The findings of the study show that not only do children need adult mediation to increase their understanding of scientific concepts, but that teacher beliefs about how children learn is also an important factor in the way science is taught. 
Teachers' pedagogy is also largely influenced by what they see 'science' as (WatersAdams, 2006). In researching four primary school teachers, British researcher WatersAdams found the generalist teacher relies more on "core beliefs" (p. 938) than an "adherence to the epistemology of specific subjects" (p. 938). A clear link has been established between the way a teacher perceives scientific knowledge and the pedagogy they adopt, or on an individual level, "our understanding of science education as a subject is clearly a result of our perspective" (Johnston, 2005, p. 12). For example, Seefeldt and Galper (2002, cited in Yoon \& Onchwari, 2006) attribute teachers' reluctance to engage in teaching science to their misconceptions that science education is difficult to teach. Citing previous research, Alexander (2000) gives an example of the influence of pedagogy by linking the teacher's personal knowledge base to their ability to ask probing questions and encourage higher cognitive thought. "When teachers lack confidence to teach science they tend to use strategies which allow them to maintain control in the class room knowledge flow but which are not appropriate ways of engaging students in science" (Alexander, 2000, p. 35). Conversely when teachers have subject knowledge they are empowered to handle children's questions and turn them into investigations. Kallery and Psillos (2001) agree, adding that turning complex science questions into 'investigatable' ones is a skill not only because of the complexity of some questions but also "because their answers, even if the teachers know them, might not be accessible to children of such a young age" ( p. 176). However, they can form the basis of science investigations.

\subsubsection{Teacher confidence}

Researching into why teachers did not teach science, over eighteen years ago, Fensham (1991) found Australian early childhood student teachers perceived they had little science knowledge and held negative attitudes toward teaching science, and many academics believe this is still the case (Fleer, 2001; Garbett, 2003; Watters et al., 2001). Watters et al. (2001) noted the significant influence of a teacher's own schooling experience which was mainly "a passive, teacher collection of facts" (Garbett, 2003, p. 469). Earlier research by Harlen (1999, cited in Alexander, 2000, p. 25), when looking at Scottish primary school teachers, found that the experiences of those who did not relate to science during their own learning had done little to increase their confidence or understanding. She notes that in the USA, as in the UK, "many teachers are neither interested in science nor confident in teaching in it" ( $p$. 30). Waters-Adams (2006) found the teachers in his study acquired confidence only 
when there was a "resonance between their ideas about how to teach science, their understanding of the nature of science, and their general beliefs about how they should be teaching children" (p. 939). English educationalists Anning and Edwards (2006) agree, adding that teachers who are confident in their subject knowledge are more likely to recognise the potential learning and know how to maximise it. The research proposed for this thesis will need to ascertain the participants' perspectives of their confidence and attitudes towards supporting children's scientific learning.

Australians Russo and Rennie (2003) researched the attitudes to science held by young children and the responses of their teachers by analysing videotaped science sessions in three locations. They found that "the children appeared more interested in science when they were able to make their own investigations or draw their own conclusions with a minimum of direction from the teachers" (p. 78). Unfortunately while the children showed great interest in science, their teachers "seemed unaware of it or unable to respond to the attitudes of the children, instead pursuing their own attitudes" (p. 70). Commenting that it was likely that the teachers' preconceived ideas about learning science influenced the way they presented science to the children, they note the teachers' interest in developing the child's knowledge base rather than promoting positive attitudes toward science. Russo and Rennie concluded that "there seemed to be mismatch between the attitudes of the children and the purposes of the teacher" (Russo \& Rennie, 2003, p. 79).

\subsubsection{Other personal influences on teaching}

There are a variety of other factors seen to influence a teacher's personal pedagogy. Zembylas' (2004) research on teaching science sees emotion as significant in establishing and maintaining teachers' self-esteem, and as such constitutive of teaching and learning: "Emotions shape the learning and teaching experiences for both teachers and students, and the recognition of their significance merits further consideration in science teaching" (p. 370). As New Zealander Smorti (2005) comments, "the atmosphere and organisation obviously influences children's learning in science" (p. 17).

Akerson et al. (2007) see teachers' intellectual development as influencing their view of science teaching. They link Perry's earlier research (1999, cited in Akerson et. al., 2007) on the intellectual development of adult learners with views of NOS. They 
propose the adult learners move to relativism also as a move to acknowledging the multiplicity of scientific notions. This implies that teachers' personal learning around intellectual development can change their views of NOS.

\subsubsection{Individual teacher beliefs and team teaching}

Beliefs are connected to self-identity and as such are strongly held and deeply embedded within the individual. Hedges and Cullen (2005) describe them as mediating between the teacher's knowledge and their performance. As Levitt (2001) explains, when citing previous research in the area, teachers' actions are "guided by and make sense in relation to a personally held system of beliefs" (p. 4). The teacher's behaviour and actions are also influenced by "their continual development of their beliefs" (p. 5) because they are reinforced or modified by ongoing teaching experiences. In looking at the beliefs about science education of American elementary teachers, Levitt is clear that teaching decisions "depend on both the beliefs and knowledge of the teacher" (p. 4). In evaluating whether the teachers' beliefs had changed since a recently implemented programme of science education reform, Levitt concludes that the challenge of changing teacher beliefs is that "teachers, as individuals change at their own pace" (p. 20). This is relevant to this present study as it is twelve years since the implementation of New Zealand's first early childhood curriculum, and as discussed later in the literature review, this has required a change in many teachers' beliefs about early childhood education.

Reiterating the complexity in relating beliefs to practice, Rivalland (2007) notes the importance of considering "how people make meaning of their reality" (p. 31). Through field observations, analysing data and conducting interviews with three early childhood professionals working at one Australian child care centre, Rivalland concluded that the teachers had developed cultural practices demonstrated through the community discourse within the centre. However, she also noted that although the official discourse was used by all teachers, the degree to which they appropriated the ideas was "dependent on the individuals' personal interpretations and level of interconnectedness to their intricate belief systems" (p. 360). In light of Rivalland's study the participant comments in this case study are likely to reflect the degree to which each team member connects and adopts the common early childhood teaching discourse in the centre, as well as the discourse of the wider early childhood teaching community. 
The research considered in this section has highlighted concerns previously proposed by researchers regarding early childhood and primary school teachers' abilities to support children's scientific learning. While the majority of research in this area has been on the individual teacher, research has also been considered that acknowledges the influences within a collective team teaching approach. The proposed research for this thesis intends to inquire into the complexity of teaching in teams as well as individual influences on teaching. In the next section the early childhood educational context will be considered with specific reference to the area of scientific learning.

\subsection{The New Zealand early childhood educational context}

\subsubsection{Historical context}

In 1986 the New Zealand government united all early childhood care and educational services together under the auspices of the Ministry of Education (Smith, 2003). This significant act changed the face of early childhood education in New Zealand. It created a platform on which an understanding of early childhood education was built that existed from birth till formal primary schooling regardless of the environment the child was in. This was a significant unifier as the services making up the New Zealand early childhood sector are very diverse (Mawson, 2006).

In 1996 the New Zealand government published the first New Zealand early childhood curriculum framework, Te Whaariki (Ministry of Education, 1996). Created in dialogue with the early childhood community (Carr \& May, 2002), the document allowed a "consensus to form around acceptable practice" (Smith, 2003, p. 8) and promoted a "shared understanding and language in early childhood" (p. 7). From the government point of view, it formed "the basis for consistent curriculum and programmes" (Ministry of Education, 1996, p. 10) in all government funded early childhood centres. While New Zealand advocates a child-orientated play-based approach, the curriculum document is eclectic, relating to a number of educational theories, but has a strong sociocultural influence (Cullen, 2001; Edwards, 2003; Kilderry, 2004; Nuttall, 2004; Robbins, 2003). It encourages teachers to incorporate the theories of Bruner, Bronfenbrenner and Vygotsky into their practice and as a result there is an emphasis on linking to children's experiences outside of the educational setting and encouraging children to lead their own learning. However, Hedges cautions: "integrated, 
play-based, child-initiated approaches do not excuse teachers from being knowledgeable about subjects such as science" (Hedges, 2003, p. 2).

The document's bicultural nature makes it unique to New Zealand and has significantly influenced early childhood education in New Zealand. The curriculum pulls together four main Māori and European educational principles (family and community, empowerment, relationships, and holistic learning) (Carr \& May, 2002; Hemera, 2000). Interwoven through these are five strands with specific goals which are "distinctively appropriate for the early childhood years" (Ministry of Education, 1996, p. 10). These are underpinned by an aspiration statement that sees children as "competent and confident learners and communicators, healthy in mind, body and spirit, secure in their sense of belonging and in the knowledge that they make a valued contribution to society" (p. 9).

Since the release of Te Whaariki the government has published a series of documents to support its introduction and implementation. The latest of these has been Kei Tua o te Pae (Ministry of Education, 2004), a series of "examples of assessments that make visible learning that is valued so that the learning community (children, families, whaanau, teachers and beyond) can foster ongoing and diverse learning pathways" (Ministry of Education, 2004, booklet 5, p. 2). In regard to science, this suggests a communal view of children's scientific learning. However, there has been little research to examine the relationship between the scientific learning occurring in centres and that in community and family settings. Smorti's (2005) research suggests scientific learning in centres generally relies on the teacher to initially " notice' learning in science, 'recognise' scientific concepts and processes, and 'respond' to children's curiosity and interest in making sense of the world" (p. 19). Adapted from Bronwen Cowie's PhD thesis (2000, cited in Ministry of Education, 2004, booklet 1), these three processes are seen as progressive filters: "Teachers notice a great deal as they work with children, and they recognise some of what they notice as 'learning'. They will respond to a selection of what they recognise" (Ministry of Education, 2004, booklet 1, p. 6).

\subsubsection{The curriculum: Te Whaariki in practice}

Te Whaariki provided New Zealand teachers with a new way to view children's learning. In the 1960s New Zealand education was dominated by the ideas of Piaget 
and it was not until the 1990s that sociocultural theorists emerged in New Zealand publications (Higgins \& McDonald, 2008). However, it was the release of Te Whaariki in 1996 that brought about an awareness of the tenets of sociocultural theory for most New Zealand early childhood teachers. Unlike a content-based curriculum document, Helen Hedges (2007) cites Te Whaariki as an example of a curriculum where the teachers are the "key curriculum decision makers" (p. 12).

At the time of the document's release, New Zealand academics commented on the shift that was required in teachers' practices to make the curriculum effective. Cullen (1996) cautioned that Te Whaariki alone would not be sufficient to ensure the implementation of sociocultural theory in early childhood centre practices. She stressed the importance of teachers' subject and theoretical knowledge in order to acknowledge and extend children's learning due to the "cognitive dimensions of development and learning" (p. 119) being embedded in the guidelines. Subsequent government supporting documents also reflect their awareness of the pedagogical shift this document required practising teachers to make. Hill (2005) reiterated these views seeing the curriculum as making "complex and ambivalent demands" (p. 21) on teachers. Jordan (2003) agreed that definitions and models in Te Whaariki are not sufficient to bring about change, adding that it will only happen when teachers examine their own beliefs and practices. As Anne Smith (2003) commented, “a careful implementation of Te Whaariki requires thought, interpretation, reflection, careful planning, and observation" (p. 9).

Jordan (2003) proposed that it is through understanding the foundational philosophies of Te Whaariki that teachers are provided with "greater depth and more freedom in interpretation of its principles, within the centre's own sociocultural environment" (Jordan, 2003, p. 268). In her $\mathrm{PhD}$ thesis looking at co-constructed learning in professional development, she noted that "current early childhood practices in support of learning are generally based on the developmental model, favouring non-directive provision of equipment and activities interspersed with teacher-directed group activities" (p. 14). Although sociocultural theory has "become the accepted umbrella paradigm for learning" (p. 3), teachers are still "coming to terms with what the adoption of sociocultural theory might mean in practice, for children and for adults" (p. 3). Brennan (2007) questions if it is even possible to achieve a total alignment with sociocultural theory given the nature of early childhood education in New Zealand. In her $\mathrm{PhD}$ thesis 
looking at children's enculturation into a child care centre she proposed that "early childhood care and education practices remain individualised and separatist because of the cultural and social organisation of childcare centres" (Brennan, 2007, p. 3). Given this, one can only discuss the degree to which teachers' practice aligns with sociocultural theory, or the curriculum document, as opposed to taking a dichotic approach that sees it as aligning or not. It will be interesting to see to what extent these comments on the alignment of theory and practice will be reflected in the case study site for the proposed research for this thesis.

\subsubsection{Dispositions}

Anning and Edwards (2006) suggest that those involved in the education of young children focus on "helping children to become resilient learners, to enjoy learning and to feel that they are people who are able to learn" (p. 54). They see these dispositions as "orientations towards the world around us" (p. 54) and suggest teachers support the development of children's orientations or dispositions. In the New Zealand early childhood context the concept of dispositions is commonly linked to Margaret Carr's (1999) theory of learning dispositions. Carr describes a disposition as "a habit of mind that disposes the learner to interpret, edit, and respond to experiences in characteristic ways" (p. 85). She has identified five specific dispositions (courage, trust, perseverance, confidence and responsibility) and linked them to the five Te Whaariki curriculum strands (well-being, belonging, contribution, communication, and exploration). The concept of dispositions is very evident in current New Zealand early childhood planning, assessment and evaluation practices. Narrative observations linked to dispositions form the basis of assessment and are called 'learning stories'. Parents, family members and children are also invited to contribute information to complement the observations and comment on possible new lines of learning inquiry as the assessment process is designed to identify children's interests as a starting point for further learning. In light of this, it is anticipated that any references to participants' assessment of children's scientific learning in the proposed research will refer to this theory.

\subsubsection{Te Whaariki and science}

In 1994 Carr wrote a paper on encouraging teachers to see children in early childhood as developing "scientific thinking processes" (p. 28) as well as working theories or understanding about their environment. Two years later, as one of the 
curriculum writers of Te Whaariki, Carr was able to incorporate these concepts into the Exploration strand of the document, specifically the third and fourth goals which refer to learning "strategies for active exploration, thinking, and reasoning" (Ministry of Education, 1996, p. 88) and "working theories for making sense" (p. 90) of the natural, material and physical worlds. However, in taking a holistic approach, learning related to science is also evident throughout all of the document's curriculum strands and principles (Smorti, 2005).

As mentioned previously, critiques of Te Whaariki suggest that teachers' understanding of the theories that underpin the document, primarily sociocultural in nature, influence their ability to use the document effectively. This critique also holds true in regard to the teacher's understanding of science and scientific concepts and their ability to use Te Whaariki to support children's scientific learning (Nuttall, 2002). For example, Cullen (2008) noted that the narrative assessment approach that complements Te Whaariki depends on “the teacher's ability to notice what particular skills and content are relevant to children's interests" (p. 10). Hedges and Cullen (2005) suggest that the philosophical belief of a subject-based curriculum as inappropriate for young children has led to the exclusion of specific teaching and learning content. This has resulted in leaving "teachers without clear guidelines for content selection in curriculum and excused them from the responsibility to be knowledgeable about children's interests" (p. 1). Nuttall (2002) takes this concern further and asks if science will become what she terms the "null curriculum", that is, "programme content that is systematically excluded from children's experience" (p. 7).

\subsubsection{NZ Early childhood science education research}

Most of the recent New Zealand early childhood research has focussed on "processes rather than measurable outcomes" (Cullen, 2008, p. 8). Cullen sees this as a result of the way Te Whaariki defines learning outcomes, "summarised as dispositions and working theories" (p. 8). While the concept of dispositions has been "explored extensively over the past few years" the concept of working theories has "been largely unexplored and remains nebulous" (Hedges, 2008, p. 2).

She suggests heightening teachers' awareness of the role working theory development plays in children's learning. She sees assessment of dispositions as increasing the teachers' understanding of the ways children approach learning, while 
assessment of working theories "provides insights into children's current understandings and thinking about the world" (p. 5). This enables teachers to provide opportunities for children to "engage in development and expression of working theories, and to improve the connections made between working theories" (p. 6).

In her PhD thesis, Hedges looked at the adoption of a 'funds of knowledge' approach in early childhood communities of inquiry. She argued that teachers interpreting children's interests requires a more analytical understanding of the child's family and community experiences. She sees the funds of knowledge approach as a framework for understanding children's lives, families, communities and cultures. This places an emphasis on the teacher's relationship with those in the child's home environment, providing a way to also acknowledge diversity. The approach is also relevant when considering how teachers support children's learning as it provides "a way to explain the range of evidence that teachers can draw upon in their planned and spontaneous curriculum and pedagogical decision-making” (Hedges, 2007, p. 283).

In her literature review on New Zealand junior primary and early childhood science education, de Kock (2005) focuses on teachers making links to children's prior learning and having sufficient scientific subject knowledge themselves. "Research has shown how children's thinking can be moved a step forward, through the help of a more skilful partner. This can only be obtained if the more skilful partner is armed with the knowledge" (de Kock, 2005, p. 8). While concerns regarding the scientific subject knowledge held by teachers are the main issue in early childhood science, de Kock notes research on teachers' knowledge of scientific procedures is minimal, and that research on teachers' understanding of NOS is not evident. On reflection this may indicate a lack of emphasis on this within the New Zealand early childhood educational community.

Garbett (2003) noted that "the calibre of the student attracted to the early childhood sector is scientifically less knowledgeable than those students attracted to primary and secondary teaching, where subjects are traditionally emphasised" (cited in de Kock, 2005, p. 5). Linking this to the teachers' lack of understanding of NOS, Garbett (2003) comments that teachers who see science as a "collection of difficult ideas and concepts" (p. 470) appear to find Te Whaariki's constructivist approach to 
science creates dilemmas for them. Yet as Smorti (2005) points out, being "subjected to traditional views of science" (p. 14) in secondary school and teacher training also reinforces the traditional beliefs about science that inhibit the less knowledgeable teacher. She suggests a few reasons for teachers' lack of subject knowledge with the primary reason being gender based. She refers to the powerful influence of "masculine images of science and technology" (p. 14). With over 99\% of those working in New Zealand government funded early childhood services being female (Farquar et al., 2006), many of whom have a poor science background (Garbett, 2003), this provides a serious ongoing concern. As Smorti (2005) commented, "beliefs about gender, science and technology are deeply embedded in society, they are very difficult to change" (p. 14).

Smorti (2007) conducted an action research project looking at the way the teachers in one centre noticed, recognised and responded to children's interest in science. Her emphasis was on "assessment tools that describe, construct, and foster learning" (p. 1). The centre had already had a strong interest in environmental science and the teachers were familiar with the use of 'learning story' narratives. Her research findings indicate the use of "teacher voices (dialogue and reflection)" (p. 2) increases teacher awareness enabling them to plan and work more effectively with children, their families and the wider community.

Helen Hedges' (2002) research into teachers', parents' and children's beliefs on subject knowledge in one kindergarten setting has been influential in how this proposed research was designed. Hedges' study originates from a contradiction in previous research on the importance of teachers' subject knowledge, and the claims in early childhood literature that subject knowledge is not important and "attention to subjects might lead to inappropriate pedagogy" (Hedges \& Cullen, 2005, p. 67). She found that the beliefs of teachers, parents and children all supported the view that subject knowledge was important. However, while evident during planned teaching interactions, Hedges found it was "underemphasised in the majority of spontaneous interactions that constituted most of the time children spent with teachers during the kindergarten session" (p. 82).

Hedges' data showed that subject knowledge can add depth and substance to children's learning, and suggested that teachers may underestimate the importance it 
plays, for example, the use of scientific language and understanding the role dialogue plays in children's learning (Hedges, 2002). At a pre-literate age dialogue becomes teachers' primary knowledge source of promoting knowledge construction within "interactions that arise from and respond to children's interests and inquiries" (Hedges \& Cullen, 2005, p. 740). Hedges urges teachers to use language such as force, gravity and evaporation to "introduce ideas and concepts that can be expanded on as children grow in experience, age and maturity" (Hedges, 2003, p. 3) as without providing the language to describe phenomena teachers limit possible learning. She calls for subject knowledge to receive more explicit acknowledgement in early childhood education and takes a sociocultural approach that sees content learning "negotiated within cultures and communities to reflect knowledge that is culturally valued and allows for multiple perspectives” (Hedges \& Cullen, 2005, p. 76).

\subsection{Rationale for research focus}

In looking at the existing literature regarding early childhood children's scientific learning and the ways that teachers might support that learning, several themes have emerged, some of which were influential in the design of this study. The first is the established barriers to New Zealand early childhood teachers' effectively supporting children's scientific learning. Early childhood teacher attitudes to teaching science (Fleer, 2001; Kallery \& Psillos, 2001) and insufficient subject knowledge (Alexander, 2000; Hedges, 2002) are clearly two barriers identified through previous research. In conjunction with this, science researchers express concerns regarding teachers' lack of understanding of NOS (Alexander, 2000; Heap. 2006; Lederman, 1992). Furthermore, New Zealand early childhood researchers' concerns are in regard to teachers' understandings of sociocultural theories (Cullen, 1996; Jordan, 2003) and use of the curriculum (Hedges, 2008; Hill, 2005). In seeking to identify how the teachers in one setting perceive their capacity to support children's scientific understandings and what they see as influencing their ability to do this, it is hoped that a greater understanding of how these barriers manifest individually will enable an increased ability to support the development of teachers' practice. Analysis for congruence with teaching practices suggested by previous researchers may also provide guidance for specific teaching strategies to focus on.

Reflection and the role it plays in developing teaching practice is another emerging theme. In response to the literature, participants will be asked to reflect on their ideas 
and opinions. It is hoped that their confidence and attitudes towards supporting children's scientific learning will also be illuminated in this way. Cochran-Smith and Lytle's (1999) term 'knowledge-in-practice' sees teachers' development of teachers' practice dependent upon enhancing their "understandings of their own practice" (p. 267). This study has been designed with this in mind and requires teacher reflection in order to answer the interview questions. As such, the proposed research also has the possibility of enhancing the participants' own teaching practice in regard to children's scientific learning.

The predominance of sociocultural theory within the New Zealand early childhood community has also been influential in the design of this study. Robbins' (2003) use of Rogoff's three planes of analysis provides a multi-levelled approach to the complexity of teaching, and enables wider influences to be examined in data analysis. As a result, analysis for this study will also consider the interactions between teacher participants in the same teaching team. It will also look at culturalinstitutional influences. Hedges (2002) proposed that teachers' use and understanding of scientific language and the role dialogue plays in children's learning illustrated the powerful role subject knowledge plays in adding depth and substance to children's learning. She suggests that teachers may underestimate the importance it plays and to this end attention needs to be given to not only the language that the participants in this study use but also their perspective of the role it plays in supporting children's scientific learning.

Hedges sees the central pedagogical issue for early childhood education as not being about the "subjects per se, but how teachers assist children to construct subject knowledge" (2003, p. 91). Do early childhood teachers still have little science knowledge and a negative attitude toward teaching science as many academics believe (Fleer, 2001; Watters et al., 2001) or is it now seen as more complex with relationships and cultural or institutional aspects influencing the individual capacities and abilities of each teacher? By considering Rogoff's (2003) foci of analysis on the "personal, interpersonal and institutional or cultural aspects of human activity" (p. 52), this study is designed to capture a broad view of teachers' support of children's scientific learning. 


\section{Chapter Three: Methodology}

\subsection{Introduction}

As a committed early childhood educator and researcher I seek to research in a way that "offers the greatest promise of making significant contributions to the knowledge base and practice of education" (Merriam, 1998, p. 1). This underlying belief has influenced my research choices and resulted in an attempt to construct research that is focused on "discovery, insight, and understanding from the perspectives of those being studied" (p. 1). The perspective this study seeks to describe is that of teachers' understanding of their teaching practice. It focuses on teachers' recognition and response when noticing children engaged in scientific learning and gives a voice to their perceptions of their teaching practices.

The research proposed for this thesis does not seek to find answers but different perspectives. With a "move toward pluralism, many social scientists now recognise that no picture is ever complete - that we need to employ many perspectives, hear many voices, before we can achieve deep understandings of social phenomena" (Denzin \& Lincoln, 2000, p. 1055). Adopting a qualitative, interpretivist case study approach, the research seeks to gain a greater understanding of the complex and interrelated factors influencing early childhood teachers' practices. Contextualised within the New Zealand early childhood community, the research has a sociocultural framework (see Section 2.2.2). It strives to represent the views of one group of teachers in a holistic and contextualised manner and is designed to possibly empower the participant and be responsive to the context of the research site.

This chapter restates the initial question and identifies supporting sub-questions. It explores the methodological paradigms, explains the rationale, and describes the data gathering and analysis methods employed. It then looks at the ethical considerations and validity of the methods employed, as well as the responsiveness of the research. Finally the context of the case study and particulars about the research participants are described. 


\subsection{Research question}

The final research question underpinning this study was:

What are professionally trained early childhood teachers' understandings of, and feelings about, the way they support young children's learning in science?

A further eight supplementary sub-questions were also formed that were designed to help in capturing and collating data. These were:

1. How do the teachers in the research define science?

2. What do the teachers believe scientific learning during early childhood looks like?

3. How do the teachers believe they teach science?

4. What do teachers believe has significantly informed their views of science?

5. How do teachers use the national curriculum guidelines, Te Whaariki, to inform their practice in this area?

6. How do teachers feel about teaching science?

7. What role do they feel confidence and ability plays in their effectiveness to support children's scientific learning?

8. What do teachers think is important in enabling them to effectively support children's scientific learning?

\subsection{Research design}

In considering the rationale for my research decisions I have realised the strong influences of my life values, educational beliefs and past experiences (see Sections 1.2 and 1.3). These have informed my choice of research question which in turn informed the research design (Mutch, 2005, p. 109). "The gendered, multiculturally situated researcher approaches the world with a set of ideas, a framework (theory, ontology) that specifies a set of questions (epistemology) that are then examined (methodology, analysis) in specific ways" (Denzin \& Lincoln, 2005, p. 211). The question driving the research for this thesis clearly indicates a desire to achieve a description of what the participant teachers' views are on supporting children's scientific investigations. A qualitative, interpretive, case study has therefore been 
adopted. As a researcher I spent four months gathering the teachers' views at one childcare centre in a variety of ways. The data were then analysed in a matrix and used as a tool for gaining further understanding of the teachers' views. These findings were then analysed in relation to Rogoff's (2003) sociocultural theory of three foci of analysis (see Section 2.2.2.1) with implications for further research deduced from this process.

Choosing a qualitative research design was validated by Creswell's comments, which resonated with my own research aspirations. He notes that qualitative research has been a common form of educational research over the past 30 years and is "best suited for research problems in which you do not know the variables and need to explore" (Creswell, 2008, p. 53). Creswell goes on to define the three characteristics of qualitative research as listening to the views of the participants, asking open-ended general questions and collecting data in the place where people are, and a recognition that research "has a role in advocating for change and bettering the lives of individuals" (p. 51).

However, Denzin and Lincoln (2005) write that qualitative research is difficult to define clearly. They claim in the introduction of their handbook on qualitative research that this is due to the multiple uses and meanings of the methods used in qualitative research. "It has no theory, or paradigm, that is distinctly its own" (p. 6). Yet the ability of the qualitative researcher to employ multiple research methods is also its strength as it allows the researcher to attempt "to secure an in-depth understanding of the phenomena in question" (p. 5) and provide rigour to the investigation. As with other qualitative research, I have employed a variety of methods (individual interviews, participant data collection and a focus group) to gather descriptive accounts (Mutch, 2005) of the research participants' views.

Qualitative research challenges the notion of value-free objective research and as such acknowledges the subjective nature of research. For me, acknowledging the subjectivity of the researcher, and researched, also acknowledges the culturally and historically specific understanding of the phenomena studied. The resulting specific, rich description of the findings can provide others with the depth of information on which to decide the degree to which the findings are applicable to their own specific situation. 
The rationale for adopting an interpretivist approach is also based on my desire to be culturally and historically specific in my research. Interpretivist research views individuals as constructing meaning within a cultural framework of socially constructed and shared meanings resulting in "interpretations of human actions and social practices within the context of meaningful, culturally specific arrangements" (Scott \& Usher, 1999, p. 26). The concept of 'bracketing' or temporarily suspending researcher subjectivity is a strategy that has been seen to minimise researcher subjectivity (Scott \& Usher, 1999). However, as Gadamer (1975, cited in Scott \& Usher, 1999) suggests, instead of bracketing in this study I intend to be aware of my pre-understandings and use them as "the essential starting point for acquiring knowledge" (p. 26). While one can question the ability of an individual to "reflect 'rationally' upon everyday experience and to comprehend their 'own' experiences objectively" (Finger, 1990, p. 27, cited in Garrick, 1999, p. 152), I believe the subjective interpretations of both the participant and the researcher also form rich research data to analyse.

An interpretivist approach emphasises the importance of researcher reflexivity where the researcher continuously identifies and reflects on their bias, values and taken-forgranted assumptions and actively writes them into their research (Creswell, 2008). These biases, values and assumptions may be deeply embedded within the researcher and are "formed through the influential discourses and power relations surrounding their practices" (Garrick, 1999, p. 154). Previous interactions between the researcher and teachers, along with my standing in the early childhood teaching community as a university lecturer, are acknowledged as possible sources of power imbalances. In acknowledging the unequal power relationships the proposed research also seeks to adopt an approach that is about "doing research with people rather than on people" (Blumer, 1962, cited in Garrick, 1999, p. 150; original emphasis).

My previous experience as a research participant and a 'critical colleague' in Kaupapa Māori research was influential in taking this approach. As a researcher, I live within a specific cultural context and historical timeframe. As a child of the 1950s I grew up in a discourse of liberal, Marxist, and radical feminist theories focussed on gender and challenging the accepted gender norms. The past twenty years have also seen cultural changes in New Zealand society with a greater acknowledgment of the tangata whenua (see Glossary) and an increased societal 
awareness of New Zealand's bicultural nature. As the society in which I grew up in debated emerging feminist and cultural theories, the nature of that society gradually changed and so too did my developing world view, one which underpins my research paradigm. As such, this has influenced my research question, methodology, analysis, and plans for disseminating the findings.

In particular feminist (Harding, 2007; Hesse-Biber, 2007) and indigenous researchers (Bishop \& Glynn, 1999) have highlighted the absence of minority voices and questioned the ability to generalise the experiences of the majority as reality for all. Feminist theory and practice aims to disrupt the dominant discourses and traditional Western ways of knowing (Hesse-Biber, 2007). It is mindful of those missing from research and the implications of this, especially when results become generalised across cultures, genders and other populations (Hesse-Biber, 2007).

An interpretivist approach sees the world being researched as socially constructed. Both the participants and researcher "construct their own knowledge and reality" (Haigh, 2001, p. 125). It is seen as a way to acknowledge a multiplicity of views recognising the context in which the experience occurs. However, I am mindful, as Garrick (1999) cautions, not to become "the coloniser of the subjects through re-telling their stories" (p. 152; original emphasis). I also acknowledge that "any voice is both an interpretation and itself in need of interpretation" (Scott \& Usher, 1999, p. 18), and that to some degree my researcher subjectivity will always exist. This is reduced to some degree in this study by the researcher and participants sharing a common understanding of New Zealand early childhood concepts and terminology. This congruence has enabled the participantresearcher dialogue to develop and encouraged participant response. As a result there was a modification of the research process, and shared analysis and interpretation of the gathered data (Haigh, 2001). This study seeks to foreground a specific group of female, early childhood teachers' voices in an authentic manner that captures a description of their thoughts and ideas on supporting children's scientific learning. This involves looking for the most effective methods to gather and present data in order to represent the participants' views. It also incorporates strategies to validate, respond to, and expand on the data with the participants. 


\subsection{Case study}

To look at what might be learnt from one specific situation the case study approach is common in educational research (Viruru \& Cannella, 2001). It gives an in-depth understanding of a specific situation and its meaning for those involved (Merriam, 1998). Taking into account the context and relevant outside forces, it focuses on a variety of variables in examining a specific phenomenon with reference to a specific population. The resulting holistic description is more open to reader interpretation (Cohen, Manion \& Morrison, 2007; Merriam, 1998) than other forms of research. In this way it aligns with a sociocultural paradigm and qualitative, interpretivist methodology. The case in this study is instrumental, designed to investigate a specific situation in order "to provide insight into an issue" (Stake, 2005, p. 445). The issue that emerged from the review of the recent literature for this thesis was early childhood teachers' ability to support children's scientific learning.

The case study approach provides a 'snapshot' of the occurrences at one time and place so there is a trade-off between "greater detail and likely accuracy of information about particular cases at the cost of being less able to make effective generalisations to a larger population of cases" (Hammersley 1992, p. 186, cited in Scott \& Usher, 1999, p. 88). This study does not seek to encourage generalisation but to provide a glimpse into another's perspective, or reality. Clearly identified as a specific, unique, bounded system (Stake, 2005), the insights from a case study can be transferred or re-contextualised to different settings. In this way case study knowledge may be seen as more concrete than other research knowledge as it resonates with one's own experiences creating implications for other people in other situations. By providing a 'thick description' it allows "individuals to ask about the degree of fit between the case studied and the case to which they wish to generalise" (Schofield, 2002, p. 183).

This makes the case selection an important factor in choosing a typical site rather than a convenient one. Considering the wide diversity of New Zealand's early childhood community (Mawson, 2006) it is hard to decide what a typical early childhood setting in New Zealand looks like. The criteria for site selection in this study were aimed at finding a situation that a large number of early childhood teachers could relate to. For this reason I wanted a medium sized (25-35 children), full day, multi-aged childcare centre located in a city suburb. I was also looking for a 
centre that employed trained teachers in line with the Ministry of Education's (2002) strategic plan. As I wanted to avoid any commercial implications or centre politics I also looked for a non-profit making, community-based centre with an elected, stable management committee.

\subsection{Research method}

Once the criteria were established the centre closest to my home that fitted the criteria was chosen. The possibility of the centre becoming a research site was then explored. The negotiation process involved inviting teachers to be part of the research and gaining permission from all those involved with the centre. This process is outlined in the later section on ethics. Six of the seven teaching staff employed at the centre became research participants with the seventh staff member joining in the focus group interview discussion. Further information on the participants is provided later in this chapter when looking at the case study context.

Individuals were asked to collect observational data, with group and individual interviews held as well. An initial interview with each participant focused on their background and initial opinions on the topic. Participants then collected observational data for three days followed by a second individual interview. During the second interview they were encouraged to discuss their data and what it meant to them. After interview transcripts were confirmed by the participants, these, along with researcher field notes and the participant data collected (mainly photographic), were analysed using matrixes around the supplementary research questions (see later in this chapter). Emerging themes were then presented back to the research participants in a focus group interview format where they were discussed further. The focus group interview data were then analysed and integrated into the original analysis and findings. Finally the implications and possibilities for further research were considered. 


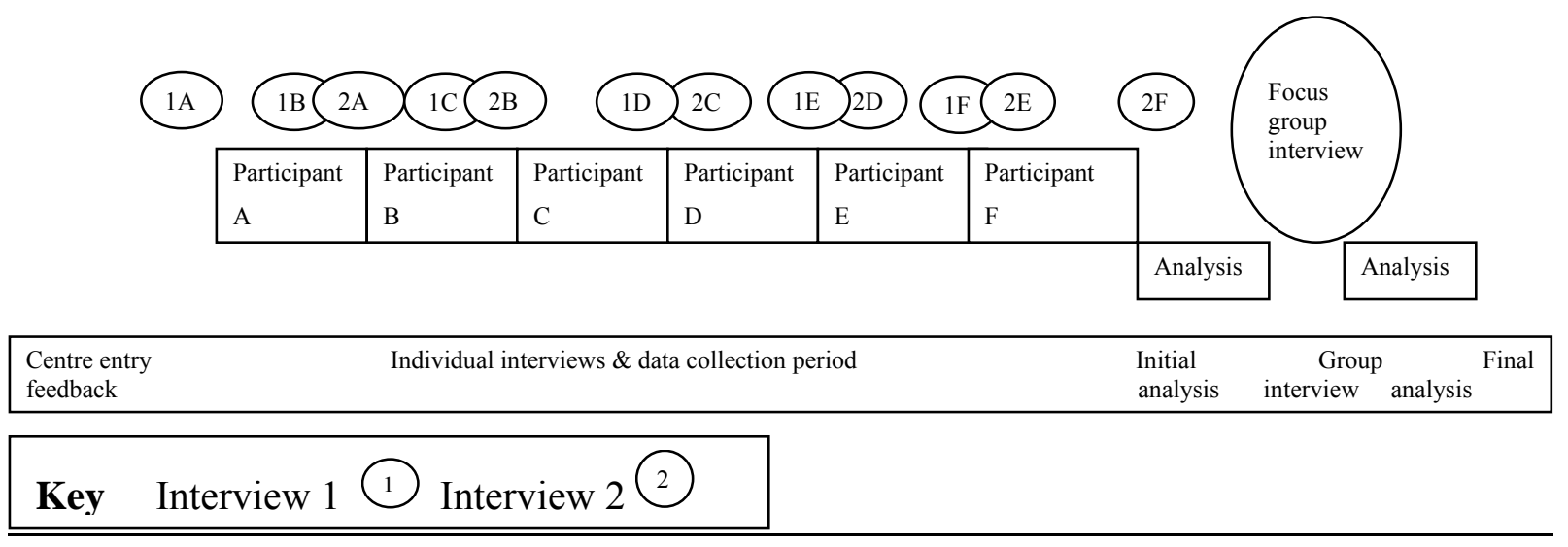

Figure 3.1: Diagram of research methods

\subsection{Interview data collection}

The primary data collection method was through individual and group interviews. While this method can provide rich descriptive data, the quality of the data is dependent on the interviewer's skills in asking, listening and interpretation. Fontana and Frey (2005) note that the use of interviews is not a neutral tool as they are "inextricably and unavoidably historically, politically, and contextually bound" (p. 695). They also stress that it is an interaction between two or more people whose "exchanges lead to the creation of a collaborative effort called the interview" (p. 696) implying it is an active process, contextually bound and mutually created. Common New Zealand early childhood terms was used in the interviews where the interviewer and respondent understood the contextual "nature of specific referents" (Fontana \& Frey, 2005, p. 713). However, the varying cultural and economic backgrounds of participants meant the researcher could not assume this of all the language used in the interview. For some this may have extended to the intended outcome of each interview (Fontana \& Frey, 2005), seeing it as more of a testing situation than a sharing of equally valid opinions.

As mentioned, the participants each had two individual interviews. The first was semi-structured around a series of background questions, generally open-ended (see Appendix A). The second was less structured and centred on the participant data collected (see Appendix B). In the latter interviews the participant generally led the interview with the interviewer prompting when further explanations or confirmation of information was desired. Several strategies were employed to build a trusting relationship with the participants in order to gather the participants' authentic views. 
These included preliminary visits, the use of a familiar on-site location, and consideration of participants' personal comfort (e.g., refreshments, negotiation of timing, and having a comfortable temperature and furniture). Individual interview transcripts were also returned to participants to check correctness, and in one case to elaborate on concepts spoken about. In this way developing ideas about concepts mentioned in the interview were also recorded, and the 'ownership' of the interview content (Schostak, 2006) remained with the participant.

The focus group was designed to primarily triangulate data to date (Fontana \& Frey, 2005), as well as 'member check' (Creswell, 2008; Mutch, 2005) initial interpretations of the data. It also illuminated insights into group dynamics and dialogues between the participants. This served to validate the experiences of other participants (McLachlan, 2005) and provided an opportunity for the researcher to identify the individual perspectives of those in the group, and how others respond to them, opening up a "window in a community of interaction" (Bouma, 1996, p. 179). I saw my role as facilitator as prompting contributions to the discussion and ensuring all participants had an opportunity to contribute their ideas. Ground rules were established for all participants and the researcher before starting the group interview. These were around communication conventions and covered confidentiality, the idea that there are no 'right' answers only equally valid ideas, respecting and allowing the time and space for other participants' ideas, and asking for clarification if unsure about any point being made. The desire for authentic representation of the participants' voice led to awareness that the listener may not gain the same meaning from the words spoken as the speaker intended.

At the start of the focus group interview the researcher presented the analysed data to date in a PowerPoint (see Appendix C) along with some of the photographs each participant had taken. Participants were encouraged to comment on any aspect of the PowerPoint as well as specifically asked to comment on questions posed in the presentation. These aligned with the supplementary research questions and were designed to gain further specific comments from all group members. However, some participants spoke to a far greater extent than others. This was largely due to the participants' prior relationships as an existing group. As an established teaching team formal and informal hierarchies had developed over time along with communication styles, role expectations, and a positioning of the value of the knowledge held by each 
team member. During the focus group interview it became evident that the social positioning between the participants also influenced, and perhaps inhibited, teachers' responses (McLachlan, 2005). This was to some degree due to the involvement of the supervisor and assistant supervisor as research participants, due to their teaching roles. Some individual participant personalities also appeared more inclined to respond or give their opinions. Barbour and Schostak (2005) note the influence of the participants' possible desires to make a good impression or conceal shady dimensions, concluding: "Trust is a delicate gift easily broken" (p. 42). This is not only the trust between the researcher and participant, but more importantly between the research participants.

The quality of the data from a focus group interview "is deeply influenced by the skills of the facilitator to motivate and moderate" (Berg, 2007, p. 148). It is acknowledged that as a novice interviewer I also influenced the focus group interview data (McLachlan, 2005). For example, pre-arranged seating, a larger room, and more control over dominant speakers, I believe, would have lessened the influence of the social positioning. Also additional visual recorders would have increased the ability to capture non-verbal communications. However, most participants did engage in discussion around the data presented, reflecting on collective notions shared and at times helping to identify and build on some of the emerging key findings.

\subsection{Participant data collection}

As mentioned, data were also collected by the participants on situations where they noticed and recognised (see Section 2.5.1) children involved in scientific investigation over a three-day period. Participants were provided with a camera, Dictaphone, note pad and pen in an easily worn bag that might be used to collect data during their teaching day. Few criteria for data collection were set enabling participants to collect data how, when and where they chose. The primary method of data collection chosen by participants was the digital camera (see Appendix D. Line 2 and 3). This was expected as it was already commonly used in the centre by teachers to collect data for children's assessment. The Dictaphone was the least used due to noise interference and unfamiliarity. 
In order to minimise the effect of the data collection on the centre's day-to-day practices, participants took turns in collecting data for a total of twenty-one days. This resulted in ongoing data collection with each participant's data often providing a context for the next participant's data, rather than collecting data on the same situations giving several view points. As a consequence of participants being present when data were collected, there was also an increased awareness of the process and possible scientific learning occurring in the centre, with previous data collection influencing the next participant's data collection.

The data collected by the participants formed the basis of the second interview. Transcripts of these interviews were coded and analysed alongside the analysis of the photos, notes and audio recordings participants had collected. The age and gender of the children participants had collected data on were noted along with the type of activity; its location, the number of children involved, and the possible inclusion of an adult (see Appendix E).

\subsection{Ethical considerations}

While there is always a required ethical process for a researcher to follow, ethical considerations begin with the researcher's own ethical values. Mutch (2005) comments that the researcher's position of power makes considering ethical research implications imperative and goes on to stress that they should reflect on their research actions and consult their own conscience (p. 34). After submitting an application outlining the ethical procedures I would undertake, the research for this thesis was approved by the Victoria University of Wellington College of Education Ethics Committee (8/1/07). Consideration was given in the application to the ethical principles of voluntary participation, informed consent, social and cultural sensitivity, and minimising harm. Along with this the research site entry, the possible disruption to centre practices, the research dissemination process and data storage were also considered. Specific attention was also given to the acquisition and use of photographs of children.

Once ethical approval was gained I began visiting the research site I had selected to gather some context about the centre as well as organise the research process. While making introductory visits I spoke with the supervisor and then all staff (including those in non-teaching roles) about using the centre as a research site. Getting a positive 
response I then formally approached the management for permission (see Appendices $\mathrm{F}$ and $\mathrm{G})$. Once this was gained all of the possible research participants were then given an information sheet about the research (see Appendix $\mathrm{H}$ ) and formally asked to be part of the research (see Appendix I). Later participants were also provided with an information sheet on the focus group interview (see Appendix J), with a separate consent form for the staff member who only attended the focus group interview (see Appendix K). My first ethical dilemma presented itself at this stage and was due to the pre-existing relationships I had with some of the research participants. The local early childhood teaching community is small and as a teacher trainee educator I already had a profile as an early childhood educator. I acknowledged this dilemma in the initial discussions with each participant and incorporated questions into the initial interview on what training influences I might have had.

After management and teacher consents were gained, parents were then informed (see Appendix L) and formally asked permission for staff to gather written and photographic data on their child as part of the research project. Parents were also asked to indicate the degree of feedback they wanted to receive (see Appendix M). Staff and parents were asked to talk to the children about the research and how they felt about being part of it, although little disruption of the children's daily routines was anticipated. While I was not present in the centre collecting data, I was often at the centre and became a common visitor. I believe the children were aware of the research being conducted and whenever children interacted with me I responded in an honest and friendly manner.

As I am researching in the New Zealand early childhood context I was also guided by New Zealanders Cullen, Hedges and Bone's (2005) ethical research framework. They consider the preparation, data gathering and dissemination through three lenses. The first lens looks specifically at children under 5 years old and asks the researcher to consider what rights young children have in the research process. While children were not research participants in this study, the research was being conducted in the children's daily centre environment and the data collected by the participants was on their activities within that environment. The children were familiar with the data collection methods as written and photographic documentation of children's learning was already a common practice in the centre. Photographic data taken of children by the staff were often shared immediately with children, or soon after. 
Due to the use of photographic data and the age of the photographic subjects (all under 5 years old), careful consideration was given to the ownership, storage and use of the photographs. It was finally decided that all photographs were the property of the centre and could be used by the teachers for assessment or display purposes, according to the centre's policies. This also enabled children, staff and parents to access them at any time. The researcher had permission to use the photographs in data analysis and keep a record of them, in a secured place, for three years after the research had been completed. Another dilemma emerged as I considered the dissemination of findings, wanting to utilise the visual data collected while still acting in an ethical manner. With awareness that images would identify the centre and children for many years to come, I carefully considered issues of anonymity. I eventually decided that any photographic data used in the thesis, or dissemination of the thesis, would require a discussion with the child and parents and a separate consent form for parents to complete (see Appendix N).

The second lens looks at researching within a team teaching environment encouraging the researcher to consider team roles and dynamics. As the research progressed the relationships between participants posed another ethical dilemma for me as I increasingly became aware of the team dynamics. While supporting the team's collaborative approach to their work I was also aware of the need for strict confidentiality of all formal and informal discussions with each of the research participants. As each incident or idea shared may result in general discussions amongst the whole team I felt I needed to minimise the degree to which my presence influenced team discussions.

Cullen et al. (2005) also urge the researcher to consider the possibility of negative implications or participant disagreement on the findings. The use of a focus group in this study is designed to minimise this by providing an opportunity for participants to discuss, confirm, modify or dispute the data findings. In this way assumptions were identified; for example, the focus group interview identified that some participants often practised teaching behaviours they had not identified but others had, such as ascertaining the child's prior knowledge about a topic, or providing feedback to the child. These participants felt that these practices were so integrated into their daily interactions with children that they had not consciously thought to identify them. 
Discussions on differences of opinion also occurred during the focus group interview highlighting the individual pedagogies held by participants.

The third lens Cullen et al. focus on is that of relationships with parents, families, whaanau (see Glossary), and communities. They encourage researchers to ask themselves if parents understand the full implications of the research, or the distinction between the research and the centre's normal teaching programme. They also raise the issues of keeping parents informed of changes in the research, and gaining additional consent for the use of visual data in presentations and publications. These suggestions were followed in the research with a brief progress report included along with copies of photos taken of each child and additional consent forms to use visual data for the dissemination process sent out to each family after the data analysis was complete.

\subsection{Analysis of data}

The data were analysed in two stages. The first formed the basis of feedback for the focus group interview (see Appendix C) and involved a thematic coding (McLachlan, 2005) of data around the supplementary research questions, as well as the photographic data participants had collected. Only the photographs were analysed, and this was seen as valid due to the high percentage $(87.5 \%)$ of photographic data (see Appendix D, Line 2). While the $12.5 \%$ of data collected via note taking and Dictaphone was also considered it often reiterated participant/child conversations verbally recalled by the participants, or provided additional context to a situation.

The analysed photographic data and interview coding were entered into a matrix to establish the breadth and frequency of data. The second stage of analysis incorporated the focus group interview transcript into the initial analysis refining the initial matrixes (see Appendix O). Teaching behaviours were compared with those suggested by Hipkins et al. (2002) (see Appendix Q). Also analysed was the type of data collected (individual or group experience, age and gender of child/ren, degree of adult initiation and interaction, and degree of spontaneity) (see Appendices D and E). In addition to this the first interview was reanalysed to provide a description of participants involved in the data and what their individual views were (see Appendix A). 


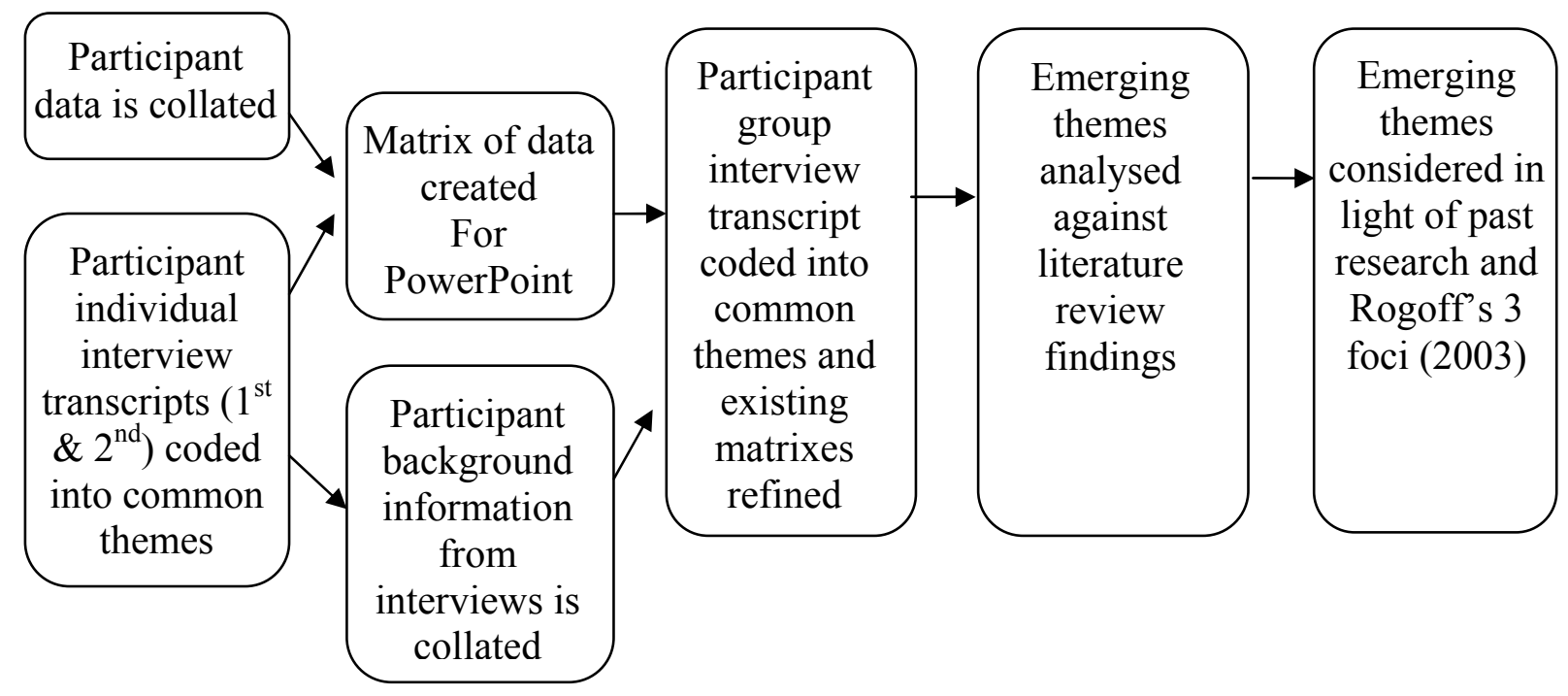

Figure 3-2: Diagram of data analysis

Collating the data in this way, they were able to be simultaneously analysed, enabling iterative thinking processes to occur "cycling back and forth from data collection and analysis to problem reformulation and back" (Creswell, 2003, p. 182). This became "an ongoing process involving continual reflection about the data, constant writing of memos, and asking analytic questions" (p. 190). A researcher diary initially captured many of these ideas although as the research progressed more was written on memos at times when the diary was not present. These ideas helped me to view, reflect and question the data in different ways, and were instrumental in considering responses to the research context and possible changes to the research. It also encouraged a degree of reflection around the consequences of the choices I had made in the analysis process. For this reason I adopted the research tool (Fleer \& Robbins, 2003) of Rogoff's (2003) three foci of analysis (see Section 2.2.2). This enabled me to analyse the data in different ways capturing the complexity of the findings emerging by focusing on one aspect of the data while the other aspects remained in the background. In this way using the three foci of analysis highlighted the participants' individual teaching pedagogy and knowledge base (personal focus of analysis), the teachers' relationships and collaboration with other teachers in the team (interpersonal focus of analysis) and the contextual, cultural, institutional and historical factors (culturalinstitutional focus of analysis), such as specific language, educational resources and the process of science inquiry. These findings were further synthesised into three main findings (see Section 7.3). 


\subsection{Validity}

The credibility of research relates to its validity. It questions if the research successfully achieves its intentions in a believable and ethical manner. In this way validity in research is "about its truthfulness and reliability about the trustworthiness of the data collection and analysis process" (Hedges, 2002, p. 61). In the past, qualitative research has been seen as 'soft', unrigorous, and subjective in comparison with quantitative research (Scott \& Usher, 1999). However, more recently external validity, or generalisation, is not seen as an essential outcome of qualitative studies (Hedges, 2007). Instead this type of research is aimed at providing a rich, descriptive depth of information, which is preferred in educational research where social reality is seen as subjective and in a state of flux. Here it is the "quality of the insight from people who have direct involvement that is important rather than the number of people who hold that view" (Haigh, 2001, p. 126). The research process for this study was guided and monitored by a qualified academic supervisor as it is part of a requirement for a Masters of Education and as such also had an external perspective on the validity of the research.

The interpretivist approach to research suggests knowledge is valid if it is an authentic representation of the participants' voice. Several research strategies were employed to address some of the internal validity issues of qualitative studies and to maximise the authenticity of the representation of the participants' views, asking "do the findings capture what is really there?" (Merriam, 1998, p. 201). The first strategy employed was a clearly indicated positioning of myself as the researcher, making explicit the assumptions and theories guiding the study. The reflexive processes used in the research acknowledged my researcher bias, openly positioning my beliefs and options and constantly questioning my research decisions about methods employed. This was also shared with participants, which minimised the possibility of a 'hidden agenda' and maximised the ability of participants to influence, and be empowered within, the research process. I believe the responsive nature of the research is a demonstration of this.

Triangulation was adopted as a tool to increase the internal validity of the research for this thesis. It was achieved by having different individual types of data (visual, written, and oral in transcript form) and multiple methods of data collection (individual interviews, participant data collection, and a focus group interview) (Creswell, 2008). 
The six research participants also expressed many ideas that aligned indicating a possible triangulation from a multiple of perspectives. However, as a case study methodology has been used in this study it is also important to remember that the congruence is only valid to that idea within that context. The reasons for this congruence were not in the scope of this study and indicate an area for further research.

The primary rationale for also using a focus group technique was to 'member check' (Creswell, 2008; Mutch, 2005) tentative interpretations of data and ask if they were plausible (Merriam, 1998). During the focus group participants were asked if they felt the descriptions were complete and encouraged to make comments on the initial data analysis. The focus group interview data also provided confirmation of tentative data interpretations made by the researcher. In this way the focus group asked if the "themes are accurate to include, and if the interpretations are fair and representative" (Creswell, 2008, p. 267). Member checking was also used by returning the interview transcript data to the participants for additions and corrections.

Research participants commented on changes to their teaching practice as a consequence of the research. This will be discussed more fully in later chapters. However, it is relevant to note this here and indicate it suggests a possible degree of catalytic validity (Cohen et al., 2007). Comments by participants during the focus group interview indicated that the articulation of their ideas during the research had encouraged a deeper understanding of their pedagogy, with some reflecting on changing and developing their teaching practice in supporting children's scientific investigations. While a further focus group at a later date might have indicated the degree to which changes in teaching practice were maintained, this was not in the scope of the research for this thesis.

\subsection{The responsive nature of the research}

During the research process there were several occasions where aspects of the process were modified in response to the context in which the research was taking place. One example of this was the participant selection criteria. The initial participant selection was based on the participants' training in early childhood education. This was later modified to include any teacher training as early childhood teacher trained participants often referred to the primary school trained teacher on the staff. During the focus group 
interview the one teaching staff member, still in training and not officially involved in the research, joined in. This was not expected but a decision the centre teaching team made as a whole, seeing themselves as one teaching unit and striving for consistency of teaching approaches. The new participant did not comment on the accuracy of the data presented but instead provided insight into the research process as an observer situated within the research site of the case study. This is significant given the absence of the researcher during the participants' data gathering and indicative of the additional data gathered in being open and responsive to the participants' views.

Not only was I as the researcher able to be responsive to the participants, but the participants were also responsive to the data gathered by those before them. As participants observed the data collection of other participants, their own views on what to gather data on and how were influenced. Some participants formed an agenda seeing data on a particular aspect of supporting children's scientific learning as more significant than others, for example, setting up more specific activities than usual or mainly looking for independent child-initiated learning situations. The ongoing professional teaching discussions that were already a common occurrence amongst the teaching team also became a source of changing attitudes and opinions amongst the participants. During the study these discussions mainly revolved around science, the individual teachers expressing their views and participating in an ongoing evaluation of the way the centre as a whole supported this type of learning (for example routine practices and resources provided for children's learning). Over the research period the participants noted that their general awareness of science learning occurring within the centre environment was heightened. On an individual level the increased awareness led to teachers evaluating and developing their own personal teaching strategies and beliefs about supporting children's scientific investigations and some of these were documented in the focus group interview. On a collective level the awareness led to suggested changes to the general centre practices.

\subsection{Context of research site}

As previously suggested the research site was located in an outer city suburb and open from 7 am in the morning until $6 \mathrm{pm}$ at night although most children did not attend for all that period of time. It was a non-profit making, full-day, multi-aged communitybased centre with an elected stable management committee. It had been established for 
over thirty years and had a large outdoor area with swings, a storage shed, a slide and a fort. The inside area was mainly an open-plan area except for a small adjoining room used on occasions. Children were able to move freely between the indoor and outdoor environments coming together for food times in the morning, midday and afternoon, as well as at the end of the day. Along with a part-time cook and office administrator, seven teaching staff were employed on a full or part-time basis, one of whom was the supervisor and another, the assistant supervisor. Thirty-five children were involved in this research study with some attending on a part-time basis and no more than 26 children attending at any one time. The children were aged between 8 months and 5 years of age and were all in the same building and grounds. However, younger children slept or rested for a period of time in the afternoon enabling teachers to support the older children's learning more specifically.

All the teachers were trained early childhood teachers, having gained their qualifications from Wellington Teachers' College (now Victoria University of Wellington, College of Education) since 1998, or were in training at the College. It is interesting to note that all teaching staff had only worked permanently at the case study site although three of the teachers had done relief teaching in other situations. The six participants were all female aged between 20 and 45 years of age. Four were New Zealand Europeans while the other two were of Indian or Māori descent. All had received some secondary school science education with the majority continuing until leaving school (see Appendix P). Comparing the scientific schooling experiences of all participants was not possible as one participant grew up in India. However, four of the other participants studied biology and two studied chemistry. None had any specific formal schooling in the area of physics.

The next two chapters present the key findings emerging from the data articulated and collected by the participants within the case study context. They are collated around the two aspects of the primary research question, how the participants viewed their support of children's scientific learning, and how they felt about the support they provided. 


\section{Chapter Four:}

\section{Perceptions of supporting young children's scientific learning}

\subsection{Introduction}

The research question for this study was divided into two parts. One aspect looked into the participants' perceptions of how they believed they supported, or could support, the children's scientific learning. This is the focus of the findings presented in this chapter which have been positioned in relation to the concept of 'notice', 'recognise' and 'respond' (Cowie, 2000, cited in Ministry of Education, 2004) (see Section 5.2.1). Findings have been further grouped around the last term 'respond' and relate to the participants' support of scientific learning in regard to children's knowledge, skills and attitudes. Finally in this chapter specific teaching strategies identified in the research that participants' employed in their responses are considered. The second part of the research question is the focus of the next chapter and centres around the participants' feelings about the support they provide. The findings for both chapters were drawn from the participants' comments in both of their individual interviews, as well as the focus group interview, where debates between participants were illuminated (see Appendix D and O). Photographic data gathered by participants were also collated in a matrix form (see Appendix E) to confirm and add depth. Further detail of the data analysis is provided in the methodology chapter (see Section 3.9).

\subsection{Notice, recognise, and respond}

Seen as progressive filters the terms 'notice', 'recognise' and 'respond' (Cowie, 2000, cited in Ministry of Education, 2004) describe the process a teacher goes through as they 'notice' learning in science, 'recognise' some of the scientific concepts and processes under investigation, and when able or appropriate 'respond' to children's curiosity and interest in making sense of the world (Smorti, 2005). These terms are common within the present New Zealand early childhood discourse and their use is seen to enhance the dissemination of the research findings of those individuals for whom it has the most relevance, those within the local context. The use of these terms specific to New Zealand also identifies the boundaries of the case and as such is appropriate for the methodology chosen. 


\subsubsection{Notice}

The participants in this study were asked to gather data when they noticed a child engaged in scientific learning. This meant that it was the participant who identified the learning as scientific and not necessarily the child, or the researcher. Participant 2 commented: “They [the children] don't realise they're talking about science but it is science" (Interview 2) indicating it is the teacher's identification of the experience as 'scientific' that initiates the teaching response. Conversely as Participant 1's comment about her participation in this research illustrates, if the concept is not noticed the teaching support does not occur. "It's really opened my eyes to see that it is happening out there and getting in there a bit more to support it" (Interview 2).

Observing children engaged in learning is a common learning assessment practice in New Zealand (see Section 2.5.3). Children's assessment information evident at the centre, and participant comments, indicate that all the participants employed observation techniques for assessment purposes on a regular basis, so were conversant with the practice of noticing children's learning, noting it down and following up on this later. For example Participant 1 (Interview 2), "I was out in the mornings for about an hour, an hour and a half, taking snapshots and what I took photos of I was able to extend in the afternoon by providing things along the same line" (Participant 1, Interview 2).

A total of 96 incidents were noticed by the participants, $87.5 \%$ of which were documented in photographic form (181 photographs) and $12.5 \%$ via notes or a Dictaphone recording (12 incidents). The analysis of the photos taken by the participants show $43 \%$ of these were of children engaged in situations planned by the participants, while 57\% were not (see Appendix E, Line 47, Columns J \& K). Participants noticed children engaged in group learning in $23 \%$ of the incidents and individual children engaged in learning in $73 \%$ of the incidents. In $4 \%$ of the incidents this was unclear (see Appendix D, Lines 17-19, Column A).

The incidents not only created data to be analysed but also the focus for participants' discussion in subsequent interviews. The table below is drawn from the analysis of the photographic data analysis (see Appendix E). 
Table 1: Demographic aspects of incidents observed and data sources

\begin{tabular}{|c|c|c|c|c|}
\hline & $\begin{array}{l}\text { Young } \\
\text { children }\end{array}$ & Toddlers & Infants & Total \\
\hline $\begin{array}{l}\text { Enrolment } \\
\text { information }\end{array}$ & $\begin{array}{l}17 \text { children } \\
49 \% \text { of total } \\
11 \text { female } \\
6 \text { male }\end{array}$ & $\begin{array}{l}15 \text { children } \\
43 \% \text { of total } \\
7 \text { female } \\
8 \text { male }\end{array}$ & $\begin{array}{l}3 \text { children } \\
9 \% \text { of total } \\
3 \text { female }\end{array}$ & $\begin{array}{c}35 \text { children } \\
18 \text { female }(56 \%) \\
14 \text { male }(44 \%)\end{array}$ \\
\hline $\begin{array}{l}\text { Photographic } \\
\text { data } \\
181 \text { children in } \\
\text { photographs }\end{array}$ & $\begin{array}{c}115 \text { children } \\
63.5 \% \text { of total } \\
70 \text { female }(61 \%) \\
45 \text { male }(39 \%)\end{array}$ & $\begin{array}{c}57 \text { children } \\
31.5 \% \text { of total } \\
23 \text { female }(40 \%) \\
34 \text { male }(60 \%)\end{array}$ & $\begin{array}{c}9 \text { children } \\
5 \% \text { of total } \\
9 \text { female }(100 \%)\end{array}$ & $\begin{array}{l}181 \text { children in } \\
\text { photographs } \\
102 \text { female }(57 \%) \\
79 \text { male }(43 \%)\end{array}$ \\
\hline $\begin{array}{l}\text { Location of } \\
\text { photograph }\end{array}$ & $\begin{array}{c}56 \text { inside }(49 \%) \\
59 \text { outside }(51 \%)\end{array}$ & $\begin{array}{c}16 \text { inside }(28 \%) \\
41 \text { outside }(72 \%)\end{array}$ & $\begin{array}{l}5 \text { inside }(55.5 \%) \\
4 \text { outside }(44.5 \%)\end{array}$ & $\begin{array}{l}77 \text { inside }(42.5 \%) \\
57 \text { outside }(57.5 \%)\end{array}$ \\
\hline $\begin{array}{l}\text { Incident } \\
\text { photographed } \\
\text { is planned or } \\
\text { spontaneous }\end{array}$ & $\begin{array}{c}58(50 \%) \\
\text { spontaneous } \\
57(50 \%) \text { planned }\end{array}$ & $\begin{array}{c}39(68 \%) \\
\text { spontaneous } \\
18(32 \%) \text { planned }\end{array}$ & $\begin{array}{c}6(7 \%) \\
\text { spontaneous } \\
3(3 \%) \text { planned }\end{array}$ & $\begin{array}{c}103(57 \%) \\
\text { spontaneous } \\
78(43 \%) \text { planned }\end{array}$ \\
\hline $\begin{array}{l}\text { Interview data } \\
96 \text { incidents } \\
\text { observed }\end{array}$ & $\begin{array}{l}59 \text { incidents } \\
62 \% \text { of total }\end{array}$ & $\begin{array}{l}13 \text { incidents } \\
13.5 \% \text { of total }\end{array}$ & $\begin{array}{l}7 \text { incidents } \\
7 \% \text { of total }\end{array}$ & $\begin{array}{c}13 \text { incidents of } \\
\text { mixed ages } \\
(13.5 \%) \\
4 \text { incidents age } \\
\text { unclear }(4 \%)\end{array}$ \\
\hline
\end{tabular}

When considering various factors, the age of the child was the main variant in data collection with the older aged children (3-5 years) in the majority of situations as shown in Table 1 . This meant there were $49 \%$ of the children attending the centre who were between 3 and 5 years of age in $63.5 \%$ of the photographs taken by participants (see Appendix E, Column E) and 62\% of the incidents commented on (see Appendix D, Line 14). The toddlers (18 months - 3 years) made up 43\% of the children at the centre and were in $31.5 \%$ of the photos and $13.5 \%$ of the incidents (see Appendix D, Line 13), while the infants (6 - 18 months) made up 9\% of the centre roll and only $5 \%$ of the photos and $7 \%$ of the incidents (see Appendix D, Line 12). Of the incidents commented on, $13.5 \%$ involved children of mixed ages and in $4 \%$, the age was unclear. The gender of the child did not appear to be an influencing factor, nor was the location of the incident except in the toddler age group.

In some cases participants developed their understanding of what science was as they reflected on how to notice it during the data gathering phase of the research. When asked about following children's scientific interests, Participant 4 (Interview 1) commented: "A little bit, if I recognise them." This indicated an acknowledgment that her lack of a scientific subject knowledge base restricted her ability to notice children engaged in some types of scientific learning. However, in the second interview the same participant indicated an increased ability to notice children 
engaged in scientific learning, along with an increased confidence in responding to what was seen: "Children doing what they normally want to do and the science being the thing that's behind it and me being more receptive to seeing, recognising it" (Participant 4, Interview 2). This suggests the focus on science within the centre during the data collection period, and the participant's reflective teaching practice resulted in a change in teaching practices, and an increase in teaching confidence, for this participant. This was also true for Participant 1 who commented:

At the beginning I was a bit nervous and I found it stressful but I think because I didn't put myself really as a confident scientific teacher. But after collecting the data I built a little bit of confidence and self-esteem to carry on and think I am on the right track. (Interview 2)

Participants noticed the level of involvement the child showed in their scientific interest as well as what that interest was. This appeared to be irrespective of age. Two photos of children engaged in exploring sand and the participants' comments have been chosen to illustrate this (permission granted by parents for the use of all photos). The first photograph is of a child,

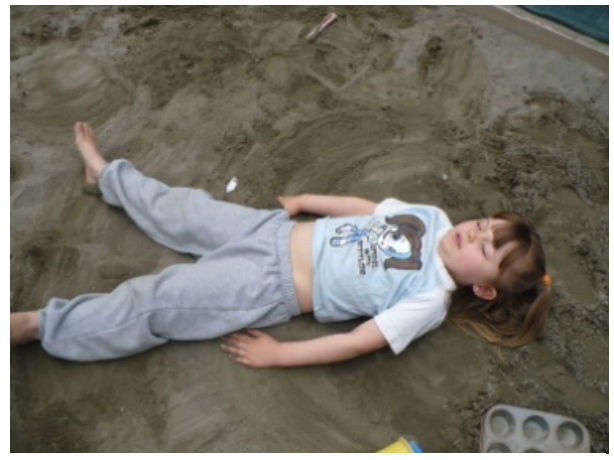

Photograph 1: Young child making castles almost 4 years old, making 'sand angels' by lying on her back in the sand and moving her arms and legs away from and back into her body (Photograph 1). In reply to the researcher's question as to what science concepts the participant recognised the child as exploring, she replied: "The feeling of sand" (Participant 2, Interview 2).

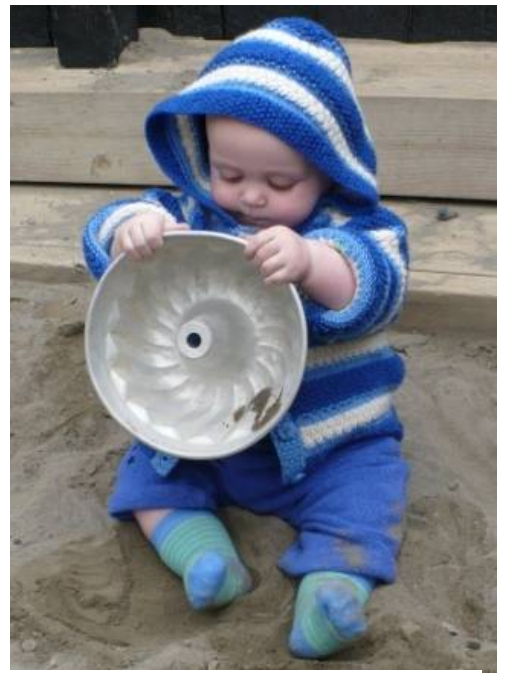

Photograph 2: Infant exploring sand
Later the same participant referred to a 7-month-old child (Photograph 2) who she saw as also exploring the feeling of sand: "She got to feel it with her hands and her feet and just explore the substance and the metal from the little dish as well. She explored that bit with her mouth as well" (Participant 2, Interview 2). Both incidents indicated the child's high degree of involvement that the participant noticed, recognising the child as absorbed in exploring the properties of sand. 


\subsubsection{Recognise}

All the participants talked about using their own subject knowledge to recognise the scientific concepts children were interested in. Most indicated they were aware that there were scientific learning situations they did not recognise (Participant 2s \& 6, Focus group interview, Participants $4 \& 5$, Interview 1) and saw the degree of subject knowledge they held as an enabler or hindrance to supporting children's scientific learning. While most participants (5 out of 6 ) indicated they thought they had sufficient subject knowledge for the age they were teaching, all acknowledged that there was also information they did not know. Two out of six referred to the infinite nature of learning subject knowledge in the focus group interview: "I think generally you can't know everything. I know there's stuff I haven't thought about" (Participant 6, Focus group interview). Previously when asked if she felt this inhibited her she had replied: "In the spur of the moment spontaneous stuff it probably does a little" (Participant 6, Interview 1). This reply is in line with Hedges' (2002) previous research where scientific subject knowledge was "underemphasised in the majority of spontaneous interactions" (p. 69) and illustrates the way subject knowledge is inconsistently used in supporting children's scientific learning.

Participants identified their subject knowledge base as developing from a variety of sources. While formal science education might begin when a child enters the compulsory schooling system, there are many opportunities before this time when a child will explore scientific concepts in order to make sense of the world they live in. All of the participants (see Appendix P, Line 10) referred to the environment they grew up in contributing to their subject knowledge base with two participants also referring to their present home environment. While there were a few references to science at primary school (1 out of 6 ), all six participants referred to secondary schooling, two negatively (see Appendix P, Line 12). This appeared to be a major influence in the participants' confidence to support children's scientific learning as well as influencing individual participants' views of NOS, and how valid they saw their own knowledge base. Participant 4 (Interview 1) indicated her lack of confidence in using her subject knowledge base was a result of her failure in secondary school assessments. Participant 5 (Interview 1) had completed her secondary schooling in India and had found the way she was taught very different to the New Zealand situation, making her recognition of children's learning harder: "I came down here [New Zealand]. I found it harder 
because Indian experiences are different to New Zealand ones. ... It's just like books. We don't, like, experiment much at that age [high school]"' (Participant 5, Interview 1).

Teacher training courses were also referred to by three of the six participants in their individual interviews. Participant 2 felt she had been taught to recognise scientific situations, "being aware of what you might find" (Participant 2, Interview 1). But Participant 3 felt the teacher training was insufficient. "One module once in training over the three years, when you think about it, is not enough to be able to come out and be confident" (Participant 3, Interview 1). When she reiterated her view in the focus group interview the reply from one participant was strongly contradictory. Participant 7 was in her final year of training so had not been involved in gathering data, but she had been involved in the focus group discussion. She felt her current training provided her with a "good grounding ... to then come out and have that confidence" (Participant 7, Focus group interview). Participant 3 felt the difference in opinions might be due to the different student teachers' previous scientific understandings, while Participant 7 questioned possible changes since Participant 3's training. A debate ensued, with Participant 6 stating that "you're never going to know everything," and that teacher education providers should focus on the "concepts rather than the content" (Participant 6, Focus group interview). Participant 1 concluded by reiterating the idea that "you can never have enough information" (Participant 1, Focus group interview). However, it is interesting to note that this was also the participant who felt she had sufficient subject knowledge for an early childhood teaching situation.

Having subject knowledge is "not simply about knowing something", but also understanding, "having a coherent, causal explanation" (Parker \& Heywood, 2000, p. 89 ). Most (5 out of 6) participants saw the ability to explain scientific theories as challenging. Participant 4 linked this to the difference between knowing an idea and being able to communicate it to others: "You'll be thinking the [teachers] might have enough [scientific subject knowledge], because of their schooling and everything. But they can't break it down to kids' level" (Focus group interview). Participant 2 reiterated the importance of effective communication as a vital teaching skill in the focus group interview: "That's the mark of the teacher isn't it, to be able to get through your knowledge to the child?" (Focus group interview). As she explained in her individual interview, "Being able to convey it to children is really important cos 
the way you do that makes a big difference to how they understand it [specific subject knowledge] as well" (Participant 2, Interview 1).

\subsubsection{Respond}

Just over half, 55\% (see Appendix D, Lines 5, $6 \&$ 7, Column A) of the incidents where participants noticed and recognised children engaged in scientific learning were responded to. It must be remembered that in the remaining $45 \%$ of situations the participants did not respond to the child's interest at that time but may have at a later date, or did not respond although a planned situation had initiated the child's interest. Participant comments indicated that not responding at the time could be due to a number of reasons, for example a teaching pedagogy of supporting peer learning: 'I'm quite happy with what I'm observing; I think it's really cool that there are times when I can step in and help them, but it's cool that they're doing it with their peers" (Participant 4, Interview 2). Some participants also referred to centre demands such as the teaching roster: "I try to [interact] probably not as much as I should cos sometimes I'm over by the music area instead. ... She just quietly gets along with it though" (Participant 2, Interview 2). These influences are elaborated further in the next chapter.

\subsection{Three types of responses to incidents noticed}

As mentioned previously participants responded to $55 \%$ of the incidents they noticed. They responded on $26 \%$ of the occasions immediately in a spontaneous way and on $28 \%$ of the occasions with planned follow-up activities. Six percent of the activities were planned for children's independent learning and spontaneously responded to by the participants (Appendix D, Lines 5, $6 \& 7$, Column A). The participants' interview comments regarding their support of children's scientific learning also indicated how participants saw their teaching role. The research data were collated around three broad categories. These were supporting the child's increasing knowledge base, supporting their developing understandings and ability to understand and use scientific processes, and supporting the child's scientific learning dispositions. The next section explores each of these types of responses in more detail. 


\subsubsection{Supporting the child's increasing knowledge base}

Only two participants overtly acknowledged their teaching role as increasing children's scientific subject knowledge although all referred to it in some way. Participants indicated they used their knowledge, as well as their lack of specific scientific knowledge, in supporting the children's increased scientific knowledge and understandings: "Just because I might not necessarily know what happens next. ... I'm quite happy to say: 'Let's go and grab the computer and look' " (Participant 6, Interview 1). In the focus group interview Participant 6 reiterated her viewpoint that a lack of subject knowledge is an advantage when it results in shared learning. "In some ways it is probably better if you don't [know] 'because then you're learning at the same - at the same pace" (Participant 6, Focus group interview).

While participants also shared their own scientific subject knowledge with children, there was also debate in the focus group interview on how much to share. This seemed to do with the participants' pedagogy, that is, understandings of NOS as well as their image of the child as a learner. In advocating for children in the centre Participant 2 commented: “we don't really point it out as specifically as we could and say 'Hey that's friction' and ... I guess I kind of think there is so little they don't understand. But they do and it's good to point it out" (Participant 2, Interview 1). However, Participant 5 had a different perspective saying, "I don't talk that much because I don't think they understand that much, I don't know. Bigger children can but little ones want to play with whatever they are doing" (Participant 5, Interview 2). For Participant 6, her ability to explain the concept in simple terms is a contributing factor to sharing her subject knowledge.

I find it hard explaining it, you know, so they'll understand it and think. But then, at the same time, I think not to dumb it down too much if they get enough exposure to it and all that stuff then they can grasp onto concepts. (Participant 6, Interview 1)

The use of scientific language as a way to expand on children's subject knowledge was debated as well. Participant 2 advocated for the use of correct terminology. "You need to use the right words for the right thing, and the children they can take it: They know even if they are little" (Participant 2, Focus group interview). However, Participant 4 expressed a reluctance to use scientific terms: "I guess it kinda freaks me" (Participant 4, Focus group interview). As Participant 6 concluded, teachers who don't use much scientific language “don't feel like they've got the knowledge or the 
confidence to back up the scientific descriptions. Or they probably want words language" (Participant 6, Focus group interview).

Along with joint learning, sharing teacher subject knowledge, and using scientific terminology, participants also gave examples of questions they had asked to encourage the child's further understanding of a scientific concept. These were constructed using the participant's scientific knowledge of the concept the child was interested in; for example, Participant 2 asking "what keeps you down on the ground?" (Participant 2, Interview 2) as she tried to encourage the child's awareness of the gravitational forces operating as she jumped.

\subsubsection{Supporting the child's developing understanding and ability to use scientific processes}

The idea of supporting children's understanding of scientific processes was also seen by the participants as an area for children to learn more about. A copy of an inquiry learning cycle was on display on the wall during the research indicating the teachers'

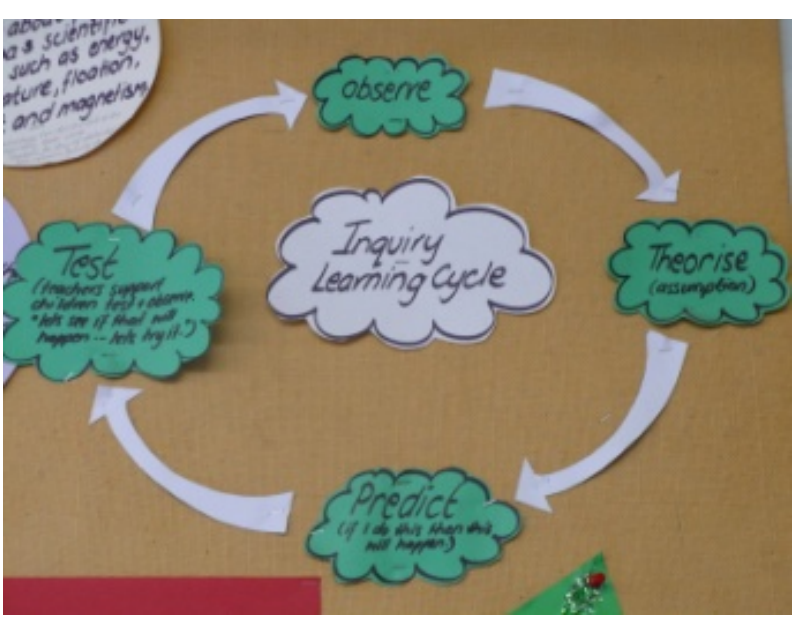

Photograph 3: Wall chart of inquiry learning cycle awareness of the cycle as well as a preference for this scientific method above others (Photograph 3). All the participants referred to the children 'finding out' or 'discovering things' with most also talking of the children needing to process their learning themselves, making links with what they already know and understand. Most participants also referred to experimentation as part of this process - as

Participant 1 (Interview 1) put it: "Prompting them to make theories of their own and discover if they try things."

This type of learning also required children to develop particular skills and participants referred to encouraging children to ask questions, build theories, find alternative solutions, observe, document and revisit their experiences (see Appendix O). For example Participant 6 spoke of turning her lack of scientific understanding into a strategy to encourage children's construction of working theories about the world 
(Hedges, 2007; Ministry of Education, 1996): “I didn't talk through the sand cos I didn't know how to explain it about wet and dry and those sorts of... but then they were talking a lot and generating their own ideas" (Participant 6). Participant 1 also spoke about providing opportunities for children to become familiar with specific scientific equipment, such as scales, and encouraged their use as tools for further inquiry.

\subsubsection{Supporting the child's scientific learning dispositions}

Learning dispositions have an important role in the assessment practices of the research site, so it was not surprising that all participants referred to encouraging children's learning dispositions in regard to science. The most common disposition mentioned was exploration (see Appendix O, Line 15). This appeared to refer to the child taking a lead in the learning inquiry and might be similar to what Carr terms as "taking responsibility" (2001, p. 24). The development of the disposition to communicate was supported through discussions where the child was encouraged to listen to the ideas of others as well as "express their own ideas in a range of ways" (Carr, 2001, p. 124). Two participants (see Appendix O, Lines 16 \& 17) also spoke about encouraging children's curiosity or "taking an interest" (Carr, 2001, p. 123). "It's about asking questions. It's getting them to ask: 'Why?' instead of just saying 'Oh, it's a rainbow'" (Participant 6, Interview 1). When asked if she saw some children as more engaged with scientific discovery than others, Participant 6 replied that it came back to the child's ability to ask questions as it moves or pushes them forward. In regard to teaching strategies that encourage children's development of dispositions Participant 2 commented on teachers' modelling dispositions: "If you show that you are curious and want to find out about things and want to find out about it then children take your lead. And science is about discovery isn't it. You know curiosity is a big part of it" (Focus group interview). Other dispositions were also evident in the data but were not explicit enough to be reliable data.

All participants also described situations where it was evident children were displaying learning dispositions such as a 2-year-old persistently and repetitively moving a toy train over carpet and lino surfaces (Participant 4, Interview 2) or a 4-year-old intrigued with balancing a variety of things on a daily basis in different situations from blocks to children. An awareness of the individual learning styles or personalities of the children seemed to be implicit in many of the participants' comments indicating their prior knowledge of the child. Participant 2 demonstrated this when she talked about "the child 
that really wants to get in there first" in group situations resulting in an adaptation of her teaching strategies, "so everyone gets a chance" (Participant 2, Focus group interview).

\subsection{Teaching strategies to support children's scientific learning}

Participants referred to a wide range of teaching strategies that they might use to support children's scientific learning depending on each situation: "Your strategies for one-on-one might be completely different to what you'd use for a group situation to cater for the majority of children" (Participant 3, Focus group interview). The next section explores various strategies used by the participants as they responded spontaneously or through planned follow-up activities. These include the use of curriculum documents and associated sociocultural learning theories to guide their responses as well as the way participants described their teaching interaction with children when supporting their scientific learning. It also includes the strategies of following the child's interest, revisiting learning situations, planning further experiences, documenting assessed learning, utilisation of the learning environment, and the employment of reflective teaching practice.

\subsubsection{Use of the curriculum}

The early childhood curriculum document, Te Whaariki (Ministry of Education, 1996), is designed to provide a framework for teachers to use and the outcomes provided within it are examples of possible outcomes and not set. However, it does refer to teachers providing children with "the knowledge, skills, and dispositions they need to tackle new challenges" (p. 9). As indicated previously (Section 2.5.2), the effectiveness of the curriculum is dependent upon the teacher's understanding of the sociocultural theories that underpin it. A direct question in regard to the participants' use of the document was not asked because it was felt that the use of jargon found within the document might not reflect participants' own personal views. Instead an analysis was done to find references made to the document, and the concepts promoted by it, directly or indirectly in individual and group interviews.

Half the participants explicitly referred to using Te Whaariki:

We use Te Whaariki a lot in our whole planning. In our long term as well as short term monthly/six weekly plans and there is always an aspect of discovery written in. We'd like children to achieve and learn and how we are going to do that. (Participant 1, Interview 1) 
Participant 2 (Interview 1) and Participant 3 (Interview 1) referred to the document's holistic and integrated nature: "It's just the science aspect is so interwoven with everything else in the curriculum" (Participant 3, Interview 1). All participants used terms commonly associated with Te Whaariki or sociocultural theory; for example, “working theories" (Participant 1 Interview 1), "scaffolding" (Participant 3 Interview 1), "dispositions" (Participant 6 Interview 1). Half the participants referred to the current planning incorporating a gardening project (see Section 4.4.5) with Participant 1 linking the project to the "exploration strand of Te Whaariki" (Participant 1, Interview 1). This appears to indicate that the participants in this study mainly drew on the curriculum document in general terms.

\subsubsection{Teaching interactions}

While the participants used a variety of terms to describe their teaching interactions with the children, all seemed to indicate a constructivist approach. However, for Participant 5 the degree to which this was done was dependent on the age (Interview 1 and 2). The diversity of terms identified in individual interviews was discussed by participants in the focus group interview and the general consensus indicated this was seen as a reflection of the individual nature of each teacher's pedagogy. This supports the point made by Hedges (2000) that variance in the use of terms indicates a difference in individual teacher pedagogy. Two of the participants (Participant 1, Interview 1; Participant 2, Interview 2) also cautioned not to 'over-guide' the child. Participant 2 pointed out in the focus group interview: "There is such a fine line between being really directive and letting the children choose their own course. ... when to stand back and when to get in there" (Focus group interview). The variation in terms is demonstrated in the table below where the principal words or term used by each participant is highlighted. 
Table 2: Participant descriptions of their teaching interaction with children

\begin{tabular}{|l|l|}
\hline Participant 1 & $\begin{array}{l}\text { Children investigating and the teacher being - assisting not necessarily } \\
\text { taking over what they are investigating }\end{array}$ \\
\hline Participant 2 & $\begin{array}{l}\text { Playing, just chatting and talking things through so they gain a deeper } \\
\text { understanding when you're there with them talking about things and } \\
\text { why things happen, the reactions that happen - so it's to guide them. }\end{array}$ \\
\hline Participant 3 & $\begin{array}{l}\text { Working alongside. Scaffolding children's learning and then } \\
\text { discovering together if you don't know the answer yourself - being } \\
\text { excited. }\end{array}$ \\
\hline Participant 4 & $\begin{array}{l}\text { It's kind of being a facilitator and just helping them to, you, know, } \\
\text { explore by the use of open-ended questions }\end{array}$ \\
\hline Participant 5 & $\begin{array}{l}\text { Basically just help them with it, if they need help. If they know about it } \\
\text { then just watch, maybe extend a little bit more. Or if there are little } \\
\text { children around tell them to help them. }\end{array}$ \\
\hline Participant 6 & $\begin{array}{l}\text { I think it's about asking questions. ... I think to definitely provide set } \\
\text { activities and stuff, stuff they might not otherwise encounter or think } \\
\text { about. }\end{array}$ \\
\hline
\end{tabular}

\subsubsection{Following child initiated learning}

Of the majority of the incidents noticed, $72 \%$ were initiated by the child (see Appendix D, Lines $9 \& 10)$. Some of these (26\%) (See Appendix D, Line 10) were followed up in some way by the participants. For example, Participant 1 talked about linking to planned activities later in the day: "I think I was just trying to work along their interest from the morning and to see how far they'd take it" (Participant 1, Interview 2). However, participants also responded immediately, as Participant 3 (Interview 2) said: “Often, if it's the child's interest, it's right now because you lose that moment." However, as Participant 6 (Focus group interview) notes, it can be hard to notice every child's interest as with 26 children a day "that might be 26 interests." Participant 3 agreed with this point of view, adding "that's a lot of relationships and it's all about relationships, the teacher and child's relationship as well as the child relating to their peers" (Focus group interview).

In the second individual interview participants related back situations where they had followed children's interests to varying degrees. This was done through discussion and resource provision, both of which require a degree of knowledge about the scientific concept concerned. Below are examples of comments from participants illustrating ways they spontaneously responded to children's interests through resource provision and discussion. 
Table 3: Participant quotes relating to following children's interests in a spontaneous way

\begin{tabular}{|l|l|}
\hline $\begin{array}{l}\text { Participant 1 } \\
\text { Interview 1 }\end{array}$ & $\begin{array}{l}\text { If I'm out on the floor and working with an individual or group or } \\
\text { something. I think I need this resource and I know that we've got it. }\end{array}$ \\
\hline $\begin{array}{l}\text { Participant 2 } \\
\text { Dictaphone } \\
\text { recorded data }\end{array}$ & $\begin{array}{l}\text { Child 1 I want there to be a rainbow. } \\
\text { Participant 2 You need rain for a rainbow. } \\
\text { Child 2 } \\
\text { Participant 2 Yoah. Rain and sun. } \\
\text { Child 2 } \\
\text { Participant 2 Yow do you know that H? } \\
\text { Yes. The sunlight goes through the little raindrops and when } \\
\text { it shines on the water it makes all sorts of pretty colours. }\end{array}$ \\
\hline $\begin{array}{l}\text { Participant 3 } \\
\text { Interview 1 }\end{array}$ & $\begin{array}{l}\text { It's [science is] something that you do quite spontaneously when you } \\
\text { see the child is interested and you think 'Oh, what could I do now?' }\end{array}$ \\
\hline $\begin{array}{l}\text { Participant 4 } \\
\text { Interview 1 }\end{array}$ & $\begin{array}{l}\text { They'll start making mountains and start talking about volcanoes, and } \\
\text { it's me being there to say yes, we can do it. ... It's trying to make it } \\
\text { happen for them trying to make them understand what goes into making } \\
\text { these things. }\end{array}$ \\
\hline $\begin{array}{l}\text { Participant 5 } \\
\text { Interview 2 }\end{array}$ & $\begin{array}{l}\text { It can happen anytime.... we can do it [floating and sinking] anytime we } \\
\text { use the water trough outside. }\end{array}$ \\
\hline $\begin{array}{l}\text { Participant 6 } \\
\text { Interview 2 }\end{array}$ & $\begin{array}{l}\text { He asked me because he couldn't do it [the body puzzle]. And I was } \\
\text { asking him, 'Oh, what comes off your shoulder?' ... And he would } \\
\text { say his hand ... but then he'd just pick up any piece and say 'Is that } \\
\text { my hand?' So then I showed him the actual hand and how it had } \\
\text { fingers like his. }\end{array}$ \\
\hline
\end{tabular}

In the focus group discussion developed around identifying exactly what the child's interests were and how the child would like to develop that interest, especially if the child is still developing language skills: "You interpret it one way and then that's the way they will then take it. It might not have been their initial interest that they brought up" (Participant 6, Focus group interview). It appears that the teacher's level of scientific subject knowledge also influences the degree to which they are able to follow the child's learning agenda rather than the teacher's version of it.

Childern's learning agendas can also change rapidly as this scenario demonstrates (Photograph 4). It started with Participant 6 (Interview 2) noticing and responding to two children's interests in sand castle making. This soon evolved into an interest in mixing sand and water, then a focus on creating rivers, followed by one on making imaginary wombat soup, and finally investigating what wombats look like on the computer with other children in a group situation (see Appendix S).

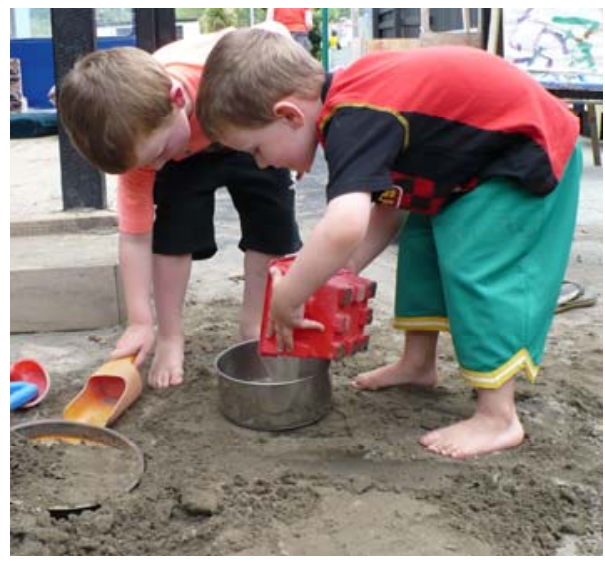

Photograph 4: Mixing sand and water 
This scenario also illustrates the integrated nature of children learning in early childhood learning as the teacher supported the children in the traditional curriculum areas of science, technology, mathematics, literacy, drama and physical development during that one situation. As Bibby (1999) pointed out, teachers having enough subject knowledge for this sort of situation can be challenging. Participant 2 explicitly mentioned the close links she saw between mathematics and science: "I did find that sometimes there was a bit of a fine a line between what I thought might be science and what I thought might be mathematics as well" (Participant 2, Interview 2). Participant 1 (Interview 2) and Participant 3 (Interview 1) took this further, indicating that the integrated nature of science can mean teachers engage in supporting children's scientific learning without consciously being aware of it: "I think science is everywhere and sometimes you have to remind yourself, oh that was science you were involved in. Or sometimes I find I unconsciously think, 'oh that was a science activity' " (Participant 1, Interview 1). Perhaps these comments also reflect the participants' views of what science (NOS) is and raise the question: can a teacher support a child's scientific learning without being aware of it?

\subsubsection{Revisiting learning}

The concept of revisiting a learning situation is increasingly being acknowledged as the next step in the process of 'notice, recognise and respond.' As the introductory booklet to Kei Tua o Te Pae states: "Feedback tells the learners what outcomes are valued in the learning community and how they are doing, and it acknowledges the goals that children set for themselves" (Ministry of Education, 2004, p. 6). This requires teachers to not only revisit learning experiences they have observed or shared with the child, but also those that the child has had outside of the learning environment. Te Whaariki has strong sociocultural theoretical links and so strongly encourages teachers to make links between the early childhood education programme and the child's home, stating that "the environment, routines, people, and happenings within and around a home provide opportunities for the spontaneous learning which should be a feature of all early childhood learning contexts" (Ministry of Education, 1996, p. 18).

The teachers at the research site followed the practice of revisiting learning situations and participants spoke regularly of talking with parents about their children's interests. As one participant commented: 
The parents offer what they're [their children] interested in at home and you can often put two and two together and come up with 'Okay, this must be a huge interest for him.' .....and you try to get out things that will fit in with that or extend it out a bit further. (Participant 3, Interview 1)

Sharing the child's learning was seen as a reciprocal process and participants also spoke of encouraging parents to link into the learning that occurs in the centre. This was generally documented in the form of 'learning stories' (see Section 2.5.3), but there were also examples of other ways given: "Allowing the adult to be able to jot down for them [the child] on their piece of paper - if they [the child] let them [the teachers], and that enables them [the child] to take it home to tell their parents about it” (Participant 4, Interview 1).

Although only half the participants, in individual interviews, overtly commented on finding out about children's prior knowledge (see Appendix O, Line 35), later in the focus group interview it became apparent that some of the participants had assumed it was a behaviour all teaching situations required and did not mention it:

I would have thought that if we were following the child's interest to extend
them more, really you need to find out what they already thought to guide
their understanding more and more. (Agreement from others) Because we
might not be extending them - we might just be going over what they already
know. (Participant 6 , Focus group interview)

This was also true for revisiting situations as again although only one of the participants overtly commented on it in the individual interviews (see Appendix O, Line 31), they all indicated its importance in the focus group interview: "If you are not going to talk to them about what they think they've learnt, and them telling you what they think they've learnt, how then to go to that next level, if there's no feedback happening” (Participant 3, Focus group interview). Participant 6 (Interview 2) also commented on children initiating revisiting situations relating an example of a 4-yearold with whom she had explored sinking and floating concepts sharing his knowledge on the topic with younger children in a peer learning situation:

It was funny 'because after I did it with one group of children - probably a week or so later and he was outside with the smaller children and it had been raining and there was water in the bottom of the plant - you know the dish the pots sit in - and they were floating sticks and things in it and he was talking about floating and sinking to the younger child. 
For some participants revisiting learning situations was also a way of addressing teaching barriers such as centre routine constraints, or other demands requiring their time.

They get involved, something so exciting, and then all of a sudden it's time's coming on, ... for example mat time, just before meal times and they tell you they don't want to leave the area. ..... But then I always try to say 'Look we can come back straight after lunch and revisit what we were working on.' (Participant 1, Interview 2)

\subsubsection{Planned responses: Daily activities and long-term responses}

Participants referred to two main ways where they planned scientific activities that supported children's scientific learning, these being planned daily activities (see Appendix O, Line 46) and long-term projects (see Appendix O, Line 47). Most of the daily activities referred to in the data were provided at a specific time of the day (between 12.30 and $1 \mathrm{pm}$ while the younger children were asleep), and specifically related to the interests of the older children attending. Activities provided at that time referred to included magnets, scales and weights, floating and sinking, and ramps. Teachers were rostered to plan for this time which explains some of the variance in participant data collection (see Appendix D, Line 3). Although not rostered on at this time, Participant 6 expressed her opinion that the activities should provide children with experiences that they might not have at home: "Well not get to do at home, but exposed to at home" (Participant 6, Interview 1). Planned daily activities also occurred at other times with all age groups involved. These were seen to promote spontaneous learning opportunities for children as well as teaching situations. Participant 2 (Interview 1) placed an emphasis on teacher planning, commenting that it's important to carefully think about "the activities you might want to set up and to have a clear understanding of what you are doing and why."

Long-term planning mentioned was in the form of a garden project to create teaching situations as well as spontaneous learning situations for children. The project started after teachers and children planted spring flowers. Due to the children's increasing interest in plants and insects the teachers decided to then create an edible garden. They asked the children what they would like to grow and staff and children planned and planted the garden together:

We did a big garden theme and we did lots of planting with the children and watching them grow and at the moment we've been regularly picking the fruit 
that we've been growing. ... Children go out and pick the silver beet for their lunches. (Participant 1, Interview 1)

Participant 1 also recalled making a teaching analogy by relating the plants' survival needs to what the children's own bodies need to survive, such as water, food, and sunlight. She commented on the high degree of spontaneous learning promoted as children were still interested in the project and regularly noticed the plants changing. "You find throughout the weeks, spontaneous moments within the day that they are going over and investigating" (Participant 1, Interview 1).

As the garden developed so did the possible learning outcomes. Participant 3 talked about what happened once some of the plants had turned to seed: "Now a lot of it has

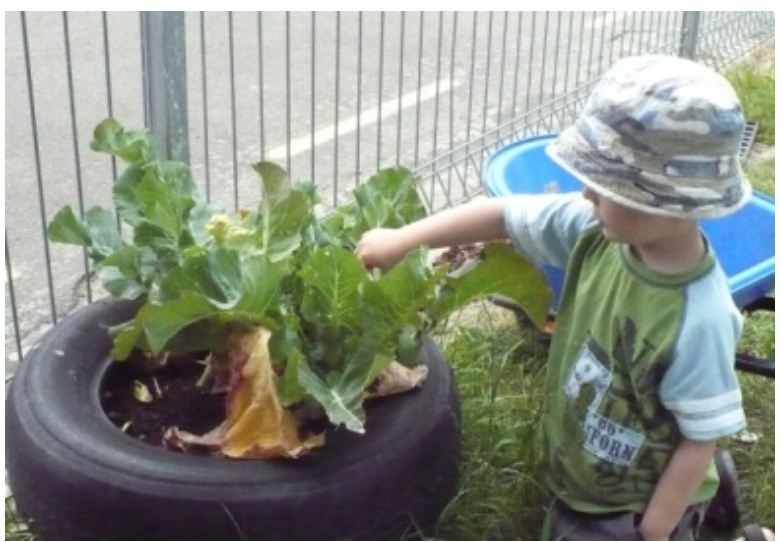

Photograph 5: Investigating plants turned to seeds. Which is another interesting concept in itself. What happens when you leave the plants and what can you do with the seeds?" (Participant 3, Interview 2). Anecdotal and photographic data identified one particular child at the centre whose knowledge of plants was extended during this project. Both Participants 1 and 3 related conversations regarding

the seeds in his pocket that he had brought from home:

As he was pointing to the head of the cauliflower he said, "Look, I've got some seeds from my house", and he brought them out and we tried to see what was different. The cauliflower is white and the seeds were black. And "what would they need to grow? Would they grow inside his pocket?' 'No' 'Why not?' And we talked about some of the things that do like to grow in the dark. (Participant 3, Interview 2)

It became apparent during the focus group interview that there had been an increase in the number of planned activities during the time of the research. This is likely to be the result of an increased focus on science teaching, for example Participant 1 following up on situations he had noticed earlier. However, it may also indicate a consistency, or inconsistency, in teaching pedagogy. Participant 3 (Focus group interview) felt that during the data gathering time the learning focus changed from the child's interest to the teacher's interest. "We were interested in doing that sort of stuff and having it out and seeing what the reaction was" (Participant 3, Focus group 
interview). Questioned if the children engaged in more scientific learning as a result of the participant teacher's increased focus in the area, Participant 6 (Focus group interview) said she "didn't notice a huge, huge difference in the way the children learned. There wasn't all of a sudden 'Oh look at this' or 'what's going on here?' or 'let's see'- you know - there wasn't that huge surge in their scientific exploration." Participant 6 was the last one to gather data due to the research data being gathered sequentially and had the opportunity to observe the changes occurring in the usual centre teaching practices as a result of the research.

\subsubsection{Documentation of assessed learning}

In line with New Zealand assessment practice (see Section 2.5.2) the learning that teachers recognised children engaged in was documented via narrative observations linked to dispositions called 'learning stories' (Carr, 1999), although as one participant commented these may not necessarily focus on science learning: "Not really heading towards making it so scientific but obviously with 'learning stories', you know I might talk about it but not actually hone in on the science aspect of it. Talk more about the interaction of it" (Participant 4, Interview 1). The 'learning stories' are usually shared and discussed with the parents, as Participant 3 reiterated in relation to one particular child. "We pick up on that [the interest] with an individual plan for him to incorporate some of the interests in that. If we are working on other things with the parents they also incorporate some of his interest as well. Things that spin, things that connect" (Participant 3, Interview 1). However, in the focus group interview it was also acknowledged by Participant 3 that some working parents find it hard to find the time to "share their interests and thoughts" (Participant 3, Focus group interview).

Participant 6 also spoke about encouraging children to document their own learning, giving an example of a chart for testing if different items float or sink. However, this was not so for other participants and in the focus group it was acknowledged that children are not very involved in the assessment process. Discussion then occurred around ways this could be built on such as a PowerPoint of the photos teachers take of children engaged in learning during the day, creating opportunities for teachers, parents, and children to revisit situations. 


\subsubsection{Utilisation of the learning environment}

Participants also used the environment of the centre as a teaching strategy to support children's scientific learning: for example, the designed landscape: "There are lots of different surfaces outside already that they go through. Like we got mulch, we got the sandpit, we've got wood and grass and lino and carpet as well" (Participant 2, Interview 1). Resources were also placed in the environment to encouarge specific types of scienitific learning (Photograph 6): "We got a pulley in the sandpit too and I do talk to them about it. Does it make it easier or harder when you pull it up?" (Participant 2, Interview 2).

Teachers also utlised the indoor environment for learning opportunities, for example the 'nature area', a small table in a corner of the centre that had a variety of objects on it, mainly

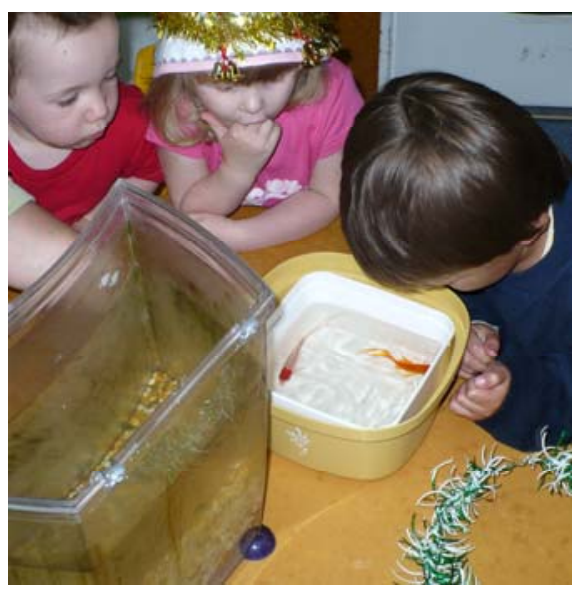

Photograph 7: Children helping to clean the fish tank relating to the natural world.

During the research period

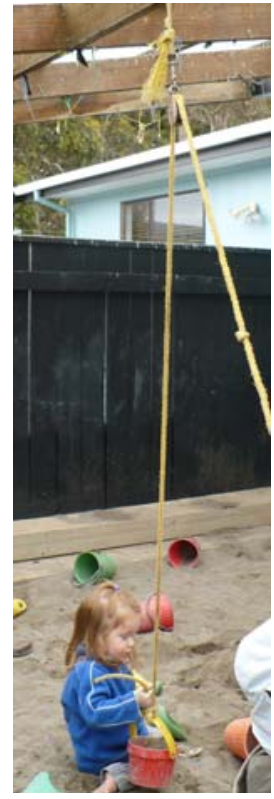

Photograph 6: The pulley

Participant 6 collected data on a group of children helping a teacher to change the water in the fish tank that is kept in this area (Photograph 7). Participant 3 also referred to changing the "nature table' around on a regular basis. All participants spoke of using centre resources, found within the learning environment, to foster children's understanding of scientific concepts. These ranged from commercial products, such as books, puzzles, blocks, slides, swings, magnets and pulleys, to recycled products such as ramps and collage.

Some participants (see Appendix O, Line 41) referred to acquiring new resources with Participant 1 (Interview 1) wondering "What else is out there on offer to enhance children's learning?" Resources were stored mainly indoors on open shelves, or placed outside daily where they were available to all the children: "It's so available there, they can approach, they can put it down low, they can go for whatever toy they like and they can experiment" (Participant 5, Interview 2). Participants also referred to regularly changing the location of some resources such 
as the large concave/convex mirror on a stand (Participant 3, Interview 2), or the outdoor challenge course (Participant 1, Interview 2).

Not all resources were available to children at all times. Participants also spoke of getting out resources as a spontaneous response to a child's interest they had observed: "I say, 'I'll go and get something that might help what we are doing, investigating.' And I'm quite happy to go off and get that to support whatever they are interested in." (Participant 1, Interview 1). The computer was also used as resource for specific subject knowledge by Participant 6:

We've got the encyclopaedia [CDRom], or we used to. It's been loved to death I think and we haven't been able to find a new one. And that was brilliant, it was really visual, it had so many pictures in it. But then the explanations were really simple. (Participant 6 , Interview 2 )

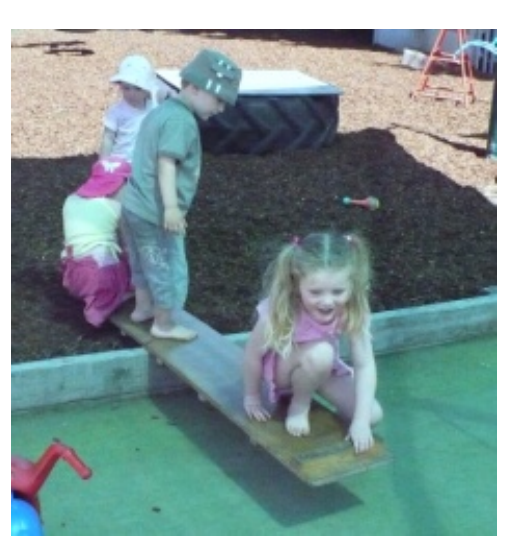

Photograph 8: Young child exploring balancing with friends
As well as supporting the teaching practice, the resources were also seen as facilitating children's independent learning. As mentioned previously these were situations where participants did not, or could not, respond to the learning situation they recognised the child was engaged in (Photograph 8).

We provide these planks just to lie around the playground and $\mathrm{H}$ initiated that play and pulled her plank over the little boundary fence where she was able to balance. ... That particular day she was encouraging her friends to get on the end to see how high she could stand on that edge lip. (Participant 1, Interview 2)

\subsubsection{Employing reflective practice}

New Zealand early childhood teachers are increasingly encouraged to adopt reflective teaching practices. For example, there are questions for practitioners to reflect on under each curriculum goal in Te Whaariki. It is therefore not surprising that all participants in this study commented on it as reflective practice is seen as a way for teachers to develop their teaching practice (Cochran-Smith \& Lytle, 1999; Fenstermacher, 1994; Gilbert \& Calvert, 2003; Hedges, 2004; Lemke, 2001; Smith, 2003). 
While this was a specific teaching strategy that the participants employed, it should also be acknowledged that the research methodology incorporated teachers' recollections and reflections of situations they had seen in the data gathering process. This required a degree of reflective thinking and fostered an increased awareness of science for some participants, for example: "I didn't realise that like throwing the ball or going up the slide and stuff like that [was science]" (Participant 5, Interview 2). For others, such as Participant 6 (Focus group interview), the research feedback also provided the opportunity to reflect on teaching strategies: "It's interesting about revisiting observations - it's just food for thought cos it's something I possibly need to think about doing more of, especially in science" (Participant 6, Focus group interview). In this way it's evident to also see how the participants used the research opportunity to reflect and develop their own teaching abilities.

Reflective practice was not only an individual endeavour but also a collective one. By the time the focus group occurred, two months after the data collection, all participants felt the degree of science learning they planned for in the centre was less: "Not noticing, recognising and responding as much as you would have been if it was still the focus" (Participant 3, Focus group interview). During the discussion on the increase in planned activities participants reflected on the possible causes and effects of this. Participant 7, who did not gather data but had observed others in the process, was only involved in the focus group interview. She too noticed there was an increase in participants' awareness of children engaged in scientific learning during the data gathering period and commented on her observation being around participants developing their own teaching styles, as well as their confidence in their ability to support children's scientific learning. As Participant 1 (Focus group interview) said: "I think in that period of time it made us all more aware." An increase in noticing children engaged in scientific learning initially appeared to result in increased learning support for the children. However, Participant 6 felt some of the participants had varied from the general socioculturally based centre pedagogy.

The table top activities were great but they were the same activities that could be brought outside. I mean lots of bugs and looking through magnifiers but we didn't take them outside and look at them. We were aware to a certain point and then it kind of stopped. (Participant 6, Focus group interview) 


\subsection{Conclusion}

Participants' understandings of the way they support children's learning in science indicated a congruence with current New Zealand early childhood practice, where teachers 'notice' children engaged in learning situations, 'recognise' the learning occurring, often 'responding' to it, and on occasions 'revisiting' the learning that has occurred. The pedagogical practices were aligned with common New Zealand early childhood practices promoted in the curriculum and supporting documents, such as following the child's interest, revisiting learning situations, sharing learning documentation, reflective practice and providing situations in the environment for children to initiate their own learning. However, the degree to which each of these practices was employed varied between participants and highlighted the interdependent nature of individual and collective teaching practices. This factor, along with participant comments on changes to teaching pedagogy during the research period, may also indicate variation in participants' understandings and incorporation of NOS and sociocultural theory into their practice. 


\section{Chapter Five:}

\section{Feelings about supporting young children's scientific learning}

\subsection{Introduction}

This chapter presents an analysis of the data that relates to the participants' feelings about their ability to support children's scientific learning. Past research (Alexander, 2000; Russo \& Rennie, 2003) has linked the way that teachers support children's scientific learning to the degree of confidence they feel. Although the term 'feeling' indicates an emotional state of mind, it may be observed and identified by the degree of confidence or attitudes shown by an individual. A number of attitudinal barriers previously identified in the research concerned teachers' confidence in, and attitudes towards, supporting children's scientific learning (Alexander, 2000; Fleer, 2001, 2009; Heap, 2006; Hedges, 2002; Kallery \& Psillos, 2001) and these are considered in the next section. However, other barriers participants felt influenced their ability to support children's scientific learning were also identified and were concerned with the way the centre operated, or what Hipkins et al. (2005) refer to as "day-to-day classroom realities" (p. 247). These are considered later in this chapter and mainly centre on participants' feelings regarding the difference between the ways they wanted to support children's learning and how they actually could support children's scientific learning within the educational structure of the centre.

\subsection{Confidence in, and attitudes toward, supporting children's scientific learning}

When asked specifically how they felt about their support of children's scientific learning, most participants in this research replied indicating that they felt positive about supporting children's scientific learning, using words such as 'love' and 'enjoy'. Participant 2 elaborated on this in the focus group interview commenting on the need for all teachers to engage in having fun with the children. Participant 3 added: "you can't just go along and say, 'well, I'm not going to do that because I don't like it.' It doesn't work like that" (Participant 3, Focus group interview). However, some participants also acknowledged that they did not feel confident about supporting children's scientific learning. One participant (Participant 2) related this feeling to gender, highlighting the predominance of the female teachers in early 
childhood (Farquar et al., 2006): "With so many females being in early childhood, I think that they do feel a bit scared and a bit worried about science" (Participant 2, Focus group interview).

During the course of the research participants' confidence in their ability to support children's scientific learning increased with half the participants indicating a significant increase in their confidence levels. Using a 10 point Likert scale, the participants self-rated their confidence resulting in half the participants seeing themselves initially as point 5 or under. The lowest self-rating was point 4 and the highest point 8 .

Table 4: Changes in participants' confidence level pre-study and post-study

(N.B. $7^{\text {th }}$ form equates to Year 13 under the present education system)

\begin{tabular}{|c|c|c|c|}
\hline Participant & Science education received & Pre-study confidence & Post-study confidence \\
\hline 1 & Not specialised in & 4 & $6-7$ \\
\hline 2 & $7^{\text {th }}$ form biology & $5-6$ & $6-7$ \\
\hline 3 & $6^{\text {th }}$ form biology \& chemistry & $8-9$ & $9-10$ \\
\hline 4 & $7^{\text {th }}$ form biology & 5 & $7-8$ \\
\hline 5 & End of school in India & 5 & $6-8$ \\
\hline 6 & $7^{\text {th }}$ form biology \& chemistry & 7 & $7-8$ \\
\hline
\end{tabular}

In the focus group interview participants acknowledged an increase in dialogue about science between themselves during the data gathering time of the research. Half the participants (3 out of 6) commented on the increased confidence this dialogue supported and changes to their teaching practice as a consequence. There was a consensus among the participants at the focus group interview that, although the research had finished and the discussions between participants were no longer focused on science, the increased confidence in noticing, recognising and responding to children's scientific learning had remained. Participant 2 once again broached the influence of gender, expressing her opinion that girls see themselves as less inclined to science (Gilbert \& Calvert, 2003).

I get the feeling that a lot of us weren't so confident as scientists, teaching science or as scientists. But when you really came down to it, doing the proposed research I think we would have realised 'yeah we can do it' and it's not so much of a boys' activity. For girls, we are actually pushing science. (Participant 2, Focus group interview)

Previous research has highlighted the significant influence of teachers' attitudes in the way they support children's learning. This relates to the teachers' confidence in, 
and attitude toward, their scientific knowledge base (Hedges, 2003; Hedges \& Cullen, 2005; Parker \& Heywood, 2000; Smorti, 2005); their attitude to 'science' and what they understand it to be, or NOS (Heap, 2006); and their attitudes to their own learning opportunities. The findings in this research confirmed previous studies and indicated the attitudes of the participants in this particular setting. These are explored in the following section.

\subsubsection{Attitudes toward scientific content knowledge}

Teachers who are confident in their subject knowledge are more likely to recognise the potential learning and know how to maximise it (Anning \& Edwards, 1999; Fleer, 2009). Participant 1, while having the least science education of all participants, did not appear as concerned about her possible lack of scientific knowledge as other participants. Instead she said the children's responses to the learning support she provided increased her confidence:

I feel pretty good... [It] makes me feel more confident that I'm on the right track, though their responses. ... Later on they might come back to me and want to revisit that same thing we've just worked on and that gives me confidence. (Participant 1, Interview 1)

While admitting that she had limited scientific knowledge (Interview 1), she saw confidence as the main enabler to teachers supporting children's scientific learning. This was not just confidence in using the scientific subject knowledge she had but also her confidence in her teaching pedagogy: "But if you're confident in helping them to investigate whatever they're interested in, I think that helps" (Participant 1, Interview 1). This indicates the complexity of the situation with confidence, attitudes and personal teaching pedagogy all influencing the way that this participant felt about her support of children's scientific learning, and consequently the teaching strategies she employed to foster children's further learning.

Most of the participants in this study related their degree of confidence to how they felt about their school science experiences. This was most noticeable in Participant 4, with the lowest confidence self-rating, "I'm not confident in what I know" (Participant 4, Interview 1). She speaks of enjoying going to classes at secondary school, and "found it quite interesting, but really, at the end of the day it didn't work for me. ... I didn't get good results out if it" (Participant 4, Interview 1). At the other end of the spectrum Participant 3, who felt the most confidence in her knowledge and 
abilities, stated that she "loved science at school" (Participant 3). As Participant 6 commented in the focus group interview:

If you hadn't had that [positive] experience you probably wouldn't feel confident or happy teaching science either. Which would make a difference to your teaching and what you did, I suppose. But if it was a positive one you'd possibly be quite out there and quite scientific in your teaching. (Participant 6 , Focus group interview)

This was certainly true for Participant 5 whose comments illustrated the immense barrier a lack of confidence in one's own scientific knowledge base can create: "Sometimes I don't want to talk about it [science concepts], maybe because I think I don't know much about it" (Participant 5, Interview 1).

This links to the idea of the teacher's confidence relating to her ability to draw on a set of correct scientific facts in order to support children's scientific learning. Providing children with 'the right' scientific explanations was seen by Participant 4 (Interview 1) as inhibiting her ability to support children's scientific learning. However, in the focus group interview Participant 3's response to this feedback was: "why would you want to 'get it right', when it's meant to be a process of discovery?" While previously indicating that they also have a discovery approach Participant 1 and Participant 6 empathised with a desire to 'get it right' and could see how teachers would not want to give misinformation. This debate illustrates the participants' understanding of NOS, maybe another factor influencing how they feel about their knowledge base. In conclusion to the debate Participant 6 expressed an opinion that how a teacher uses the information would make a difference to the type of approach taken. An illustration of this might be Participant 2's earlier comment (Interview 1) about using reference books to plan activities "just to make sure I get it right as well." This would enable her to teach in a co-constructive manner while still feeling confident in her knowledge base as she draws on it.

However, it also indicates that how a teacher feels about their knowledge base also influences the types of situations they engage in to support children's learning. This resulted in more support of children's scientific learning occurring during formal as opposed to spontaneous situations (Alexander, 2000; Hedges, 2002) (see Sections 4.2.2 and 4.2.3). In her first interview Participant 2 indicated her preference for planned science experiments rather than the unpredictability of spontaneous situations: "I would personally like to gain more confidence and more understanding 
about the concepts and ideas that could happen spontaneously" (Participant 2, Interview 1). Unfortunately, limiting the teachers' support of children's scientific learning to planned situations results in many missed learning opportunities for the child to relate their scientific working theories to their everyday centre experiences (Fleer, 2009; Hedges, 2002). The link "between knowing science and knowing science as it relates to the everyday cognition of children is significant" (Fleer, 2009, p. 1074). If teachers have inadequate subject knowledge does the pre-literate child's reliance on the teacher's possibly incorrect subject knowledge base as a source of knowledge result in unusual connections being made between ideas, and a misunderstanding of scientific concepts?

\subsubsection{Attitudes towards NOS}

Although it was not an initial emphasis of the proposed research, during the analysis it soon became evident that the way the participants viewed NOS strongly influenced the way they felt about their teaching. In the initial interview research participants were asked what they thought science was. While the majority of participants referred to science as an action word, seeing it as "exploring and finding out things" (Participant 2, Interview 1), the replies to this question were broad. Some, like Participant 1, also acknowledged a lack of understanding of NOS: "I've always been scared of science but I think sometimes I don't have a really good understanding about it" (Participant 1, Interview 1). The research analysis clearly indicated that the participants had varied understandings of what science was (NOS). Some participants spoke of supporting the development of children's scientific subject knowledge (see Section 4.3.1). The development of specific skills (see Section 4.3.2) was also seen by some as necessary. The primary school trained participants (Participant 2 \& Participant 6) placed the most emphasis on scientific processes, one stating science was "a way of finding out why" (Participant 6, Interview 1). It is interesting that while the early childhood curriculum makes no reference to concepts of NOS, the primary school curriculum describes NOS as an overarching and unifying strand where children "learn what science is and develop the skills, attitudes, and values that provide a foundation for further study" (Ministry of Education, 2007, p. 20). 
Table 5: Participant answers to: "What do you think early childhood science is?” (Interview 1)

\begin{tabular}{|c|c|}
\hline Participant 1 & $\begin{array}{l}\text { Having children explore and investigate. And like using their actions } \\
\text { on what they do with, whatever they might be working with. }\end{array}$ \\
\hline Participant 2 & $\begin{array}{l}\text { Children learning and exploring ideas and exploring things around } \\
\text { them. Because they are all scientists, they are all inquisitive and it's } \\
\text { just finding out what things do and where things go. }\end{array}$ \\
\hline Participant 3 & $\begin{array}{l}\text { The beginnings and formations of concepts about science, and getting a } \\
\text { child's interest. }\end{array}$ \\
\hline Participant 4 & $\begin{array}{l}\text { The beginning of their science introduction. Introduction to science and } \\
\text { it's the basics. The base to what they could do in the future with } \\
\text { science. }\end{array}$ \\
\hline Participant 5 & Science for children is whatever they do, whatever they experiment. \\
\hline Participant 6 & $\begin{array}{l}\text { I think it's about asking questions. It's getting them to ask 'Why?' } \\
\text { instead of just saying 'Oh, it's a rainbow.' }\end{array}$ \\
\hline
\end{tabular}

During the research all participants commented on science as an everyday occurrence embedded in the daily events of the centre. While this view of science seems synonymous with NOS, it may also disguise a legitimisation of a lack of scientific awareness for some participants: "I think I you can probably find the science aspect in anything really" (Participant 6, Focus group interview); "You don't realise what's science until you really have a look at what's happening out there and they're doing it all the time" (Participant 1, Interview 1). Yet the way this idea was translated into teaching situations showed a variation in the way this belief was held. For example, the increase of planned activities during the time when participants were gathering research data suggested a change in what some participants' view of science education was (see Section 4.4.5). Debate in the focus group interview questioned the degree to which the planned teaching activities were in line with what some participants thought they 'should be doing' to support children's scientific learning rather than what they usually did (see Section 4.4.5). Participant 1 (Focus group interview) reflected on her teaching: "I sometimes wonder if there wasn't that level of interest there. It was just about science." In contrast, Participant 6 felt there was no change in her teaching during the research time, possibly indicating her strong understanding of NOS.

I don't think I respond any differently now to a science concept than I did then. .... I don't think I set up the level of science activities for children at times often cos, well.... I was one of those people who think science is in everything anyway; even washing your hands is a scientific concept if the children are asking about water and all that sort of stuff. So I still think that if a child asked that question I'd still certainly respond to it in a scientific way. (Participant 6, Focus group interview) 
Those who felt confident in supporting children's scientific learning appeared to have a view of NOS synonymous with the definition put forward by Adb-El-Khalick, Bell and Lederman (1998, cited in Heap, 2006). This sees NOS as: tentative; empirical; inferential, imaginative and creative; subjective and theory laden; and finally socially and culturally embedded (p. 16) (see Glossary). Other participants' actions and comments, particularly those who identified themselves as less confident, did not always indicate the same degree of congruence. For example, some participants (4 out of 6) spoke about specific science experiments, giving examples such as watching baking soda and vinegar react together (Participant 4, Interview 1), and trial and error with floating and sinking objects (Participant 5, Interview 1), which appeared to have no link to other learning experiences about those scientific concepts.

Hipkins et al. (2005) suggest that a lack of supporting children's understanding of NOS by teachers is largely due to "educational traditions and day-today classroom realities" (p. 247). Half the participants referred to high school experiences leaving an impression that science was a specific body of knowledge learnt through a series of specific experiments. For some this view of NOS initially impeded their ability to notice children engaged in scientific learning. However, this changed during the course of the research with most (4 out of 6) participants identifying an increased awareness of children engaged in scientific learning during the research period and as such also developed their understanding of NOS. When asked after data collection if she had noticed much scientific learning occurring, Participant 4 replied:

\footnotetext{
I think I saw it quite easily because I felt like I was more open to seeing it. I think I was more conscious of seeing it wasn't just me looking at the actions. It was me looking at the actions and the science behind it. (Participant 4, Interview 2)

When you think about science, you know, experiments an all that. ... Then going further, going from that one belief, 'yeah, that's science', to seeing all science happening and thinking, 'Oh, that's science and I didn't think of it that way before.' (Participant 4, Interview 2)
}

Participant 4 explained how her personality and her school experiences are still influencing her understanding of what science is: "I'm a person who likes to do things right. I suppose that impacts on my attitude to how much science I do because of my not too flash past with science" (Participant 4, Interview 1). Although this participant specialised in biology to $7^{\text {th }}$ form level (Level 13) at secondary school, she found her belief in a need to remember specific scientific facts still inhibited her ability to support children's science. 


\subsubsection{Attitudes to learning opportunities}

An attitude of openness to learning from a variety of sources was evident in all participants' comments. This attitude was not only to their own learning endeavours but also learning with the children and from children. One narrative that emerged from the data involves half the staff and is about a child's interest in viscosity (see Appendix Q). The interest had developed at home and while one participant knew about viscosity, for other participants this was a new scientific concept to learn about.

Table 6: Participant comment on their own scientific learning

\begin{tabular}{|c|c|}
\hline Participant 1 & $\begin{array}{l}\text { I think personally that if you go in on the same equal par as the child it } \\
\text { helps me learn and the child learn at the same time. }\end{array}$ \\
\hline Part & $\begin{array}{l}\text { I believe that we are always learning. Everybody's learning all the time, so } \\
\text { I believe that we learn with the children with the science ideas. }\end{array}$ \\
\hline Partic & $\begin{array}{l}\text { I learn by doing - very much - my own learning style is by doing - writing } \\
\text { and doing and pulling apart - yes that's my way of learning. }\end{array}$ \\
\hline Partic & $\begin{array}{l}\text { I think other teachers' support is one. I want to use the internet quite a bit. } \\
\text {.... I'm not really one to go to the library and get books. ... When there's } \\
\text { another teacher around it doesn't depend on me sometimes it could be that } \\
\text { the other teachers have the knowledge of that. }\end{array}$ \\
\hline Participant 5 & $\begin{array}{l}\text { The main thing for me is that when somebody sees something and they ask } \\
\text { me about it. And that way I am getting knowledge as well as them getting } \\
\text { something out of it - I just go for it. }\end{array}$ \\
\hline Participant 6 & I like looking things up and finding out why and all that sort of stuff. \\
\hline
\end{tabular}

The increased teacher dialogue around science during the research period also supported a growing knowledge base and understanding for some participants. For Participant 4, her increased awareness of children engaged in scientific learning enabled her to use more available resources to support children's scientific learning. This was demonstrated in her articulation of the science learning occurring at the swing area.

That is $\mathrm{H}$ and she's talking away about, 'Do I need to push you?' ... And it's her using the force behind her to get them to go because they're telling her they want to go high and fast and it's her trying to get in behind them and help make it happen. (Participant 4, Interview 2)

Half the participants overtly referred to their own attitudes to learning, or learning dispositions as described by Carr (1999, 2001) (see Section 2.5.3): "Taking an interest" (Carr, 2001, p. 25), or having an inquisitive disposition, was identified by 
participants as "curiosity" (Participant 2, Focus group interview) and "exploration" (Participant 3, Interview 1). All participants spoke of the importance of "being involved" (Carr, 2001, p. 28). For example, Participant 1 (Interview 1) commented that she was "a more spontaneous person than planned" and referred to being a "hands on person." Participant 3 (Interview 1) also identified "persisting with difficulty" (Carr, 2001, p. 300) or determination: "I'm quite a determined person. Perseverance, once I get hold of something it's not often that I ditch it." When asked if that was in regard to supporting children's learning, she indicated her assent by giving examples of questions she would use indicating her own attitude to learning: “Let's find out. Are you happy? Have you found out? If you haven't found out, what do you need to know? What are we going to do to know more? How are we going to manage that?" (Participant 3, Interview 1). "Communicating with others" (Carr, 2001, p. 32) was a learning disposition often commented on especially in regard to drawing on and learning from the knowledge of others in the teaching team. Finally participants spoke about "taking responsibility" (Carr, 2001, p. 34) in furthering their own scientific learning and expressing their point of view within the teaching team. For example Participant 1's response to her lack of subject knowledge was to seek additional training, "I might need to do some professional development for myself to encourage science and how I can implement it more" (Participant 1, Interview 1).

\subsection{Day-to-day realities: Barriers and enablers in supporting children's scientific learning.}

The day-to-day realties of having children of a wide variety of ages in one educational setting, multiple demands placed on the participants in their teaching roles, and perceived time constraints were all identified as sometimes inhibiting the participants' ability to support children engaged in scientific learning. Rather than participant attitudes inhibiting their ability to support children's scientific learning, these barriers were in regard to the educational structure of the centre. Not all influences were negative with having adequate resources, employing reflective teaching practices, and collaborative team teaching practices all identified as enabling participants in their support of children's scientific learning. These are explored in the following section. 


\subsubsection{Teaching infants, toddlers and young children in one setting}

Up to 26 children aged 8 months to 5 years attend the case study childcare centre at any one time with a total of 35 attending the centre during any given week. All the participants commented on the range of ages providing challenges to teaching:

I think depending on your setting and the age range of your children, it does make things a little bit more difficult. We're a mixed centre catering for children from 4 months to 5 so we have that huge range. And to leave out lots of science things for the older children to do may not be the right thing to do for all children within the centre. (Participant 3, Interview 1)

Half the staff ( 3 out of 6 ) mentioned the babies', or infants', presence as inhibiting certain activities, for example the use of certain chemicals or small wires (Participant 5, Interview 1). As Participant 3 (Interview 1) said, "Sometimes a health and safety issue can become quite frustrating for those older children."

As indicated previously (see Section 4.4.4), participants saw ways in which children's scientific learning was also supported by being amongst older children, and more knowledgeable peers. Participant 3 gave an example of this situated in the sandpit.

There was a birthday party happening in one corner. .... And then over on the side were $\mathrm{Z}$ and $\mathrm{S}$. And as the bigger girls were tipping and pouring $\mathrm{S}$ was picking up the sand in her hands above her head and then just letting it go. (Participant 3, Interview 2)

She mentioned that the younger children carried on the activity long after the older ones had left. "These little ones were just sitting and watching and doing their own thing on the side but always mindful of what the other girls were doing" (Participant 3 , Interview 2).

Comments in regard to providing age appropriate activities for children were also expressed by one participant in the individual interviews, once again highlighting the strong influence of teachers' personal pedagogy in the way they support children's scientific learning. Perhaps this is an indicator of "coming to terms with what the adoption of socio-cultural theory might mean in practice" (Jordan, 2003, p. 3). During the focus group feedback Participant 3's response to this was immediate: "that's not the way we all do it" (Participant 3, Focus group interview) indicating a tension regarding the apparent variance in personal pedagogies. 


\subsubsection{Multiple demands}

The multiple demands placed on participants in their diverse teacher roles were also seen as influencing the ways participants felt about their support of children's scientific learning. It was mentioned as a reason for not immediately responding to learning incidents, as well as the degree of focus given when responding to the child's interest. Participant 6 commented "You know that if there are only 2 children involved ... there are also another 10 children outside you have to be there for" (Participant 6, Interview 1). Also acknowledging the impossibility of following every child's interest she comments that "the child's interest might even take a back seat" (Participant 6, Interview 1). Her response to the situation was to modify her teaching strategies: "If the child is not very social it might be an opportunity to kind of incorporate them more at group time" (Participant 6, Focus group interview).

Some participants ( 2 out of 6 ) mentioned how the care requirements of the younger babies at times required precedence over other teaching roles:

They [the children] ask questions and you've got 50 million things to do and a baby that you're feeding. So if you can remember to come back to it, or grab them a book or something that they can look at for themselves. (Participant 6 , Interview 1)

One of the strategies employed by all participants to address the multiple demands on them was to work together collaboratively:

[It] was really good, that helped because there was T [Participant 6]. And one parent was there and they were with the little children. And the little children played in that area while the other area's free for the other children, the older children. (Participant 5, Interview 2)

\subsubsection{Time constraints}

While the participants also supported children's scientific learning in a spontaneous manner, having insufficient time for planning activities was seen as inhibiting for some participants (3 out of 6). However, Participant 2 points out: "You might think 'Oh, I might not have enough time' but I also think that's probably a personal thing too, because you can always make time, and you can always do things over days or weeks" (Participant 2, Interview 1). Participant 6 commented: "There never seems to be enough hands, or time in the day" (Interview 1). 
Another time restraint impacting on the effectiveness of the participants' learning support was the daily timetable of centre routines. Participants commented on children's learning and their own teaching opportunities being interrupted by these: "You think 'I've only just started, now I've got to put it away' " (Participant 3, Interview 1). However, centre routines were also used to maximise children's learning. Most participants felt the optimum way to foster complex science concepts and encourage the older children's scientific learning were through the planned activities provided just after lunch, when the younger children would be asleep and the child/teacher ratios would be lower.

\subsubsection{Resourcing}

All participants spoke about easily accessing specific resources purchased by the centre as well as recycled materials, such as the equipment used by Participant 2 for making 'telephones'. Participant 3 had the responsibility for additional purchases and felt the price of commercial resources that help teachers to support children's scientific learning was often expensive, limiting her choices. Participant 5 pointed out the problem of too many resources at one time in the outdoor area: "They wanted to play ball but there were lots of bikes out" (Participant 5, Interview 2). However, at the focus group interview it was felt that generally there was ample space. Most (4 out of 6) of the participants spoke about using books as a resource for their own learning, as well as for the children's learning. Participant 2 commented on how the long working hours make it harder to access the library, while Participant 6 overcame this by using the centre's library card and going with the children. This once again illustrates the differing teaching pedagogies within the teaching team at the research site.

\subsubsection{Reflective teaching practice}

The research data indicated many situations where the participants used reflective teaching practice as a way to increase the effectiveness of the scientific learning support they provided for children. Being a research participant increased Participant 4's and Participant 5's ability to notice children engaged in scientific learning along with increased confidence in responding. Participant 6's reflections increased her awareness of how she went about supporting children's scientific learning. "I thought I only did 'set up' things and I didn't use the spontaneity and chances offered as much as what I did" (Interview 2). Reflective comments emerging from the focus 
group discussion on the increase in scientific table top activities (see Section 5.3.5), and providing more feedback to children on their learning (see Section 4.4.8), illustrate the way that the participants also reflected as a team, resulting in challenges and possible changes to practice.

\subsubsection{Teacher collaboration}

Collaboration between teachers was often mentioned as a solution for barriers by participants. It was seen as providing teaching support and increased learning opportunities for children. Participant 1 commented on the good communication skills this requires: "Communication from myself and the teaching team for you [a teacher] to be able to get in there in those teachable moments and be able to work and extend children" (Participant 1, Interview 1). Collaboration took a variety of forms such as participants sharing their knowledge and skill base, as well as jointly implementing centre planning for children's learning, and providing opportunities for each other to teach. This indicates that teacher collaboration is a significant factor to consider when looking at the way individual teachers support children's scientific learning.

During the interviews it became clear that Participant 3 and Participant 6 were viewed as having more knowledge in the area of science by Participant 4 and Participant 5. Participant 4 (Interview 1) commented on the other teachers help: "when you get stuck being able to help to explain something, being able to help build your personal subject knowledge" (Participant 4, Focus group interview). This was commented on further by Participant 3:

There's each other's knowledge, because there's some of us that would have a love of science and wanting to do those things. And some who, for whatever reason, do take a little bit of a back step in it, because of a confidence thing. And when you can draw on someone who has the expertise to be able to give yourself the confidence to try something. (Participant 3, Focus group interview)

Scientific knowledge was not the only form of knowledge shared, as Participant 4 was referred to as the centre's technologist especially in regard to computers.

Participants often referred to jointly implementing the centre's learning plans: "You have a feeling that you're the only one doing it, but you've actually got everyone around you having some input into that" (Participant3, Interview 1). Participant 2 
(Interview 2) also commented building on teaching experiences children may have had with other teachers, especially in regard to one child's fascination with inclined planes and balancing. A collaborative approach to teaching situations was also evident in the documentation of children's learning: "I am still able to write up a learning story about children I've seen there and pass it on to the next colleague and vice versa" (Participant 1, Interview 1).

Sometimes other teachers in the team also provided physical support for participants to overcome the barriers of multiple demands and time issues: "If you're on babies and you have something you want to do with the children you can say 'hey, do you want to swap with me for an hour?" (Participant 6, Focus group interview). Participant 3 gave a different example where the support provided involved several teachers at one activity.

\begin{abstract}
You need another set of eyes to see things as well, because you're busy trying to include all the children and keeping your eye on them. And you may miss something and that's really important. And just because you're tied up and that ... it just goes and you lose it. (Participant 3, Focus group interview)
\end{abstract}

\title{
5.4 Conclusion
}

All the participants in this study had a positive attitude towards supporting children's scientific interests, although some felt unsure of their abilities to do this. Secondary school experiences of learning science appeared influential in the development of most participants' confidence to support children's scientific learning. For some this reinforced a lack of scientific subject knowledge that hindered their teaching role. But this was not true for all as some turned their lack of knowledge into opportunities for shared learning. Secondary school experiences also appeared to influence the participants' understanding of NOS. This indicates an alignment with research linking teachers' views of NOS to types of teaching strategies employed (Alexander, 2000). Understandings of NOS varied between participants and for some changed during the course of the research. The complexity of attitudinal teaching influences and the way they interrelate was further demonstrated by the attitude of the participant with the least amount of secondary science schooling who engaged confidently in supporting children's scientific learning, thereby negating barriers other participants felt. 
The other main enabler in supporting children's scientific learning identified by the participants was teacher collaboration. This proved to be a significant factor in considering how individual teachers support children's scientific learning and was evident not only in providing additional subject knowledge, but also by providing a means to address barriers created by the day-to-day realities of a wide age range of children in one setting, and multiple demands on participants' teaching time. 


\section{Chapter Six: \\ Taking personal, interpersonal and cultural-institutional \\ foci of analysis}

\subsection{Introduction}

In the past two chapters the research findings have been presented in line with the two parts of the research question. In this chapter Rogoff's (2003) three foci of analysis - the personal, interpersonal and cultural-institutional (see Section 2.2.2) have been used as a way to discuss these findings in light of past research. This sociocultural model of analysis has been adopted to capture the complexity and breadth of the findings. The three foci enable the findings to be viewed in light of the individual participant, the individual participant's interactions with others and the cultural-institutional influences on the individual participant. In this way an integrated description of how these early childhood teachers perceive their support of children's scientific learning is derived.

\subsection{The individual participant}

In the first focus of analysis, the personal, the findings on the individual participants are considered. Of note was the interplay of teaching influences such as various teacher attitudes or different day-to-day teaching realities experienced within the educational setting. While there were many commonalities in the participants' descriptions of their support for children's scientific learning, there were also many ways in which participants expressed their own personal individual viewpoint, or pedagogy, illustrating the individual nature of teaching. Significant differences in viewpoints emerged around individual participants' teaching pedagogies, participants' understandings of NOS and their perceptions of their subject knowledge. This is similar to Rivalland's (2007) findings on the "interplay between personal beliefs and practices" (p. 30). She found that the degree to which the participants in her study appropriated the official discourse "was dependent on the individuals' personal interpretations and level of interconnectedness to their intricate belief systems" (p. 36). 


\subsubsection{Individuals' pedagogies}

The main ways the participants in this study supported the scientific learning of the children at the research site during the data gathering time reflect the socioculturallybased teaching pedagogy promoted by the New Zealand government as well as the early childhood teaching community. Rather than providing a programme of learning around a pre-selected scientific concept, the participants identified children demonstrating an interest in specific scientific concepts. The children's environment was carefully constructed and resourced to engage children in learning experiences. Both in recognising the child's scientific interest and creating a scientifically engaging environment, the participants used their knowledge of the child, the scientific concept the child was interested in and their early childhood teaching pedagogy, or PCK (see Section 2.3), to encourage the child's further understanding, or working theory of scientific concepts. However, the majority of observations were not immediately responded to, mostly due to teacher pedagogy and conflicting requirements within the educational setting.

Participants spoke of documenting some of the learning situations they did respond to, both spontaneous and planned, and sharing these with the parents. The comments parents made and the participants' reflective teaching practices often resulted in planned situations for children to revisit ideas and explore. In this way the participants 'noticed' children engaged in learning situations around concepts they 'recognised' as scientific. They sometimes 'responded' to these, and on occasions documented and 'revisited' them in order to support the child's scientific learning. The idea of progressive filters (Ministry of Education, 2004, booklet 1) can be seen as the participants "respond to a selection of what they recognise" (p. 6).

Discussions with parents regarding children's learning made explicit what the participants and the parents saw as valued knowledge, for example an interest in viscosity (see Appendix Q). The discussion also provided the opportunities for parents and participants to gain a greater understanding of the child's exploration of their scientific interest. Gaining a greater understanding of the context in which children's prior understandings of a concept are formed enabled both parents and participants to contextualise and make links when supporting the child's further understandings of that concept. As Fleer (1997) stresses, when the child takes the lead in their own 
learning and the teacher discusses their view of the child's learning with the parents, diverse cultural perspectives are able to be acknowledged and supported.

While the strategies outlined above illustrate the congruence with current New Zealand early childhood practice, it is also important to remember that although the official discourse was used by all teachers, the degree to which they appropriated the ideas was dependent on the their personal interpretations and the level of interconnectedness they felt with their "intricate belief systems" (Rivalland, 2007, p. 360). This was evident in the different terminology individual participants used to describe their teaching interactions when extending children's scientific understandings, and confirmed in the focus group discussion: "I think as individuals we all have different degrees and different ways of doing things with children" (Participant 3, Focus group interview). However, the terminology also referred to differing degrees of support offered by the teacher (Hedges, 2000). Thus the variation in terminology also signals a variance in pedagogy and the way the teachers have interpreted the sociocultural concepts embedded in their curriculum documents. The focus group interview served to highlight a number of areas where participants had different pedagogical views. These included the use of scientific language and degree of scientific explanation given to the child (see Section 4.3.1). In this way the participants' individual pedagogies were evident in the different teaching strategies they emphasised, as well as specifically identifying them in the interviews (see Section 4.4.2). Table 7 below highlights individual teaching strategies that were prominent in participant comments. This has been combined with the terms predominantly used by each participant to illustrate commonalities as well as variation in participants' individual teaching pedagogy (see Section 6.2.1). This indicates the nature of the scientific learning support provided within the whole centre environment, while also highlighting the individual approaches of the participants. 
Table 7: Comparisons of participants’ preferred teaching strategies

\begin{tabular}{|c|l|l|l|}
\hline & \multicolumn{1}{|c|}{ Comment example } & \multicolumn{1}{c|}{ Pedagogical idea } & Terminology \\
\hline $\begin{array}{c}\text { Participant 1 } \\
\text { Interview 1 }\end{array}$ & $\begin{array}{l}\text { I think you have to value the child, each } \\
\text { child as an individual and, no matter if } \\
\text { they are older or younger let them join } \\
\text { your work with you. }\end{array}$ & $\begin{array}{l}\text { Inclusion of all } \\
\text { children as capable } \\
\text { learners }\end{array}$ & Assisting \\
\hline $\begin{array}{c}\text { Participant 2 } \\
\text { Interview 1 }\end{array}$ & $\begin{array}{l}\text { If you're not there they wouldn't get as } \\
\text { deep an understanding. }\end{array}$ & $\begin{array}{l}\text { Importance of teacher's } \\
\text { role \& teacher's } \\
\text { knowledge }\end{array}$ & Guide \\
\hline $\begin{array}{c}\text { Participant 3 } \\
\text { Interview 1 }\end{array}$ & $\begin{array}{l}\text { If I don't know the answer, let's go and } \\
\text { have a look in a book or let's pull it apart } \\
\text { and put it back together and see what we } \\
\text { can find out. }\end{array}$ & $\begin{array}{l}\text { Teachers encouraging } \\
\text { children's investigation }\end{array}$ & Scaffold \\
\hline $\begin{array}{c}\text { Participant 4 } \\
\text { Interview 1 }\end{array}$ & $\begin{array}{l}\text { Like it doesn't have to start with me } \\
\text { saying 'Hey shall we make a volcano.' } \\
\text { Cos I don't know if you've noticed, but } \\
\text { out there they'll start making mountains } \\
\text { and start talking about volcanoes...” }\end{array}$ & $\begin{array}{l}\text { Child initiated learning } \\
\text { salt water. }\end{array}$ & Facilitate \\
\hline $\begin{array}{c}\text { Participant 5 } \\
\text { Interview 2 }\end{array}$ & $\begin{array}{l}\text { If they are doing something else, because } \\
\text { they are so much into it, like the slide. } \\
\text { whey were so much into that they didn't } \\
\text { wante to interact. }\end{array}$ & $\begin{array}{l}\text { Child as a capable } \\
\text { independent learner }\end{array}$ & To help them \\
\hline Participant 6 & $\begin{array}{l}\text { I think it came from looking at ice on } \\
\text { tater and stuff, and so then we started } \\
\text { saltew }\end{array}$ & $\begin{array}{l}\text { The flexible nature of } \\
\text { learning }\end{array}$ & $\begin{array}{l}\text { Ask and } \\
\text { provide }\end{array}$ \\
\hline
\end{tabular}

Differences in pedagogy not only influenced the teaching strategies used by individual participants, but also inhibited, or enhanced, their ability to respond to the scientific concept the child was exploring. For example, participants noted that while teaching situations started as child-initiated, when the teacher identified the child's interest it became increasingly teacher-led especially with less verbal children: "You interpret it one way and then that's the way they will then take it. It might not have been their initial interest that they brought up" (Participant 6, Focus group interview). This is congruent with Russo and Rennie's research (2003) which found that teachers had their own teaching agenda. It also links to Alexander's (2000) research indicating that the less subject knowledge the teacher has the more prescriptively or traditionally they will teach, thereby leading the learning agenda. However, the use of reflective practices is one teaching strategy identified in the study that minimised the influence of diverse teaching pedagogies and personal teaching agendas in one teaching team. All participants in this study acknowledged the role this teaching strategy played in developing their teaching practices further, often referring to reviewing and revising their teaching practices. 
Supporting children's scientific understandings in a holistic manner is endorsed as not only a main principle of the curriculum but also a promoted socioculturallybased teaching strategy. What is unclear in this study is the distinction between holistic, credit-based teaching strategies and teaching strategies designed to compensate for a lack of ability to notice children engaged in scientific learning, recognise the scientific concept under investigation, or be able to respond appropriately so that the child gains a greater understanding of that concept. For example, Participant 6 saw spontaneous situations where she lacked specific subject knowledge as ones where she might engage in constructivist shared learning strategies, while other participants showed more of an inclination to let the child engage in independent scientific investigation. Does just noticing a child's interest indicate a belief that children are so involved in their scientific investigation that no teacher intervention is required, or does it indicate a response to a lack of knowledge about the concept under exploration by the child? During the study some participants commented that it was after reflecting on a situation that they realised they were supporting the child's scientific knowledge. They linked this to teaching in such a holistic manner, but the question then arises: Are teachers able to respond in a manner that supports the child's scientific learning if they are unable to recognise the scientific concept the child is interested in? Fleer (2009) is clear on the answer stating adult mediation is required "if children are to pay attention to the scientific concepts that may be afforded through interacting with the resources provided by the teachers" (p. 1086).

In continuing to link the findings of the proposed research with previous research, the teaching behaviours listed by Hipikins et al. (2002) have been compared with those articulated by the participants in this study (see Appendix S). Although Hipkins et al.'s literature review was concerned with the junior primary years of school, the similarity of issues in both sectors gives merit to comparisons. It is interesting to note that the teaching strategies suggested by the authors were evident in the research data as was the additional behaviour of employing reflective teaching practices. This might reflect the increased emphasis reflective teaching practice has had in New Zealand teaching in recent years. Hipkins et al.'s list also contains one more teaching strategy not evident in the research data. That is, the teachers' ability to develop children's conceptual knowledge, procedural knowledge and understanding of NOS. While the participants referred to developing children's 
conceptual and procedural knowledge, there was no direct reference to developing children's understandings of NOS. Participants made indirect comments indicating a degree of awareness of NOS, as well as direct comments about supporting children's dispositions in science. These indicated they were supporting the child's understanding of NOS even if they were unaware of it.

\subsubsection{Individuals' understandings of NOS}

A teacher's view of NOS is a significant factor in the way they see science and their ability to support children's scientific learning. Findings demonstrated that some participants' secondary schooling experiences led to structured 'preconceived ideas about learning science" (Russo \& Rennie, 2003, p. 79) and how to support children's learning. In viewing the ever changing nature of science as interpretations of individuals' observations, teachers encourage children to use their imagination and individual past experiences to make their own interpretations, while still keeping in mind the body of scientific knowledge already produced within the larger society and culture. However, it should be remembered that what NOS was had not been a question that participants had considered before, resulting in their having no explicit understanding of the concept. The question that arises from this is: What understandings of NOS are teachers constructing with children when they are unaware of the concept? Comments on participants' feelings about their knowledge base, or the type of science activities they planned and provided, suggested a variance in the views of participants as this piece of focus group discussion illustrates.

\footnotetext{
Participant 2: That's the mark of the teacher isn't it, to be able to get through your knowledge to the child, isn't it?

Participant 6: In some ways it is probably better if you don't cos then you're learning at the same - at the same pace.

Participant 3: And it's quite cool because then you're actually helping children understand that it's okay not to know the answers.
}

This raises a further question of how early childhood teachers' understandings of NOS should, or could, be developed? Perhaps the holistic nature New Zealand early childhood education may encourage teachers to be less inclined to focus and reflect on science as a specific curriculum area. While all teachers said science is everywhere, this belief was not clearly demonstrated by all participants. 


\subsubsection{The influence of individuals' perceptions of their subject knowledge}

All participants felt they did and always would lack specific subject knowledge in some areas (see Section 4.2.2), thus acknowledging the infinite nature of knowledge and the challenges generalist teachers face (Bibby, 1999). While it was not in the scope of the proposed research to ascertain each participant's level of subject knowledge, the level of secondary science education they received has been taken as an indicator for this research project. In doing this it became evident that the way the participants felt about the degree of subject knowledge they held created more of a significant enabler or barrier than their actual lack of subject knowledge as it influenced their view of themselves as a capable and competent teacher in this area (Farquar, 2003; Fleer, 2001; Kallery \& Psillos, 2001). As de Kock (2005) comments, "it is doubtful that teachers will be able to identify, analyse and extend children's scientific interests, if they are not comfortable with imparting the scientific knowledge themselves" (p. 2). For example, Participant 1 with little formal science education, gathered the most data on situations where she had noticed children engaged in scientific learning (see Appendix E, Line 1) and cited responding to these with a variety of teaching strategies. However, Participant 4, who received a higher degree of science education, often referred to her lack of scientific subject knowledge, and saw her research participation as a way to increase her knowledge of what to 'notice'.

Participants 4's views reinforce past studies on the influence of teachers' secondary school experiences (Harlen, 1999, cited in Alexander, 2000; Smorti, 2005) and highlight the significance of the teachers' own learning experiences. When considering Participant 1's approach, it appears that she effectively uses her knowledge of teaching strategies designed to generally foster children's learning to support children's scientific learning. That is, are teachers able to support the child's scientific learning without recognition of, and knowledge about, the concept the child is exploring? It is interesting to note that Participant 1 , while acknowledging there is a lot she does not know, feels she has sufficient subject knowledge for the early childhood situation. This is a belief noted in previous research (Garbett, 2003; Hedges, 2002) suggesting some teachers underestimate the importance scientific subject knowledge plays in early childhood teaching. Yet the consistent use of scientific knowledge supports children's learning by providing them with opportunities to relate their scientific working theories to their everyday centre experiences (Fleer, 2009). 
All of the participants were positive about increasing their subject knowledge. As with Hedges' (2002) study some of the participants in this study saw the planned situations as opportunities to strengthen and increase their own knowledge base before working with the children. However, other participants in this study adopted co-constructive teaching strategies, learning with the children, indicating a positive attitude toward their ability to support the child's scientific learning. There were also situations where participants referred to learning from children, such as the example of the child who was interested in viscosity (see Appendix E). These ways all suggest that the participants' knowledge base was expanding around the areas that were relevant to the socio-historical context in which they were teaching (Cochran-Smith \& Lytle, 1999; Hedges \& Cullen, 2003; Rogoff, 2003), that is, the scientific interests of those that made up that centre's learning community, the children, parents, teachers and wider community.

\subsubsection{Summary}

Shulman (1986) suggests that teachers need PCK in order to effectively support children's learning. If teachers' content knowledge is a crucial factor in quality science education then the knowledge base that is valued, the type of knowledge it is and the degree to which it is held by teachers become very important. How the knowledge is used by the teacher is also of significance as subject knowledge alone is insufficient for quality teaching. This study has acknowledged the need for a specific subject knowledge base that relates to the community the teacher is working in. It also questioned the effectiveness of teachers' learning support when there is little understanding of the scientific concept under exploration, or indeed science itself, raising questions for further inquiry. The influence of the teachers' pedagogical knowledge has also been considered, in this case largely influenced by the socioculturally based guiding curriculum documents. In considering both the content knowledge and the pedagogical knowledge it suggests that teachers' pedagogical knowledge influences their ability to support children's scientific learning when they have little content knowledge. Participant 1's and Participant 6's inclination for co-constructive teaching strategies minimises the effects of their own lack of knowledge about the child's scientific interest, while Participant 4's inclination to share her 'right' knowledge with the child appears to prevent her from engaging in this strategy. 
Shulman's third aspect, the knowledge of the learner (Miller, 2007), also appears to be influenced by the teachers' pedagogical knowledge. In this study, the socioculturally based pedagogical practices promoted by the curriculum documents and taught in training institutions emphasise the importance of this knowledge base. Practices such as building on the children's interests, learning from and with children, and sharing documented learning with parents all require and develop the teacher's knowledge of the learner. However, as mentioned earlier, the participants' understanding of what sociocultural theories look like in practice appears to vary. While the teachers in this study used teaching practices that aligned with the preferred pedagogy of the centre and New Zealand curriculum, there was also an individual expression about the degree to which this was evident. In line with previous research (Alexander, 2000; Fleer, 2001, 2009; Heap, 2006; Hedges, 2002; Kallery \& Psillos, 2001) most variance stemmed from the different scientific knowledge bases held by individual participants, their attitudes to that knowledge base, and their understanding of what that knowledge base should be, or NOS.

Participants often referred to following the child's interest as the beginning of their support of children's scientific learning. In teaching this way the teacher needs to have enough understanding of specific scientific concepts to be able to recognise the scientific learning and know how to respond in such a way that the child's understanding will develop. A solid understanding of NOS is also required in order to also use specific teaching strategies such as modelling scientific processes and dispositions such as curiosity. Those participants who showed most inclination to support children's scientific learning were not necessarily those with the highest scientific qualifications. Instead they were those participants who described their teaching in terms of strategies that support the development of a child's interest in inquiry, such as shared learning, rather than an increased knowledge base. In this way they demonstrated their alignment with accepted conventional views of NOS. Although the proposed research did not set out to examine this, so has produced no conclusive evidence, there is room to argue that a greater understanding of NOS could provide teachers with increased confidence to work with children engaged in scientific learning as well as develop their own scientific knowledge base further. This is clearly an area for further research. 


\subsection{The interrelationships between participants}

The second focus of analysis, the interpersonal, brings in the element of teacher collaboration. There were several discussions between participants about science and science teaching on a formal (focus group interview) and informal (daily discussions) basis during the research. These served to not only highlight individual differences amongst participants but also illustrated the collaborative nature of team teaching. The collective knowledge and abilities of the group were used by the individual participants to address what they felt were barriers to their support of children's scientific learning. Other team members also supported individual participants' understandings of how children's scientific learning could be supported. Rogoff refers to this as the process of "participatory appropriation" (Rogoff, 1995, cited by Robbins, 2003, p. 97; original emphasis) where individuals "transform their understanding of and responsibility for activities through their involvement in those activities" (p. 97). That is, being involved in teaching science with other teachers can enhance a teacher's ability to support children's scientific learning. In considering the interpersonal focus of analysis, the influence of the relationships between the participants is highlighted as a significant factor in how an individual teacher supports children's scientific learning, as well as their ability to provide that support.

\subsubsection{Debate, reflection and development of teaching ideas}

This case study encapsulates the individual viewpoints of several members of one teaching team. However, there are numerous references to conversations held between participants that indicate the viewpoints of one team member influenced the viewpoint of another. For example, Participant 4 refers to drawing on other participants' subject knowledge, while Participant 3 refers to drawing on Participant 4's technological knowledge. Focus group comments indicate this process is an acknowledged and a deliberate strategy within this teaching team. The team appears to see individual teachers as the novices in some situations and experts in others (Macklin, 2007). In this way it is evident to see how the participants in this case study work together in a 'community of practice' (Wenger, 2000) in that they share a concern or a passion about early childhood teaching, learning, and gaining expertise by discussing ideas on a daily basis, for example, the way participants drew on each other's scientific subject knowledge base to support the teaching strategies they were 
using such as providing simple explanations for scientific concepts. In this case study the individual participant's knowledge is influenced by the discussion, debate and discourse within the group. As well as debate, participants influenced each other's teaching practices through modelling teaching strategies, providing each other with practical support, and drawing on each other's 'learning stories' (see Section 2.5.3) to plan future learning experiences. Rivalland (2007) concluded from her research that the teachers had developed cultural practices demonstrated through the community discourse within the centre, and this appears true for this study as well.

The question arises: Can this also operate in a negative manner? In the focus group one participant challenged another over the predominance of more structured, specific scientific activities planned during the research gathering period, indicating that group influences may also support inadvisable practices by perpetuating the status quo. Subsequent focus group discussion indicated this challenge had provided opportunities for ongoing reflection and debate around teaching pedagogy between teaching team members. The use of reflective practice by the participants encouraged them to consider other perspectives on how to support children's learning and thus influenced their personal teacher development. Examples of reflective practice that reinforced and developed existing practice were evident through the research findings. For example, there were positive responses to the initial research findings at the focus group on providing feedback to children, and these resulted in an increase in this teaching strategy. This could be seen as example of what Cochran-Smith and Lytle (1999) refer to as "knowledge-in-practice" (p. 274) due to the participants seeking to understand and improve their teaching practice by drawing on the knowledge of others and their own reflective practices to expand their knowledge base. In this study the supervisor of the centre also contributed significantly to this process seeing her role as one of fostering reflective practices: "By listening to how the teachers are interacting and extending out those children more, and in some cases not extending them and why, I can just put in my little 2 cents worth. 'Have you thought about such and such? Why aren't you doing such and such?' "' (Participant 3, Interview 2).

The research findings also reflect what Cochran-Smith and Lytle (1999) refer to as "knowledge-of-practice" (p. 274). This is where knowledge becomes socially constructed by not just the teachers but also the children and parents, as well as the 
wider community and academic theorists. The end product is "a locally developed curriculum" ( $p$ 274) that reflects the knowledge that is valued by that community. Not only did the participants' knowledge grow as a result of the other teachers' support but also as a result of children and families' interests (e.g., viscosity) and discussion with families about them. Smorti (2005) suggests the use of "teacher voices (dialogue and reflection)" (p. 2) is an important part of this process.

\subsubsection{Summary}

The way the participants in this study were mutually involved, communicating their ideas about that involvement and working toward a united approach, is reminiscent of Rogoff's concept of "guided participation" (Rogoff, 2003, p. 283; original emphasis). While often associated with children's learning, in this situation it was the more 'expert' members of the community, primarily other teachers, as well as parents and children, guiding the participant. This illustrates that while not all participants appeared to adopt sociocultural teaching practices to the same degree, the centre as a whole had a sociocultural approach that saw the participant's subject learning as being driven by the child's interests (Rivalland, 2007). These teaching practices reflected knowledge that was culturally valued by children and their families, as well as participants, and allowed "for multiple perspectives" (Hedges \& Cullen, 2005, p. 76). This idea stresses the notion that while teaching is an individual endeavour, in this situation it is not a solitary one and interactions within the wider teaching team, and indeed the wider centre community, need to be taken into account when considering how individual teachers support children's scientific learning. It also stresses the importance of group reflective practice as a means of assimilating new ideas and incorporating these in future teaching practices.

\subsection{Cultural-institutional influences on participants}

The third analytical lens has a focus on cultural-institutional influences. Critical constructivists such as McNaughton (2004) assert the importance of considering wider societal influences of culture and power. Teachers, just like children, exist in a culture that can distort, limit and even exclude the meaning of things "due to the conditions under which the meaning takes place" (p. 46). Some of the influences are obvious such as the devastating influence of negative secondary school experiences for one participant. However, many are subtle and implications can be suggested but 
not assumed. For example, in this study an adherence to the scientific learning cycle, (see Section 4.3.2) could be seen as a cultural tool preferred by this teaching team. This indicates the centre practices promoted may not always be congruent with AbdEl-Khalick \& Boujaoude's (1997, cited in Heap, 2006) definition of NOS, seeing it as "inferential, imaginative and creative" (p. 16) and challenging the misconception that the scientific method is the only way to do science. In this way the cultural tools participants chose to use and their comments in regard to cultural institutions reflect underlying wider societal influences. Examples of the participants' use of cultural tools, resources and language are provided in the next section along with a consideration of structural influences such as the curriculum and the early childhood setting. These reflect wider underlying influences on the individual participant's support of children's scientific learning.

\subsubsection{Language}

One of the significant cultural tools of science is the specific nature of the language. As Coltman (2003) points out, "the use of increasingly sophisticated or refined vocabulary" (p. 271) is often regarded as an indicator of increased scientific knowledge. Its use by teachers demonstrates a view of children as competent learners, and empowers the child to express and discuss their working theories of scientific concepts. The degree to which specific scientific language should be used was a topic debated by the participants in the focus group interview. Some participants felt simpler words should be used, for example 'slippery' in the case of viscosity. Other participants disagreed and suggested instead that this approach indicates participants' own lack of specific scientific language and limited ability to use it. However, it could also reflect the participants' lack of understanding of NOS and how to support the children's scientific learning in line with this.

Child: I want there to be a rainbow.

Participant 2: You need rain for a rainbow.

Child: $\quad$ Yeah. Rain and sun.

Participant 2: How do you know that H?

Child: $\quad$ My mummy told me.

Participant 2: Yes the sunlight goes through the little raindrops and when it shines on the water it makes all sorts of pretty colours. 
In the Dictaphone data transcribed above, Participant 2 appears to inform the child of the scientific 'facts', as she understands them, in a simplified manner. In doing this she insinuates the rainbow is caused by sunlight shining through the raindrops as well as "on the water." This is not only confusing but also places an emphasis on the importance of facts as a part of science learning. Use of terminology such as 'splitting light' might indicate to the child more conventional explanations of the phenomena and provide the child with the scientific words to express and develop their working theory. In considering the subtle messages communicated in the way language is constructed, the simplification of scientific language may indicate to children what the teacher's learning expectations of them are. The story of viscosity (see Appendix Q) is a good example of what can happen when a child is empowered with the language to describe the scientific concept of interest. In this case the child's use of the terminology exceeded most of the teachers' and engaged them and other children in further exploration of the concept.

\subsubsection{Resources}

The findings in this study highlight the use of specific cultural tools, or resources, to engage children's scientific interests and provide situations for children's autonomous learning within an educational environment. Participants spoke about using these cultural tools not only to supplement or complement their scientific subject knowledge but also to provide learning support when they were not able to be present: "I just brought it out and they all like 'Oh, oh. Give me the puzzle.' So all I had to do was just bring out the puzzle" (Participant 2, Interview 2). Resources were set up or brought out by participants during the day as part of planned experiences to encourage children's development of scientific working theories, such as marble rolling, magnets, and the body puzzle. They were also requested by children, or used by participants, to support children's scientific interests they had identified such as planks, scales, or an array of wheeled toys. Specific consideration had also been given by participants to the case study learning environment, for example the windsocks or daily obstacle course outside and the nature corner, blocks or wall posters inside.

\subsubsection{Te Whaariki}

The New Zealand early childhood curriculum, Te Whaariki, guides early childhood teaching practice in the country and as such is an important cultural tool. The 
participants in this study sometimes used the curriculum in a formal manner when planning or documenting children's learning. However, they mainly used it in an informal manner and drew on their knowledge of the theories and concepts within the document, such as working theories, rather than using the document as a constant reference. While the sociocultural ideas proposed in the document suggested very new ways of teaching in 1996 when released, all the participants in this study had completed their training after this date and appeared to have integrated some practices so thoroughly that they had not thought to specifically identify them in individual interviews, for example the focus group discussion on the small number of comments made by participants concerning their learning about the child's prior knowledge of a concept or providing learning feedback.

In line with the current Ministry of Education assessment exemplars designed to support the use of Te Whaariki, all participants 'noticed', 'recognised' and 'responded' to children engaged in scientific learning, with some also revisiting situations. However, as mentioned previously, there was also inconsistency in teaching pedagogy that reflected a diverse understanding of Te Whaariki and the theories it draws on. As Jordan (2003) noted, some teachers are still "coming to terms with what the adoption of socio-cultural theory might mean in practice, for children and for adults" (p. 3). Unfortunately, as successful implementation of Te Whaariki relies on teachers' understandings of the theories that underpin it (Cullen, 1996; Hedges, 2007; Hill, 2005; Jordan 2003), this also indicates a variance in the effectiveness of the document to guide teachers in supporting children's scientific learning. For example, the findings from this study question teachers' understanding of the curriculum principle of holistic development asking if it is interpreted by some teachers as due cause not to give consideration to individual traditional curriculum areas. Most participants in this study seemed unable to articulate what science might be defined as, with some also unsure of how to specifically support children's learning in this area. Previous concerns expressed by researchers (Garbett, 2003; Hedges, 2003) that teachers appear unaware of the importance of specific scientific subject knowledge appear to be validated here. The ways that participants made general links with Te Whaariki may indicate that references to scientific learning are so embedded in the document that teachers do not always make a conscious connection between the curriculum and their support of children's scientific learning. 


\subsubsection{The day-to-day realities}

As mentioned previously (see Section 5.3), the multi-aged, busy, routine-oriented nature of the learning environment was seen by participants to limit, as well as enhance, their abilities as teachers to support the children's scientific learning. Participants referred to several strategies they used to minimise a negative effect, for example, revisiting situations when less busy or providing certain activities at specific times to support older children's learning that may be compromised in a mixed age setting with much younger children. Participants also encouraged children's independent learning and employed collaborative teaching strategies when other teaching duties carried out in the centre requiring priority, such as the needs of infants, impeded their ability to work with the child personally. This aside, all participants in this study also clearly expressed a viewpoint that the mixed age setting also provided additional educational opportunities for children, especially the younger ones.

\subsubsection{Summary}

In viewing certain teaching strategies as using cultural tools, the teachers' preference for specific tools can indicate their underlying assumptions and beliefs about learning, for example, a belief in children's autonomous learning supported through the provision of cultural tools in the learning environment, or the type and frequency of scientific language used indicating a belief in the child's learning capabilities. In the case of the curriculum document, Te Whaariki, perhaps the most powerful cultural tool for the New Zealand early childhood teacher, it also indicates a variation in the participants' interpretations of the curriculum pedagogies promoted within it. The curriculum's ability to support teachers in science teaching is called into question due to teachers requiring a certain degree of subject and theoretical knowledge to use it effectively.

Findings also indicated institutional influences on ways that the participants supported children's scientific learning. Participants' use of Te Whaariki indicates the influence of government policy and the early childhood educational discourse of the time, while it has been suggested that wider societal influences may be seen in the scientific inquiry processes being valued in the centre. However, the main institutional influence emerging from this study appeared to be the childcare centre itself, that is, the fact it was multi-aged, open-planned, with a diverse teaching role of care and education. The development of specific teaching strategies and resource provision to address issues of time, age differences and multi-tasking served to 
ensure scientific learning was supported to the best of the teachers' abilities although a variation in these abilities must be acknowledged.

\subsection{Conclusion}

Data analysis is "an ongoing process involving continual reflection about the data" (Creswell, 2003, p. 190) and in using Rogoff's (2003) three foci the researcher is encouraged in further reflection and thought regarding their findings. In considering this it appears the participants in this study are positive toward, open to, and reflective of their support of children's scientific learning. In this way reflective practice is one of the cultural tools that the participants in this study employed to support children's scientific learning. As Rogoff comments, "as people develop through their shared use of cultural tools and practices, they simultaneously contribute to the transformation of cultural tools, practices, and institutions" (Rogoff, 2003, p. 52). This indicates that participants' abilities to support children's scientific learning are always in a state of flux as teachers discuss, debate, reflect on and modify their teaching strategies.

The team nature of New Zealand early childhood teaching serves to support not only individual teachers in their daily routines, but also their own personal understanding of, and abilities to support, children's understanding of scientific concepts. In this study the dialogue between participants was instrumental in all participants developing a greater understanding of how they supported children's scientific learning. This resulted in an increasing awareness of ways in which they might do this more effectively in the future. While there was congruence between the participants' teaching practices, promoted by the curriculum document, Te Whaariki, and the sociocultural theories it draws on, each participant also had their own personal teaching pedagogy, or interpretation of what they thought it looked like in action. Hence there was a variation in the degree to which the espoused ideas had been assimilated into the participants' everyday teaching practices. For example, participant comments indicated pedagogical differences in the use of teachers' scientific subject knowledge when supporting the children's learning.

Also indicated was a variation in the participants' attitude to using their subject knowledge base and understanding of the concept of NOS. The influence of personal reflective practice, collaborative team teaching practices and an overarching curriculum 
driving sociocultural teaching practices all serve to mitigate the effects of teachers having little scientific subject knowledge or a positive attitude toward science in general. However, teacher subject knowledge plays a vital role in supporting children's scientific learning (Fleer, 2009; Hedges, 2002). While there is also no easy solution to increasing the amount of scientific subject knowledge that early childhood teachers have, I believe, encouraging teachers to use the knowledge they do have and develop an attitude to learn more will help significantly. As seen with one participant the influence of negative science schooling experiences for a teacher can have negative effects for all the children they subsequently teach, or do not teach, science.

The influence of teachers' understating of NOS was not an original focus of the proposed research. However, as the study progressed it became evident a strong understanding of NOS appeared congruent with those participants who felt more comfortable in using the knowledge base they had at that time to support the children's learning as well as extending their knowledge base with the child. In understanding the way science is changing and challenges itself, teachers are more inclined to employ teaching strategies that empower the child in their learning. Variation in the participants' understandings of this concept is highlighted in the focus group debate that indicated that while all the participants noticed children's scientific interest, the child's learning agenda was not always followed when responding to these. It also became evident that NOS was not a concept the participants had thought a lot about before the study. This brought into question the understandings of NOS that they were fostering in children and what significance they gave it considering the degree to which scientific learning goals were embedded in the curriculum document.

By having a focus on each of the three lenses suggested by Rogoff (2003) a wide variety of factors have been illuminated as influential in the teacher participants' ability to support children's scientific learning. Several factors are reflected in each focus demonstrating the complexity of how they interrelate. The main influences emerging are: the teachers' personal knowledge base and pedagogy (PCK), team teaching strategies, the availability and use of cultural tools such as resources, language and curriculum, the institutional structure of the ECE centre, and dominant ECE pedagogical discourse at that time for that community of teachers, parents and children. 


\section{Chapter Seven:}

\section{Conclusion}

\subsection{Introduction}

The past chapters have explained and explored the rationale, processes and findings of this study in relation to the research question. The research methods used have been presented and previous research considered. Chapter Six contextualised the findings within a sociocultural paradigm and raised issues for further reflection and research. In this concluding chapter the key findings are presented along with possible implications of these. Recommendations are also suggested for teaching practice, teacher education and policy decisions. The strengths and limitations of the research are then identified, and lastly the implications this study might have for further research are also considered.

\subsection{The research question}

This research sought to identify how the teachers in one setting perceived their capacity to support children's scientific understandings and how they felt about their abilities to do this. This was done in a way that was consistent with the researcher's desire to carry out research with people rather than on people. However, it must be acknowledged that this thesis presents the researcher's interpretations of the participants' view. Initially, building on aspects of Hedges' (2002) earlier research (see Section 2.5.5) this study sought to gain further understanding of the early childhood teacher's perspective. In doing this a number of factors influencing teaching decisions have been explored bringing an emphasis on the difference between capacity and propensity, that is the teacher's available knowledge, skills and resources, and their inclination to use them. Highlighting the teachers' perspective has emphasised the significant role other people play in an individual teacher's ability to support children's scientific learning, bringing about a more pluralistic approach to the issue of early childhood teachers' support of children's scientific learning.

The data gathering process for this research involved two interviews with each of the six participant teachers. These provided opportunities for the participants to articulate 
their ideas. The interviews revealed both consistencies and inconsistencies within participants' views, as well as between participants' points of view. Research participants were also engaged in gathering data and commenting on initial research findings in a focus group format. After a further analysis including focus group data, Rogoff's (2003) theory of three analytical foci was used to explore and describe the data within the complexity of the issue. This enabled the data to be viewed in regard to the individual teacher, the interpersonal relationships and the cultural or institutional influences identified in the context in which the study was located.

From those data a description emerges that incorporates the teaching strategies of 'notice, recognise and respond' (Ministry of Education, 2004) currently referred to within the New Zealand early childhood discourse. It supports Hedges' (2002) findings that teachers' subject knowledge was under-emphasised by the participants in the majority of spontaneous interactions with children. However, while some of teachers in this study felt "they lacked some confidence in the personal knowledge base they drew upon in their interactions with children" (Hedges, 2002, p. 146), not all did. A variety of factors that appeared to influence the variation between participants were identified in the research data. This emphasised the influence of individual teachers' attitudes, scientific understandings, and personal pedagogy in responding to scientific learning opportunities afforded within the context of the case study situation. By taking three different, though interrelated, foci of analysis (Rogoff, 2003) the individual and collective nature of teaching was highlighted and the implications of this are now considered.

\subsection{Key research findings and implications}

While several supplementary sub-questions helped define the research there was one overarching grand question. This was: What are professionally trained early childhood teachers' understandings of, and feelings about, the way they support young children's learning in science? There are three key findings listed below. The first is in regard to the first part of the research question regarding the way the participants saw their support of children's scientific learning. It highlights specific strategies employed by the participants built on the interdependent nature of team teaching relationships and is the unique contribution this study makes. The second relates to the second part of the research question on how the participants felt about 
their support of children's scientific learning. The third and final key finding identifies and builds on the congruence found with previous research on teacher confidence and attitudes, adding complexity to the issue by also considering the role of the teachers' understanding of NOS. There are a variety of implications from these findings that have relevance for early childhood teachers, teacher educators, policy makers and future researchers and these are explored further below.

\subsubsection{Key findings}

1. Participants indicated their support of children's scientific learning was seen as an individual and collective endeavour, highlighting the interdependent nature of teaching relationships.

2. How capable and competent the participants felt related to what they saw 'science' as and what role they thought the teacher should play in science education, emphasising the importance of subject knowledge and a solid understanding of NOS.

3. The influence of participants' confidence in, and attitudes towards, supporting children's scientific learning is further complicated when considering them in relation to the role of the teachers' understanding of NOS.

The fact that the participants in this study used the collective knowledge and support of the teaching team as a deliberate teaching strategy to support children's scientific learning is significant. Past research into individual teachers' capacities in science education does not appear to have considered the effect of collective knowledge and support. However, in this study the participants' use of other teachers' expertise, knowledge, experiences, and physical support was noticeable and often resulted in individual participants' learning and increased confidence. This implies a teacher's ability to work within a teaching team situation can increase their ability to support children's scientific learning, regardless of their 'novice' or 'expert' status (Macklin, 2007). However, it should be remembered that this study only investigated the teaching within one team teaching situation and that other factors affecting the way a teaching team operates, such as hierarchies and power, would influence the degree to which this was evident. In viewing the teacher as only one element within a teaching team, that is, supporting children's scientific learning, it is implied that the perceived degree of cohesion within a teaching team influences the quality of science education a child receives, and in fact education in general. This leads to the question of how to 
facilitate the diversity of the collective knowledge base within an educational setting, and what makes for effective use of that knowledge base.

The discourse that developed between participants during the research appeared to unify a 'centre' approach to supporting children's learning, and support the development and capabilities of the individuals within the group. This indicated teacher dialogue is a significant influence in the scientific education children receive (Smorti, 2007). Although evidence of dialogue regarding science education was found in daily teaching interactions between participants, it was particularly evident in the focus group debates. These provided a window into "a community of interaction" (Bouma, 1996, p. 179) and an indication of common teacher interactions within the case study setting. In this way the participants' use of group reflective practice was highlighted. The debates served to provoke reflection about the way the centre as a whole supported children's scientific learning and the dialogue between the participants created a forum for critique and encouraged reflection. As a result of reflective practice the subsequent confirmation, exploration and challenges of the ways they supported children's scientific learning positively influenced the participants' perceived abilities, and subsequent confidence to engage in science education. It appeared that individual reflective comments could lead to a collective reflection amongst the teaching team, and the collective reflections encouraged individual reflection amongst teachers. This implies that both the individual and group reflections, and the interplay of those reflections, influence the scientific learning support children receive. It appears that while reflection may be seen as an individual process, it may be even more effective if it is also a social one. If teachers' abilities and the pace at which they develop their teaching practice are limited by their beliefs and assumptions, then it is possible that the teaching team discourse will encourage individual teachers to acknowledge and challenge their beliefs and assumptions in regard to science education. This makes whole centre professional development significant when considering the most effective means of developing the teaching practice of those in the field.

While there was a collective unification of ideas and support provided for individual teachers, this study has also identified a variation in the individual participants' teaching beliefs. The participants' views of their support of children's scientific learning were in line with current New Zealand early childhood pedagogy. 
However, their personal pedagogies created variation in the ways they interpreted the culturally predominant teaching norms. For example, the degree to which specific scientific language was used could be seen as an indicator of how capable and competent the child was seen as a learner. While all the teachers in this study had undergone teacher training, professional development and government audit reviews that were based on a preference for socioculturally-based teaching practices, some clearly did not always adopt these in regard to children's scientific learning. This implies the degree to which the teacher understands the culturally dominant theories underpinning teacher practice influences the way they support children's scientific learning (Cullen, 1996; Jordan, 2003). The variation also highlights the individual nature of teaching. As each teacher has their own unique experiences in life, they form their own unique knowledge base influencing their own teaching pedagogy. This implies that there will always be some degree of personal interpretation of culturally dominant teaching norms. However, the degree to which a personal interpretation of an overarching document is possible while still retaining a national approach has not yet been established.

The second major finding of this research concerns how capable and competent the participants felt in regard to their support of children's scientific learning. Findings indicated that how they perceived their teaching role was influenced by the way they felt about the amount of subject knowledge they held, and the participants' understanding of NOS. This implies teachers' development of their understanding of scientific concepts and NOS will result in increased teacher confidence in supporting children's scientific learning, as well as an increased ability. However, what sort of concepts the teacher learns more about is also of relevance. In this study there was evidence that the participants' knowledge base increased in accordance with the interests of the children, parents, other teachers and the wider community. This implies that the knowledge base of the teachers in this particular educational setting was related to the interests and knowledge valued by the associated learning community, enabling the teacher to encourage the child to make links between their everyday experiences and scientific concepts (Fleer, 2009). It appears an emphasis on identifying scientific knowledge that is valued by the community a teacher works within is of more value than trying to increase a teacher's general knowledge base. This would result in a knowledge base that is locally contextualised, open to a variety of perspectives, and of relevance to the child. In this way the teacher's relationship 
with the child and their family is vital in supporting the development of the child's scientific working theories (Fleer, 1997). This implies the teacher's relationships with the rest of the learning community influence their ability to make links between what children already know and their learning experiences supported in the educational setting. Conversations with parents about the child's learning experiences were seen as a way for parents to share their perceptions of the child's learning, and in turn influenced the way the participants supported the child's learning.

The role teachers saw content knowledge playing in their support of children's learning appeared to be guided by their understanding of NOS and in turn influenced their teaching pedagogy and preferred teaching strategies. This implies that the individual teachers' understanding of NOS impacts on their perception of their content knowledge base which in turn impacts on their ability to use it effectively when supporting children's scientific learning. For some of these participants the science education teaching discourse during the research period increased their understanding of NOS and consequently their ability to notice children engaged in science, suggesting that if there is little understanding of what science is then there is less possibility of its recognition in children's learning experiences. If teachers are to "weave together intricate patterns of linked experience and meaning rather than emphasising the acquisition of discrete skills" (Ministry of Education, 1996, p. 41) then they need a solid understanding of those specific skills. This implies teachers need a solid understanding of NOS to effectively support children's scientific learning in a holistic manner. Without this understanding there is a danger of holistic teaching practice becoming an excuse for not addressing specific gaps in teachers' knowledge. Even teachers who are unsure or have misconceptions of what science is still support children's working theories around NOS whether they are aware of it or not.

The third key finding looks at how the science learning support provided by participants in this study was also influenced by the degree of scientific competence the participants felt they had, their confidence, and their attitudes. In this study one participant's enthusiastic and positive attitude to providing support for children engaged in scientific learning regardless of her knowledge base appeared to overcome barriers that had inhibited other participants' teaching support. This was 
largely due to her attitude and pedagogy. This implies that while a lack of scientific content knowledge may be evident in teachers' ability to first notice the child's engagement, and then recognise the scientific concept they are exploring, it appears that a positive attitude and confidence in using what knowledge base does exist leads to a willingness to respond to what is noticed and recognised. Although teachers may lack the ability to provide extension activities or simple explanations, unless they feel confident to respond to children's scientific interests they will not use what subject knowledge they have. In this study another participant's secondary school experiences inhibited her ability to feel confident in using her subject knowledge. Thus it is the teacher's positive beliefs about their science knowledge that enable it to be used.

While previous research has also identified the influence of confidence and attitudes, (Alexander, 2000; Rivalland, 2007; Russo \& Rennie, 2003), this study adds further complexity to the situation when considering these in light of the teachers' understating of NOS. Participants in this study with a solid understanding of NOS appeared to approach their lack of knowledge in a child's interest as a positive opportunity to utilise co-constructive teaching strategies and learn more, while those who demonstrated less understanding of NOS were inhibited by their lack of confidence in their ability to provide the child with support. It appears that a number of interrelated factors influence teachers' feelings in regard to their support of children's scientific learning. This suggests that there is no one solution to encouraging teachers to engage in more effective scientific learning support (Hipkins et al., 2002). For example, also identified in this research was the influence of the day-to-day realities of teaching in an early childhood childcare environment. While the participants did not view all these as negative, such as the possibilities created for peer learning, it implies that the structure of a learning institution also influences the science education the child receives. Nevertheless, the interconnected myriad of teaching influences does indicate ways in which teachers' negative perceptions towards science education might be challenged and changed. A solid understanding of NOS and the current teaching theories, along with a positive attitude to one's subject knowledge base and a supportive teaching team, are four already discussed. Valuing the knowledge and interests of all the families attending the centre and encouraging teachers to seek more knowledge about these would seem to be another. 


\subsection{Recommendations}

\subsubsection{For teaching practice}

A sound understanding of scientific subject knowledge is required if teachers are to support children's understanding of specific scientific concepts and any professional development opportunities teachers take to increase their scientific subject knowledge will improve their ability to support children's development of those scientific concepts. However, this study also indicates this support increases in its effectiveness if the teacher has a sound understanding of NOS and the current teaching theories, and adopts reflective teaching practices. It is therefore recommended that teachers reflect on their understanding of these concepts. However, in order to have a reflective focus a teacher must first examine the attitudes they have developed toward science. This involves reflecting on past experiences that have been influential in forming attitudes such as family, cultural or schooling experiences. It also involves reflecting on the strategies chosen to support children's scientific learning, and questioning the degree to which they empower the child to make sense of the scientific concept in relation to their everyday experiences. While this may be something individual teachers, or teaching teams, may do, it may be a more effective process when it is facilitated within a professional development situation.

The findings from this study suggest reflective practice may be a collective teaching strategy as well as a personal one. In this study not only did the team consider the influence of the environment, resources and routines on their support of children's learning, but at times they also challenged individuals within the group to reflect on their viewpoint and teaching practice. It is recommended that teachers therefore consider the ways in which their teaching team does, or could, support their reflective practice. This is liable to depend on how well the teaching team works together, indicating the degree to which cohesion within a team influences individual teachers' ability to support children's learning. Consideration of the ways in which the teaching team provides, or could provide, support for individual teachers when encouraging children's scientific learning is also recommended. Team teaching situations have the possibility of minimising the effects of individual teachers lacking specific knowledge when there is a climate of discussion, critique, and knowledge sharing amongst the team members by maximising the knowledge of each individual teaching team member so it can be drawn on by the team as a whole. 
Finally the relationships teachers had with children and parents enabled a development of the teachers' subject knowledge base in accordance with the interests and knowledge valued by those involved in the centre, i.e., the learning community (Hedges, 2007). In light of this it is recommended that teachers are encouraged to further their learning in scientific subject areas of interest to them, the children they teach, the families the children are part of, and the community in which they reside. It is also recommended that teachers reflect on how to increase their understanding of the child's prior knowledge and family interests in order to gain a greater understanding of the knowledge that is valued and build links between experiences, which lead to a 'fund of knowledge' approach (González, Moll \& Amanti, 2005a, cited in Hedges, 2007).

\subsubsection{For teacher educators}

As mentioned previously, the possibilities that reflective practice provides make this a vital skill of an effective teacher and as such needs to be acknowledged in teacher education. This may be when teachers are in training or during professional development they receive subsequently. Reflective teaching not only enables the teacher to gain a greater understanding of how they teach but also why they prefer to teach that way, and as such is a powerful agent for change in teacher pedagogy. This study recommends that reflective practice and other teaching practices promoted that are in line with the current teaching theories, such as team teaching or being able to 'notice, recognise and respond' (Ministry of Education, 2004), should be specifically linked to the teacher's support of children's scientific learning. This will not only help teachers to see the way each domain's knowledge may be supported, integrating practice and theory, but also encourage a recurring focus on each domain. Without a continual awareness of the place scientific learning may have in children's learning there is a danger of it becoming what Nuttall (2002) terms "null curriculum", that is, "programme content that is systematically excluded from children's experience" (p. 7).

Some of the teachers in this study had a 'naive' understanding of NOS which influenced their choice of teaching strategies and their view of themselves as competent and capable of supporting children's scientific learning. If this is to be addressed (Heap, 2006; Hipkins et al., 2002) then it is recommended there is an explicit acknowledgement of the role the teachers' understanding of NOS plays in their support of children's scientific learning, as well as a strengthening of their 
understanding of what NOS is. This endorses the notion that teachers need a solid understanding of what science is if they are to support each facet of a child's learning and teach holistically.

This study also recommends that teacher educators reflect on ways in which teachers can be encouraged to be open to learning from a wide variety of sources, increasing their subject knowledge in line with the interests of the children and families that attend the centre as well as their own. A propensity to focus solely on increasing teachers' content knowledge during training can reinforce an understanding of science as a series of fixed facts. However, this is inconsistent with the accepted view of NOS (Adb-El-Khalick \& Boujaoude, 1997, cited in Heap, 2006). Focus on increasing a specific content knowledge base also assumes that the teacher will be in teaching situations where that knowledge will be relevant and that they will feel confident enough to recall that knowledge and use it at that time. However, encouraging teachers to develop their content knowledge in line with the interests of the learning community they work with gives the teachers relevant knowledge and increases their sensitivity to the knowledge bases valued in that learning community.

The implications of having so many influencing factors are that they all need to be considered when supporting teachers in training or post-training and the links made evident to the teachers. For example, while focusing on team teaching techniques may not obviously appear to enhance children's scientific learning, a teaching team that is effective enables all its members to support children's scientific learning, not just those teachers within the team that are more knowledgeable in that domain area.

Finally, during the focus group discussion on teacher training in regard to science education participants made their own recommendations for teacher educators. One participant felt that there was insufficient time given in training to the area of science. Unfortunately this is not always possible to change given the difference for training institutions between a preferred teacher training pedagogy and what an institution's budget constraints allow. Other participants considered the training they received provided them with a good grounding in science education that gave them confidence in teaching in this area, one specifically identifying learning to recognise possible scientific situations. The final suggestion made by one of the participants was to provide a training focus on concepts about science rather than the subject knowledge. 


\subsubsection{For policy makers}

There is no doubt that sociocultural theories are currently the predominant teaching theories driving early childhood teaching practice in New Zealand. These underpin the national curriculum document, Te Whaariki and while they are not the only theories promoted in the document, they complement other theories used such as Bronfenbrenner's ecological model (1979, cited in Ministry of Education, 1996). This study endorses an ongoing call from others (Brennan, 2007; Cullen, 1996; Hedges, 2007; Hill, 2005; Jordan, 2003) for policy makers to strengthen the support teachers receive to develop their understanding of sociocultural theory and what it might look like in practice. It also recommends a strengthening of the teacher support provided for children's scientific learning. In this study the teachers made explicit links to the curriculum only in their long-term, project approach plans, as opposed to weekly or daily ones. This reflects the emphasis placed on using the curriculum document as a framework to draw on rather than as an indicator of specific learning outcomes that should be attained by the child. While this allows for flexibility in the ways the document may be interpreted, it also assumes teachers have sufficient knowledge to be effective "key curriculum decision makers" (Hedges, 2007, p. 12). This is not only knowledge of sociocultural theory but also subject content knowledge. If a holistic integrated curriculum is to support children's scientific learning then the connection between supporting children's specific curriculum domain knowledge and the curriculum principles, strands and goals needs to be made more explicit for teachers. This may be in the form of a curriculum review or additional supporting curriculum documents.

This study recommends that teachers have access to documents that not only contain subject knowledge relating to a specific curriculum domain but also a clear notion of what that domain is, in this case NOS. It also recommends that these documents make explicit links to the curriculum and sociocultural theory, thus enabling teachers to see how the theory might look in practice. In this way teachers can access additional information that is presented in line with the preferred theoretical paradigm of the country. Presently teachers rely on information from a variety of sources that may recommend teaching strategies that are not socioculturally based, thereby relying on the teachers' knowledge of sociocultural theory to reject or modify the ideas proposed. 
Finally the study recommends the renewed support of government sponsored research that employs teacher-researcher collaboration, such as previous Centres of Innovation (COI). These document teaching innovation and encourage the teaching team in that and other early childhood teaching situations to reflect in a collective manner. The research findings provide examples of effective teaching practice underpinned by sociocultural theory and create a dialogue within the wider early childhood community that serves to encourage further reflection and ongoing changes in teaching practice. As Anne Smith (2003) comments, "a careful implementation of Te Whaariki requires thought, interpretation, reflection, careful planning, and observation" (p. 9).

\section{5 Strengths and limitations of this study}

The very nature of the methodology chosen indicates the main limitations and strengths of this research. As a case study it is a specific, unique, bounded system (Stake, 2005) and as such these findings are specific to this case only. The philosophy of the centre in this research was developed in consultation with the community, parents and whaanau. In this way the views of the participants in the study, while congruent, may only reflect the valued principles of that centre and cannot easily be generalised to any other. However, although the New Zealand early childhood sector is diverse (Mawson, 2006), the findings demonstrate similarities between the teaching behaviours of those in this research and previous research about other early childhood teachers in New Zealand. As such, at this time there is evidence that there is some degree of generalisation possible.

By providing a rich description of the participants' thoughts and feelings about the way they teach, it is anticipated that these may resonate with other teachers' experiences and encourage their reflection on the topic. By using three different lenses to view the data (Rogoff, 2003), the emerging description of teaching behaviours demonstrates the complex interplay of factors that influence a teacher's choice of these. The methodology is now seen as a strength as it creates a holistic description that is more open to reader interpretation (Cohen et al., 2007; Merriam, 1998) than other forms of research. 
This research was designed to investigate a specific case in order to provide insight into a specific issue (Stake, 2005) identified in literature, that of many early childhood teachers not engaging in support of children's scientific learning. It focused on the teachers' perceptions of their teaching but in doing this must acknowledge the difference between opinion and what a teacher actually does, or how effective their teaching actually is. However, in taking this approach participants were enabled to develop their own teaching practices through their engagement with the research process and articulation of their ideas. This highlighted the effects of reflective practice and increasing the teachers' awareness of how they teach (Fenstermacher, 1994). It has also brought about a wider range of findings as the participants' ideas led the interview conversations. However, those factors not previously considered by the researcher, for example, the notion of a community of learners or the influence of centre routines on children's learning, may only be seen as indicators as it was not the specific intent of this research to investigate these factors in any depth.

The manner in which the data were collected was another significant limitation and strength of this study. The open-ended interviews led to an increase in the depth and breadth of some ideas participants commented on, and highlighted the role of reflective teaching practice. It also led to inconsistency in the amount of data collected from each participant in relation to each emerging finding. Due to some participants also having a senior teaching role, the way and degree to which different participants engaged in the focus group interview also created limitations. Conversely, the debates that resulted between most staff revealed the significance of the interactions between teachers in a team situation. These were also evident in the dialogue that developed between participants over the data collecting period. This dialogue further served to demonstrate the important role reflection had in developing the participants' teaching practice. However, the dialogue also made it impossible to define ideas as unique to any one participant but instead indicated the evolving nature of teaching as participants' thoughts developed and changed between interviews.

Strengths and limitations are also found in the way the data were analysed. The interview transcripts provided one set of data for analysis; the data collected by participants (primarily photographic) provided another; and a third set of data was 
formed by analysing the type of data collected by the participants, e.g., age of child, location, degree of response. These sets of data were then compared to form a degree of triangulation. However, it was limited by the subjective nature of the coding of interviews and categories for analysis. The analysis findings were then viewed through three analytical foci enabling a wider perspective of the findings that illuminated the significance of varying factors influencing teaching practice. However, it also served to identify factors that had not previously been considered and therefore were not incorporated into the research design.

\subsection{Implications for further research}

Two specific aspects to consider when conducting educational research emerged during this research. The first was the complex, interrelated way that a variety of factors have on one situation. Adopting theoretical models, such as Rogoff's (2003), enables this complexity to be identified and articulated. Secondly, this research illustrates that knowledge is not static with participants' views developing between the interviews. Research design that is able to encapsulate the way participants' views evolve, in my view, will also add to the depth of understanding of any research findings. The following questions emerged during the course of this research indicating areas to be considered with regard to future research in early childhood education.

- What ideas do teachers have of NOS and how do these ideas shape what they do in supporting children's scientific learning?

- To what degree do teachers learn about and reflect on the knowledge base of the communities they teach?

- In what ways do teachers' perceptions of the capabilities of children's scientific learning, for example ability to understand and use specific scientific language, inhibit their ability to support a child's scientific learning?

- How do teachers' own experiences of learning science at school influence their perceptions of their ability to support children's scientific learning?

- In what ways can the diversity of the collective knowledge base within an educational setting be harnessed, and what makes for effective use of that knowledge base? 
- How does the consistency of pedagogy within a team influence the support they provide for children's scientific learning?

- What do early childhood teachers see holistic teaching as? How do these views influence their practice of teaching specific subject domains such as science?

\subsection{Concluding statement}

This research set out to investigate the perceptions of one group of teachers about the way they supported children's scientific learning and what they thought of that support. It found an alignment with the current dominant teaching theories driving early childhood teaching practice in New Zealand. The participants noticed children engaged in learning that they recognised as scientific. On occasions they responded to these observations with teaching strategies that encouraged the child's understanding, or working theory, of the concept recognised. There were a number of factors that influenced the teaching decisions made regarding when to respond and how. The findings also indicated the interrelated nature of these, for example the participants' understanding of NOS influenced their personal pedagogy which in turn influenced the scientific learning support they provided for children.

The complexity of individuals teaching within team situations has been highlighted in this study indicating ways in which the participants' teaching abilities were supported through the use of collective team knowledge and interplay of individual and group reflective practice. Variation between teachers was found in the degree to which they understood the current dominant teaching theories and the concept of NOS, as well as their personal attitudes toward their subject knowledge base. Findings suggest that teachers could, and do, increase their scientific knowledge in line with the scientific interests of the other teachers, children and families attending the centre. It is proposed that in this way the knowledge base of the teachers can be developed in relation to the interests and knowledge valued by the associated learning community. This can result in a locally contextualised knowledge base that is open to a variety of perspectives, and of relevance to the child. Therefore the teacher's relationship with the child and their family is vital in supporting the development of the child's scientific working theories. 
It is suggested that enhancing early childhood teachers' abilities to support children's scientific learning is a complex issue involving several interrelated factors. It is proposed that an increased awareness of these factors might bring about a greater effectiveness and consistency in the way teachers support children's scientific learning. A teaching pedagogy that utilises teaching strategies, such as noticing, recognising, responding and revisiting children's learning, empowers children to make connections between everyday events and scientific learning and supports their understanding of the place of science in their lives. Rogoff reminds us that "individuals and generations shape practice, traditions, and institutions at the same time that they build on what they inherit in their moment in history" (Rogoff, 2003, p. 62). This study suggests that the individual and collective endeavours of teachers to support children's scientific interests develop the individual teacher's practice, and that of their co-teachers, as well as the scientific understandings of the future generation. In this way teaching practices link to changes within the wider society as increasingly scientifically literate citizens contribute to the way the society is shaped. 


\section{References}

Akerson, V., Buzzelli, C., \& Donnelly, L. (2007). Early childhood teachers' view's of nature of science: The influence of intellectual levels, cultural values and explicit reflective teaching. Journal of Research in Science Teaching, 45(6), 748-770.

Anning, A., \& Edwards, A. (2006). Promoting children's learning from birth to five: Developing the new early years professional $\left(2^{\text {nd }}\right.$ ed.). Maidenhead, England: Open University Press.

Alexander, P. (2000). An investigation into teacher and student teacher confidence in their own understanding and abilities to teach science and technology in primary schools in Northern Ireland. Unpublished $\mathrm{PhD}$ thesis, Queens University of Belfast.

Backshall, B. (2000). Science for infants and toddlers. The First years: Nga tau Tuatahi: New Zealand Journal of Infant and Toddler Education, 2(2), 10-12.

Barbour R., \& Schostak J. (2005). Interviewing and focus groups. In B. Somekh \& C. K. Lewin (Eds.), Research methods in the social sciences. Thousand Oaks, CA: Sage.

Bell, B. (2005). Learning in science: The Waikato research. New York: RoutledgeFalmer.

Berg, B. (2007). Qualitative research methods for the social science (6 $6^{\text {th }}$ ed.). Boston: Pearson/Allyn \& Bacon.

Bibby, T. (1999). Subject knowledge, personal history and professional change. Teacher Development, 3(3), 219-231.

Bishop, R., \& Glynn, T. (1999). Culture counts: Changing power relations in education. Palmerston North: Dunmore Press.

Brennan, M. (2007). Beyond child care-how else could we do this? Sociocultural reflections on the structural and cultural arrangements of contemporary western child care. Australian Journal of Early Childhood, 32(1), 1-9.

Bouma, G. (1996). The research process ( $3^{\text {rd }}$ ed.). South Melbourne: Oxford University Press Australia.

Carr, M. (1994). How come? So what" And what if? Science in early childhood. Australian Journal of Early Childhood, 1(2), 29-36.

Carr, M. (1999). Being a learner: Five learning dispositions for early childhood. Early Childhood Practice, 1(1), 82-99.

Carr, M. (2001). Assessment in early childhood settings: Learning stories. London: Paul Chapman. 
Carr, M., \& May, H. (2002). Te Whaariki: curriculum voices. In H. Penn (Ed.), Early childhood services: Theory, policy and practice (pp. 53-73). Buckingham: Open University Press.

Cochran-Smith, M., \& Lytle, S. (1999). Relationships of knowledge and practice: Teacher learning in communities. In A. Iran-Nejad \& C.D. Pearson (Eds.), Review of research in education (Vol. 24, pp. 251-307). Washington, DC: American Educational Research Association.

Cohen, L., Manion, L., \& Morrison, K. (2007). Research methods in education ( $^{\text {th }}$ ed.). London: RoutledgeFalmer.

Coelho, P. (2007). Life: Selected quotations. New York: HarperCollins.

Coltman, P. (2003). How many toes has a newt? Science in the early years. In D. Whitehead (Ed.), Teaching and learning in the early years (pp. 269-282). London: Routledge Falmer.

Creswell, J. (2008). Research design: Qualitative, quantitative and mixed methods approach $\left(3^{\text {rd }}\right.$ ed.). Thousand Oaks, CA: Sage.

Creswell, J. (2003). Research design: Qualitative, quantitative and mixed methods approach ( $2^{\text {nd }}$ ed.). Thousand Oaks, CA: Sage.

Cullen, J. (1996). The challenge of Te Whaariki for future developments in early childhood education. Delta, 48(1), 113-126.

Cullen, J. (2001). Assessment dilemmas in a socio-cultural curriculum. Keynote address to TRCC seminar, Wellington.

Cullen, J. (2008, November). Outcomes of early childhood education: Do we know, can we tell, and does it matter? Jean Herbison lecture presented at NZARE Annual Conference, Palmerston North.

Cullen, J., Hedges, H., \& Bone, J. (2005). Planning, undertaking and disseminating research in early childhood settings. Childforum Research Network. Retrieved October, 14, 2006, from http://childforum.com.

Davis, E. (2003). Knowledge integration in science teaching: Analysing teachers' knowledge development. Research in Science Education 34, 21-53.

de Kock, J. (2005). Science in early childhood. Auckland College of Education Papers, 16, 1-10.

Denzin, N., \& Lincoln, Y. (2005). The Sage handbook of qualitative research $\left(3^{\text {rd }}\right.$ ed.). Thousand Oaks, CA: Sage.

Denzin, N., \& Lincoln, Y. (2000). The Sage handbook of qualitative research $\left(^{\text {nd }}\right.$ ed.). Thousand Oaks, CA: Sage. 
Edwards, A. (2001). Researching pedagogy: A sociocultural agenda. Pedagogy, Culture and Society, 9(2), 161-186.

Edwards, S. (2003). New directions: Charting paths for the role of socio-cultural theory in early childhood education and curriculum. Contemporary Issues in Early Childhood Education, 4(3), 251-264.

Farquar, S. (2003). Quality teaching early foundations: Best evidence synthesis. Wellington: Ministry of Education.

Farquar, S., Cablk, L., Buckingham, A., Butler, D., \& Ballantyne, R. (2006). Men at work: Sexism in early childhood education. Childforum Research Network. Retrieved October14, 2006, from http://childforum.com.

Ferguson, R. (2007). Constructivism and social constructivism. Theoretical frameworks for research in chemistry/science education (pp. 28-50). Upper Saddle River, NJ: Pearson Education.

Fensham, P. (1991). Science education in early childhood education: A diagnosis of a chronic illness. Australian Journal of Early Childhood, 8(3), 3-11.

Fenstermacher, G. (1994). The knower and the known: The nature of knowledge in research on teaching. Review of Research in Education, 20, 3-56.

Fleer, M. (1997). Science, technology and culture: Supporting multiple world views in curriculum design. Australian Science Teachers' Journal, 42(3), 13-18.

Fleer, M. (2001). Science education over 40 years. Australian Journal of Early Childhood Education, 26(1), 39-45.

Fleer, M. (2008). Understanding the dialectical relations between everyday concepts and scientific concepts within play-based programs. Research in Science Education, 39, 281-306.

Fleer, M. (2009). Supporting scientific conceptual consciousness or learning in a 'roundabout way' in play-based contexts. International Journal of Science Education, 31(8), 1069-1089.

Fleer, M., \& Robbins, J. (2003). "Hit and run research" with "hit and miss" results in early childhood science education. Research in Science Education, 33, 405-431.

Fontana, A., \& Frey, J. (2005). The interview: From neutral stance to political involvement. In N. Denzin \& Y. Lincoln (Eds.), The Sage handbook of qualitative research $\left(3^{\text {rd }}\right.$ ed.). Thousand Oaks, CA: Sage.

Garbett, D. (2003). Science education in early childhood teacher education: Putting forward a case to enhance student teachers' confidence and competence. Research in Science Education, 3, 467-481.

Garbett, D., \& Yourn, B. (2002). Student teacher knowledge: Knowing and understanding subject matter in the New Zealand context. Australian Journal of Early Childhood, 27(3), 1-6. 
Garrick, J. (1999). Doubting the philosophical assumptions of interpretive research. International Journal of Qualitative Studies in Education,12(2), 147-156.

Gilbert, J., \& Calvert, S. (2003). Challenging accepted wisdom: Looking at the gender and science education question through a different lens. International Journal of Science Education, 25(7), 861-878.

Ginsburg, H., \& Golbeck, S. (2004). Thoughts on the future of research on mathematics and science learning and education. Early Childhood Research Quarterly, 19, 190-200.

Grobstein, P. (2005). Revising science in culture: Science as storytelling and story revisiting. Journal of Research Practice, 1(1), Article M1. Retrieved August 6, 2007, from http://jrp.icaap.org/index.php/jrp/article/viewArticle/9/18.

Haigh, M. (2001). Aspects of case study research. Auckland College of Education Papers, 8, 113-132.

Harding, S. (2007). Feminist standpoints. In S. N. Hesse-Biber (Ed.), Handbook of feminist research: Theory and praxis (pp. 45-70). London: Sage.

Hesse-Biber, S. (2007). Feminist research: Exploring the interconnections of epistemology, methodology, and method. In S. Hesse-Biber (Ed.), Handbook of feminist research: Theory and praxis (pp. 1-28). London: Sage.

Harlen, W. (1999). Effective teaching of science: A review of research. Edinburgh: The Scottish Council for Research in Education.

Haynes, M. (2000). Teacher education for early childhood through the New Zealand curriculum framework. New Zealand Research in Early Childhood, 3, 163-176.

Heap, R. (2006). Myth busting and tenet building: Primary and early childhood teachers' understanding of the Nature of Science. Unpublished master's thesis, Massey University, Auckland.

Hedges, H. (2000). Teaching in early childhood: Time to merge constructivist views so learning through play equals teaching through play. Australian Journal of Early Childhood, 25(4) 16-21.

Hedges, H. (2002). Subject content knowledge in early childhood curriculum and pedagogy. Unpublished master's thesis, Massey University, Palmerston North.

Hedges, H. (2003). Avoiding magical thinking in children: The case for teachers' science subject knowledge. Early Childhood Folio, 7, 2-13.

Hedges, H. (2007). Funds of knowledge in early childhood communities of inquiry. Unpublished $\mathrm{PhD}$ thesis, Massey University, Palmerston North, New Zealand.

Hedges, H. (2008). "Even when we're big we'll still be friends": Working theories in children's learning. Early Childhood Folio, 12, 2-6. 
Hedges, H., \& Cullen, J. (2003). The tooth fairy comes, or is it just your Mum and Dad? A child's construction of knowledge. Australian Journal of Early Childhood Education, 28(3), 19-24.

Hedges, H., \& Cullen, J. (2005). Subject knowledge in early childhood curriculum and pedagogy: Beliefs and practices. Contemporary Issues in Early Childhood, 6(1), 66-79.

Hemara, W. (2000). Maori pedagogies: A view from the literature. Wellington: New Zealand Council for Educational Research.

Higgins, J., \& MacDonald, G. (2008). Sociocultural theory: Its use and interpretation in New Zealand. Cultural Studies of Science Education, 3, 507-515.

Hill, D. (2005). Curriculum: Challenges of context and complexity in early childhood settings. The First Years: Nga tau Tuatahi. New Zealand Journal of Infant and Toddler Education, 7(1), 21-25.

Hipkins, R., Bolstad, R., Baker, R., Jones, A., Barker, M., Bell, B. et al. (2002). Curriculum learning and effective pedagogy: A literature review in science education. Wellington: Ministry of Education.

Hipkins, R., Barker, M., \& Bolstad, R. (2005). Teaching the 'nature of science': Modest adaptations or radical reconceptions? International Journal of Science Education, 27(2) 243-254.

Johnston, J. (2005). Early explorations in science: Exploring primary science and technology education ( $2^{\text {nd }}$ ed.). Berkshire, England: Open University Press.

Jones, A., \& Baker, A. (2005). Curriculum, learning and effective pedagogy in science education for New Zealand: Introduction to special issue. International Journal of Science Education, 27(2) 131-143.

Jordan, B. (2003). Professional development making a difference for children: Coconstructing understandings in early childhood centres. Unpublished $\mathrm{PhD}$ thesis, Massey University, Palmerston North, New Zealand.

Jordan, B. (2004). Scaffolding learning and co-constructing understandings. In A. Anning, J. Cullen, \& M. Fleer (Eds.), Early childhood education (pp. 4354). London: Sage.

Kallery, M., \& Psillos, D. (2001). Preschool teachers' content knowledge in science: Their understanding of elementary science concepts and of issues raised by children's questions. International Journal of Early Year's Education, 9(3), 165-179.

Kilderry, A. (2004). Critical pedagogy: A useful framework or thinking about early childhood curriculum. Australian Journal of Early Childhood, 29(4), 333-338.

Lederman, N. (1992). Students and teachers' conceptions of the nature of science: A review of the research. Journal of Research in Science Education, 29(4), 331359. 
Lemke, J. (2001). Articulating communities: Sociocultural perspectives on science education. Journal of Research in Science Teaching, 38(3), 296-316.

Levitt, K. (2001). An analysis of elementary teachers' beliefs regarding the teaching and learning of science. Science Education, 86, 1-22.

Lorsbach, A., \& Tobin, K. (1993). Constructivism as a referent for science teaching. NARST (National Association for Research in Science Teaching) News. Retrieved August 20, 2008, from http://www.ilstu.edu/ awlorsb/referent.pdf.

McNaughton, G. (2004). Exploring critical constructivist perspectives on children's learning. In A. Anning, J. Cullen, \& M. Fleer (Eds.), Early childhood education. (pp. 43-54). London: Sage.

Macklin, A. (2007). Communities of practice. In G. Bodner \& M. Orgill (Eds.), Theoretical frameworks for research in chemistry/science education. (pp.204227). Upper Saddle River, NJ: Pearson Education.

Manning, S., \& Loveridge, J. (2009). Parents as educators at playcentre: Understanding the constraints and enablers of teaching practice. New Zealand Research in Early Childhood Education Journal, 1, 55-71.

Mawson, B. (2006). Facing the challenge: Integrating early childhood and primary education practices. New Zealand Research in Early Childhood Education Journal, 9, 67-77.

McLachlan, C. (2005). Focus group methodology and its usefulness in early childhood research. New Zealand Research in Early Childhood Education Journal, 8, 113-123.

Merriam, S. (1998). Qualitative research and case study application in education. San Francisco: Jossey Bass.

Miller, M. (2007). Pedagogical content knowledge. In G. Bodner \& M. Orgill (Eds.), Theoretical frameworks for research in chemistry/science education (pp. 86105). Upper Saddle River, NJ: Pearson Education.

Ministry of Education. (1996). Te Whāriki early childhood curriculum: He whāriki mātauranga mō ngā mokopuna a Aotearoa. Wellington: Learning Media.

Ministry of Education. (2004). Kei tua o te pae. Assessment for learning: Early childhood exemplars professional development. Wellington: Learning Media.

Ministry of Education. (2007). New Zealand curriculum framework: Te anga marautanga o Aotearoa. Wellington: Learning Media.

Monk, M., \& Dillon, J. (2000). The nature of scientific knowledge. In M. Monk \& J. Osborne (Eds.), Good practice in science teaching: What the research has to say (pp. 72-88). Buckingham, UK: Open University Press. 
Moorefield, J. (2005). Te Aka Māori-English, English-Māori dictionary and index. New Zealand: Longman/Pearson Education. Retrieved September 7, 2009, from http://www.maoridictionary.co.nz/.

Mutch, C. (2005). Doing educational research: A practitioner's guide to getting started. Wellington: NZCER Press.

Nuttall, J. (2002). Negotiating the meaning of 'curriculum': Can we awaken the 'sleeping beauty'? Early Education, 28, 5-9.

Nuttall, J. (2004). Why don't you ask someone who cares? Teacher identity, intersubjectivity, and curriculum negotiation in a New Zealand childcare centre. Unpublished $\mathrm{PhD}$ thesis, Victoria University of Wellington, Wellington.

Pajares, F. (1992). Teachers' beliefs and educational research: Cleaning up a messy construct. Review of Educational Research, 62(3), 307-332.

Parker, J., \& Heywood, D. (2000). Exploring the relationship between subject knowledge and pedagogical content knowledge in primary school teachers' learning about forces. International Journal of Science Education, 22(1), 89111.

Rivalland, C. (2007). When are beliefs just 'the tip of the iceberg'?: Exploring early childhood professionals' beliefs and practices about teaching and learning. Australian Journal of Early Childhood, 32(10), 30-37.

Robbins, J. (2003). Moving through understanding rather than to understanding: A sociocultural perspective on young children's conceptions of the rain. Journal of Australian Research in Early Childhood Education, 10(1), 93-108.

Rogoff, B. (2003). The cultural nature of human development. Oxford, England: Oxford University Press.

Russo, S., \& Rennie, L. (2003). "I put the caterpillar in because he was tired": Young children's attitudes and teachers' responses in science lessons. Journal of Australian Research in Early Childhood Education, 10(3), 70-80.

Schofield, J. (2002). Increasing the generalizabilty of qualitative research. In A. Huberman \& M. Miles (Eds.), Qualitative researchers companion (pp. 171204). Thousand Oaks, CA: Sage.

Schostak, J. (2006). Interviewing and representation in qualitative research. Maindenhead, England: Open University Press.

Scott, D., \& Usher, R. (1999). Researching education: Data, methods and theory in educational inquiry. London: Continuum.

Shulman, L. (1986). Those who understand: Knowledge growth in teaching. Educational Researcher, 15(2), 4-14. 
Smith, A. (2003, July). Te Whaariki: Diversity or standardisation? Innovative aspects of the New Zealand early childhood curriculum. Paper presented at conference, Education in the early Years: International Development and Implications for Germany in Munich, Germany.

Smorti, S. (2005). Why don't we teach science? Early Education, 38, 13-20.

Smorti, S. (2007). Teachers' role in promoting children's interest in science. Iti rearea. Retrieved December 10, 2008, from http://www.nzca.ac.nz/makingscinecvisible.

Snively, G., \& Corsiglia, J. (2001). Discovering indigenous science: Implications for science education. Science Education, 85(1), 6-34.

Stake, R. (2005). Qualitative case studies. In N. Denzin \& Y. Lincoln (Eds.), The Sage handbook of qualitative research ( $3^{\text {rd }}$ ed.). Thousand Oaks, CA: Sage.

Traianou, A. (2006). Teachers' adequacy of subject knowledge in primary science: Assessing constructivist approaches from a sociocultural perspective. International Journal of Science Education, 28(8), 827-842.

Viruru, R., \& Cannella, G. (2001). Postcolonial ethnography, young children and voice. In Grieshaber \& G Cannella (Eds), Embracing identities in early childhood education: Diversity and possibilities. New York: Teachers College Press.

Waters-Adams, S. (2006). The relationships between the understanding of the nature of science and practice: The influence of teachers' beliefs about education, teaching and learning. International Journal of Science Education, 28(8), 919944.

Watters, J., Diezmann, C., Grieshaber, S., \& Davis, J. (2001). Enhancing science education for young children: A contemporary initiative. Australian Journal of Early Childhood Education, 26(2), 1-7.

Wenger, E. (2000). Communities of practice and social learning systems. Organization, 7, 222-225.

Wells, G. (2008). Learning to use scientific concepts. Cultural Studies of Science Education, 3, 329-350.

Yoon, J., \& Onchwari, A. (2006). Teaching young children science: Three key points. Early Childhood Education Journal, 33(6), 419-423.

Zembylas, M. (2004). Emotional issues in teaching science: A case study of a teacher's views. Research in Science Education, 43, 343-364. 


\section{Appendix A: Initial Interview Questions}

- As this interview is going to be recorded could you please state your name? Thanks

- Firstly I would like to learn a bit about your background as an early childhood teacher

1. Where and when did you train?

2. Did I teach you for science?

3. What qualification did you gain?

4. Have you gained any more since then?

5. When did you start teaching?

6. Have you only taught in this centre? - if so go onto question 9

7. Where else have you taught and for how?

8. How did it differ from this centre?

9. What type of service was it?

10. What ethnicity would you class yourself as?

- Now I'd like to know about your own experiences of science.

1. What do you think 'science' is?

2. Did you study it at school?

3. If so what aspects and to what level?

4. How do you think those school experiences influenced the way you see/feel about science?

- Lastly I'd like you to talk about your views on teaching science - tell me about

1. What do you think 'early childhood science' is?

2. What do you think the teacher's role is in early childhood science education? Your ideas about teaching science?

3. How do you go about supporting children's scientific learning?

4. Documentation of children's learning \& documentation by children?

5. Do you see some children more involved in science investigation than others?

6. How do you feel about what you do? Confidence level $1-10$

7. What do you think influences the way you teach science?

8. What values do you think influence the way you teach science?

9. What beliefs do you think influence the way you teach science? 
10. What attitudes do you think influence the way you teach science?

11. What about family? Culture?

12. What do you think is important in enabling you to effectively support children's scientific learning? What do you need what's important? What helps you do what you are talking about? What helps you do the things you want to do in order to support children's scientific investigation?

13. What do you do with your science knowledge?

14. What hindrances?

15. Any others frustrations?

16. Sometimes people say that ECE teachers don't have enough content knowledge do you find your content knowledge? Do you find your content knowledge holds you back in teaching science or wanting to teach science?

17. What do you do when about when children have misconception theories eg rain?

18. Any other things to add as far as teaching science? Is it an area you have focused on?

19. What she remembers of her ECE science training experiences 


\section{Appendix B: Discussion Interview Questions}

General;

- What way of collecting data worked best for you?

- What problems did you incur when collecting the data?

- What were the most memorable incidents/ photos?

- What were the most unusual incidents/ photos?

- What was the most science related incidents/ photos?

Specific photos;

- Which incidents recorded did you get involved in?

- What sort of knowledge did you draw on to support this specific incident/photo?

- What sort of things do you think influenced the incident photographed?

- Did you set up any specific activities or events during the data gathering period?

- Which were child initiated?

- Which do you think were initiated by the resources/environment provided?

- What sort of things do you think influenced the way you felt about the photograph?

Conclusion;

- Where these usual occurrences in the centre?

- What sort of knowledge did you draw on to support the children's scientific interests?

- In what ways do you see the centre planning influencing your teaching during the data gathering period?

- In what ways do you Te Whaariki influencing your teaching during the data gathering period?

- What did you notice about the way you teach science after thinking about the photos taken? 


\section{Appendix C: Focus Group PowerPoint (minus the pictures)}

1

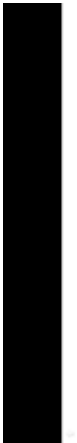

The inside story

Early childhood practitioners' perceptions of teaching science.

Kayto Edwards

Victoria University of Wellington

2

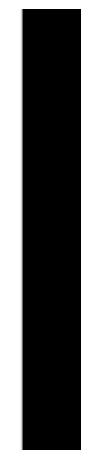

\section{6 incidents noted}

- Physical (70) natural (16) material (8) all worlds (2)

- Outdoor situations (40) indoor learning (56)

- Child initiated (70) teacher (26)

- Learning identified - process13/knowledge 24

- Almost 3x spontaneous to planned

- Most planned activities indoor 2/21

- Most spontaneous linked to physical world - few to natural \& material worlds

- Young children 66 ; toddlers 26 ; infants 8

3

\section{The question?}

"What are professionally trained early childhood teachers' understandings of, and feelings about, the way they support young children's learning in science?"

- What they think early childhood science is

- How they perceive their support of young children's scientific learning

4

- What knowledge and skills they believe they draw on to

\section{What they think early childhood} science is?

- All saw science as everyday

- Some mentioned the embedded nature -doing science without realising

Science is:

'whatever they do'

'finding out why'

'learning about the world \& people \& places'

'a foundation or introduction'

Other comments;

- You can find science in everything.

- The child learns intentionally \& unintentionally

- The blurring of boarders between curriculum areas

- Stressing the importance of the teachers role in the child's scientific learning 
- Through spontaneous \& planned situations

- Supporting skill development in scientific processes

- Encouraging positive scientific attitudes \& dispositions

- Majority encourage experimentation \& discovery

- $1 / 3^{\text {rd }}$ support increased understanding of scientific concepts

$7 \quad$ Following the child's interest (5)

- Child chooses interest regardless of age (5)

- Child able to independently learn (4)

- Linking to home experiences (3)

- Find out child's prior understandings (2)

- Teacher's knowledge of child used (2)

- Asking for child's ideas (2)

- Relating concept to child's world (2)

- Supporting child's documentation (1)

- Providing feedback to child (1)

- Changing nature of the child's interest (1)

8

\section{Teacher roles}

- Ask question (6)

- Increase content knowledge and scientific understanding (6)

- Reflective (5)

- Talking to (5) with (3) \& showing (2) children

- Involvement in situations (4)

- Plan for (4) \& document (5) children's learning

- Observe (4) \& purposefully not-engage (2)

- Resource nrovision (4)

9 - Extend child's knowledge - scaffold (3)

- Guide child's learning (3)

- Not 'over guide' (3)

- Having a specific teaching intention (2)

- Providing new experience (2)

- Use of specific scientific language (2)

- Enabler of child's experience (2) - behaviour issue (1) problem-solver (1)

- Re-visit observation (1)

- Providing age-appropriate situations (1)

\section{Teacher attitudes (6)}

- Enjoy

- Want to get it right

- Positive

- Enthusiastic

- Excited

- Curiosity

- Interested 
- Attitudes of exploration (6) fun (3) solution seeking (1) risk of trying something new (1)

- Try things out - experiment (5)

- Find out-discover (5)

- Independent learning (4)

- Increased understanding of scientific concepts (3)

- Development of working theories (2)

- Asking questions - inquiry (2)

- Observation(1)

- Documentation (1)

- Problem solving (1)

- Re-visiting (1)

12

\section{Debate over;}

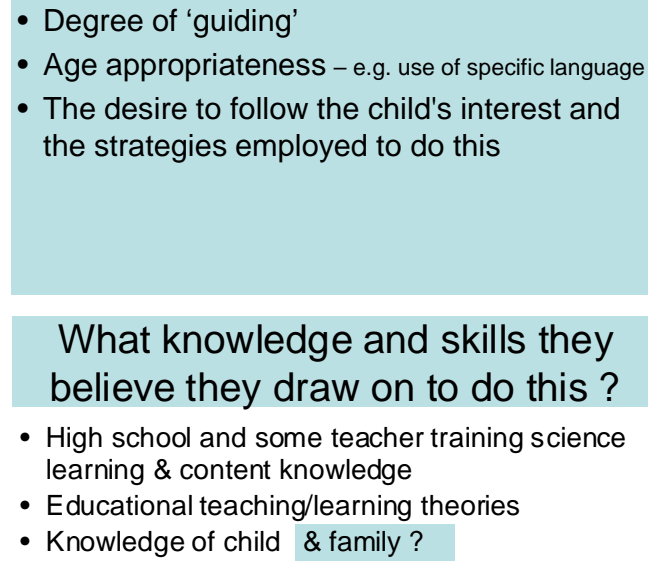

What knowledge and skills they believe they draw on to do this?

- High school and some teacher training science learning \& content knowledge

- Educational teaching/learning theories

- Knowledge of child \& family ?

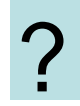

- Shared learning -ako (5)

- Peer learning - Tuakana/Teina (5)

- Following the child's interest (5)

- Parent partnership in learning (2)

- Transferred or generalised learning (2)

Teacher content knowledge

Feel they have enough for ECE situation Don't know how to explain in 'simple' way Want to learn more content knowledge 
What they believe influences their teaching views and practices in this area?

- Teacher's confidence in their content knowledge

- Teacher's attitude to enjoying \& learning science

- Teacher's own home environment experiences

- Teacher's culture

17

Teaching influences identified Cont...

- Teacher's high school learning experiences (positive \& negative)

- Teachers personal pedagogy - teaching theories adopted

- Teacher's personal values - e.g. seeing the child as an individual; inclusion; all questions are good to ask

- Teacher's own scientific interest - natural; action/reaction/curiosity

- Other teachers

- Degree of focus on science

What they think is important in enabling them to effectively support young children's scientific learning?

- Time - to teach, to study (4) between routines (2)

- Content knowledge resources (4)

- Physical space (2)

- Other teachers - team teaching (3)

- Personal content knowledge (2)

- Ability to explain at their level (2)

- Increased budget for resources(1)

\section{Working together}

Referring to ...

- Other teacher's work with children

- Other teacher's knowledge

- Teaching together

- Planning/documenting together

- Supporting each other's teaching endeavours 
Enablers and hindrances

- Mixed age setting - babies

- Teacher confidence

- Multiple teaching situations - business \& other children's needs/ peer, teacher 'guided' \& independent learning,

- Most activities resource based

\section{Changes in teaching}

- Increased awareness of children engaged in scientific learning

- Increased awareness of teaching style in supporting children's scientific learning

- Increased confidence in ability to support children's scientific learning 
Appendix D: Analysis of Incidents Noticed by Participants

\begin{tabular}{|c|c|c|c|c|c|c|c|c|}
\hline Column & & A & $\mathrm{B}$ & $\mathrm{C}$ & $\mathrm{D}$ & $\mathrm{E}$ & $\mathrm{F}$ & $\mathrm{G}$ \\
\hline Line & & Total & Participant 1 & Participant 2 & Participant 3 & Participant 4 & Participant 5 & Participant 6 \\
\hline 1 & Number of incidents noticed & 96 & $24(25 \%)$ & $10(\mathbf{1 0 \%})$ & $21(22 \%)$ & $22(23 \%)$ & $14(\mathbf{1 4 . 5 \% )}$ & $5(5 \%)$ \\
\hline 2 & Photographs & 84 (87.5\%) & 23 & 9 & 21 & 12 & 14 & 5 \\
\hline \multirow[t]{2}{*}{3} & Notebook or dictaphone & $12(\mathbf{1 2 . 5 \% )}$ & 1 & 1 & in addition to & 10 & 0 & 0 \\
\hline & \multicolumn{8}{|c|}{ Participant's responses to incidents noticed } \\
\hline 4 & Non response & $43(45 \%)$ & $15(62.5 \%)$ & $4(40 \%)$ & $6(29 \%)$ & $12 *(54.5 \%)$ & $4(28.5 \%)$ & $2(40 \%)$ \\
\hline 5 & Responded spontaneously & $24(25 \%)$ & $2(8.5 \%)$ & $2(20 \%)$ & $8 *(38 \%)$ & $6(27.5 \%)$ & $4(28.5 \%)$ & $2(40 \%)$ \\
\hline 6 & Responded with a planned activity & $23(24 \%)$ & $7(29 \%)$ & $4(40 \%)$ & $4 * *(\mathbf{1 9 \%})$ & $2 *(9 \%)$ & $5 *(36 \%)$ & $1(20 \%)$ \\
\hline \multirow[t]{2}{*}{7} & Planned for spontaneous response & $6(6 \%)$ & 0 & 0 & $3(14 \%)$ & $2(9 \%)$ & $1(7 \%)$ & 0 \\
\hline & \multicolumn{8}{|l|}{ Initiator of incidents and responses } \\
\hline 8 & Child initiated participant observed & $44(46 \%)$ & $15(62.5 \%)$ & $4(40 \%)$ & $6(29 \%)$ & $13(59 \%)$ & $4(28.5 \%)$ & $2(40 \%)$ \\
\hline 9 & Child initated participant engaged & $25(26 \%)$ & $2(8.5 \%)$ & $2(20 \%)$ & $9(43 \%)$ & $6(27.5 \%)$ & $4(\mathbf{2 8 . 5 \%})$ & $2(40 \%)$ \\
\hline 10 & $\begin{array}{l}\text { Teacher initiated participant } \\
\text { engaged }\end{array}$ & $\begin{array}{c}12 \\
(\mathbf{1 2 . 5 \% )}\end{array}$ & $1(4 \%)$ & $3(30 \%)$ & $3(14 \%)$ & $1(4.5 \%)$ & $3(21.5 \%)$ & $1(20 \%)$ \\
\hline \multirow[t]{2}{*}{11} & $\begin{array}{l}\text { Teacher initiated participant } \\
\text { observed }\end{array}$ & $\begin{array}{c}15 \\
(\mathbf{1 5 . 5 \% )}\end{array}$ & $6(25 \%)$ & $1(\mathbf{1 0} \%)$ & $3(14 \%)$ & $2(9 \%)$ & $3(21.5 \%)$ & 0 \\
\hline & \multicolumn{8}{|l|}{ Age of children in incidents noticed } \\
\hline 12 & Infant (6-18 mths) & $7(7 \%)$ & 0 & $1(\mathbf{1 0 \%})$ & $2(9.5 \%)$ & $1(4.5 \%)$ & $3(21.5 \%)$ & 0 \\
\hline 13 & Toddler (18 mths - 3 yrs) & $13(\mathbf{1 3 . 5 \% )}$ & $4(\mathbf{1 6 . 5 \% )}$ & $1(\mathbf{1 0} \%)$ & $5(24 \%)$ & $3(\mathbf{1 3 . 5 \% )}$ & 0 & 0 \\
\hline 14 & Young child (3 - 5 yrs) & $59(62 \%)$ & $17(71 \%)$ & $5(50 \%)$ & $9(43 \%)$ & $16(73 \%)$ & $8(57 \%)$ & $4(\mathbf{8 0} \%)$ \\
\hline 15 & Mixed age group (6 mths - $5 y$ rs $)$ & $13(\mathbf{1 3 . 5 \% )}$ & $2(8.5 \%)$ & $3(30 \%)$ & $3(14 \%)$ & $2(9 \%)$ & $2(14.5 \%)$ & $1(20 \%)$ \\
\hline \multirow[t]{2}{*}{16} & Unclear & $4(4 \%)$ & $1(4 \%)$ & 0 & $2(9.5 \%)$ & 0 & $1(7 \%)$ & 0 \\
\hline & \multicolumn{8}{|l|}{ Number of children in incidents noticed } \\
\hline 17 & Group situations & $22(23 \%)$ & 6 & 4 & 4 & 4 & 3 & 1 \\
\hline 18 & Individual child & $70(73 \%)$ & 17 & 6 & 15 & 18 & 10 & 4 \\
\hline 19 & Unclear & $4(4 \%)$ & 1 & 0 & 2 & 0 & 1 & 0 \\
\hline
\end{tabular}




\section{Appendix E: Analysis of Photographic Data Collected by Participants}

\begin{tabular}{|c|c|c|c|c|c|c|c|}
\hline Column & $\mathrm{A}$ & $\mathrm{B}$ & $\mathrm{C}$ & $\mathrm{D}$ & $\mathrm{E}$ & $\mathrm{F}$ & $\mathrm{G}$ \\
\hline 1 & age $12 / 07$ & gender & incidents & inside & outside & spontaneous & planned \\
\hline 2 & \multicolumn{2}{|l|}{ Infants } & $5.00 \%$ & & & & \\
\hline 3 & 0yr 08mth & $\mathrm{F}$ & 1 & 1 & 0 & 1 & 0 \\
\hline 4 & 0yr 10mth & $\mathrm{F}$ & 2 & 2 & 0 & 1 & 1 \\
\hline 5 & $1 \mathrm{yr} 04 \mathrm{mth}$ & $\mathrm{F}$ & 6 & 2 & 4 & 4 & 2 \\
\hline 6 & 3 & 3 & 9 & 5 & 4 & 6 & 3 \\
\hline 7 & $8.57 \%$ & & & $55.55 \%$ & $44.44 \%$ & $6.66 \%$ & $3.33 \%$ \\
\hline 8 & \multicolumn{2}{|l|}{ Toddlers } & $31.50 \%$ & & & & \\
\hline 9 & $1 \mathrm{yr} 07 \mathrm{mth}$ & $\mathrm{M}$ & 3 & 1 & 2 & 2 & 1 \\
\hline 10 & 1yr 09mth & $\mathrm{M}$ & 1 & 0 & 1 & 1 & 0 \\
\hline 11 & $1 \mathrm{yr} 09 \mathrm{mth}$ & $\mathrm{M}$ & 1 & 0 & 1 & 1 & 0 \\
\hline 12 & $1 \mathrm{yr} 10 \mathrm{mth}$ & $\mathrm{F}$ & 2 & 1 & 1 & 1 & 1 \\
\hline 13 & $1 \mathrm{yr} 11 \mathrm{mth}$ & $\mathrm{F}$ & 1 & 0 & 1 & 1 & 0 \\
\hline 14 & $2 \mathrm{yr} 01 \mathrm{mth}$ & $\mathrm{F}$ & 1 & 0 & 1 & 1 & 0 \\
\hline 15 & $2 \mathrm{yr} 02 \mathrm{mth}$ & $\mathrm{F}$ & 3 & 1 & 2 & 2 & 1 \\
\hline 16 & $2 \mathrm{yr} 04 \mathrm{mth}$ & $\mathrm{M}$ & 6 & 3 & 3 & 3 & 3 \\
\hline 17 & $2 \mathrm{yr} 05 \mathrm{mth}$ & $\mathrm{F}$ & 8 & 0 & 8 & 7 & 1 \\
\hline 18 & $2 \mathrm{yr} 05 \mathrm{mth}$ & $\mathrm{M}$ & 6 & 1 & 5 & 6 & 0 \\
\hline 19 & $2 \mathrm{yr} 09 \mathrm{mth}$ & $\mathrm{F}$ & 1 & 1 & 0 & 0 & 1 \\
\hline 20 & $2 \mathrm{yr} 0 \mathrm{mth}$ & $\mathrm{F}$ & 7 & 3 & 4 & 2 & 5 \\
\hline 21 & $2 \mathrm{yr} 0 \mathrm{mth}$ & $\mathrm{M}$ & 5 & 4 & 1 & 3 & 2 \\
\hline 22 & $2 \mathrm{yr} 0 \mathrm{mth}$ & $\mathrm{M}$ & 3 & 1 & 2 & 2 & 1 \\
\hline 23 & $2 \mathrm{yr} 11 \mathrm{mth}$ & $\mathrm{M}$ & 9 & 0 & 9 & 7 & 2 \\
\hline 24 & 15 & $7 \mathrm{~F} / 8 \mathrm{M}$ & 57 & 16 & 41 & 39 & 18 \\
\hline 25 & $42.86 \%$ & & & $28.07 \%$ & $71.93 \%$ & $68.42 \%$ & $31.58 \%$ \\
\hline
\end{tabular}




\begin{tabular}{|c|c|c|c|c|c|c|c|}
\hline Column & A & B & $\mathrm{C}$ & $\mathrm{D}$ & $\mathrm{E}$ & $\mathrm{F}$ & $G$ \\
\hline 26 & \multicolumn{2}{|l|}{ Young ch'n } & $63.50 \%$ & & & & \\
\hline 27 & $3 \mathrm{yr} 01 \mathrm{mth}$ & $\mathrm{M}$ & 4 & 1 & 3 & 2 & 2 \\
\hline 28 & $3 \mathrm{yr} 02 \mathrm{mth}$ & $\mathrm{F}$ & 0 & 0 & 0 & 0 & 0 \\
\hline 29 & $3 \mathrm{yr} 03 \mathrm{mth}$ & $\mathrm{F}$ & 7 & 3 & 4 & 4 & 3 \\
\hline 30 & $3 \mathrm{yr} 04 \mathrm{mth}$ & $\mathrm{M}$ & 10 & 5 & 5 & 7 & 3 \\
\hline 31 & $3 \mathrm{yr} 04 \mathrm{mth}$ & $\mathrm{M}$ & 4 & 2 & 2 & 2 & 2 \\
\hline 32 & $3 \mathrm{yr} 05 \mathrm{mth}$ & $\mathrm{F}$ & 6 & 3 & 3 & 1 & 5 \\
\hline 33 & $3 \mathrm{yr} 05 \mathrm{mth}$ & $\mathrm{F}$ & 2 & 1 & 1 & 1 & 1 \\
\hline 34 & $3 \mathrm{yr} 06 \mathrm{mth}$ & $\mathrm{F}$ & 1 & 1 & 0 & 0 & 1 \\
\hline 35 & $3 \mathrm{yr} 09 \mathrm{mth}$ & $\mathrm{F}$ & 4 & 3 & 1 & 1 & 3 \\
\hline 36 & $3 y r 0 \mathrm{mth}$ & $\mathrm{M}$ & 11 & 4 & 7 & 6 & 5 \\
\hline 37 & $3 \mathrm{yr} 10 \mathrm{mth}$ & $\mathrm{M}$ & 12 & 5 & 7 & 7 & 5 \\
\hline 38 & $3 \mathrm{yr} 11 \mathrm{mth}$ & $\mathrm{F}$ & 14 & 7 & 7 & 9 & 6 \\
\hline 39 & $3 \mathrm{yr} 04 \mathrm{mth}$ & $\mathrm{F}$ & 7 & 4 & 3 & 1 & 5 \\
\hline 40 & $4 \mathrm{yr} 05 \mathrm{mth}$ & $\mathrm{F}$ & 9 & 7 & 2 & 2 & 7 \\
\hline 41 & $4 \mathrm{yr} 05 \mathrm{mth}$ & $\mathrm{F}$ & 11 & 6 & 5 & 7 & 4 \\
\hline 42 & $4 \mathrm{yr} 05 \mathrm{mth}$ & $\mathrm{F}$ & 9 & 2 & 7 & 6 & 3 \\
\hline 43 & $4 \mathrm{yr} 05 \mathrm{mth}$ & $\mathrm{M}$ & 4 & 2 & 2 & 2 & 2 \\
\hline 44 & 17 & $11 \mathrm{~F} / 6 \mathrm{M}$ & 115 & 56 & 59 & 58 & 57 \\
\hline 45 & $48.56 \%$ & & $102 \mathrm{~F} / 79 \mathrm{M}$ & $48.70 \%$ & $51.30 \%$ & $50.44 \%$ & $49.56 \%$ \\
\hline 46 & 35 in total & $18 \mathrm{~F} / 14 \mathrm{M}$ & 181 & 77 & 104 & 103 & 78 \\
\hline 47 & Percentage & $56 \% / 44 \%$ & $57 \% \mathrm{~F} / 43 \% \mathrm{M}$ & $42.50 \%$ & $57.50 \%$ & $57 \%$ & $43 \%$ \\
\hline
\end{tabular}




\section{Appendix F: Management Information Sheet}

TE WHARE WĀNANGA O TE ÜPOKO O TE IKA A MĀUI

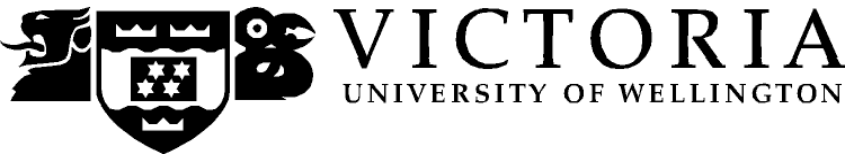

\section{Title of project:}

The inside story: Early childhood practitioners' perceptions of teaching science.

\section{Researcher:}

Kayte Edwards: School of early Childhood Teacher Education, Victoria University of Wellington

As the centre management committee I wish to approach you regarding the possibility of conducting my Masters Thesis research at the centre over a period of 2 - 3 months toward the end of this year. The research I am undertaking intends to look at early childhood science teaching. I wish to specifically look at the teacher's perspective; what do they see as science in early childhood education, how teacher's think they support children's scientific learning, what teacher's draw on to do this, what factors teacher's think influences the way they teach science and how teachers feel about teaching early childhood science.

I have outlined the research process below and would appreciate your approval by filling out the accompanying consent form and returning it in the reply paid envelope within a week. Please feel free to contact me for any further questions or clarification of the process.

After meeting with all trained teachers employed at the centre I hope to explain the research and gain individual consent from each trained teacher interested in being a teacher participant. Initial individual taped interviews would be designed to gather teacher participant background data and their views of science. Then teacher participants would be asked to take photos and record their thoughts about children involved in scientific investigation (independently or with teachers) in the centre over a specific period of time. To do this they would be provided with a digital camera, Dictaphone and notebook diary. I envisage that data collection for each teacher participant would be for $3-5$ days. At the end of this time another taped individual interview would take place where teacher participants hand over all data and discuss their interpretations of the data they have gathered. 
After an initial analysis of the research data I intend to ask teacher participants to comment on the research findings to date in a facilitated focus group. This is intended to check that the findings represent the data they have gathered as well as to create an opportunity to discuss emerging concepts. I anticipate the centre's involvement in the study taking $2-3$ months and hopefully occurring toward the end of this year.

Participation in the project is voluntary and all participants are able to withdraw up until the data collection is complete. While I realise that the research could disrupt teaching practices in the centre during this time, I hope to minimise this by deciding on a specific process for data gathering with you and the teacher participants before beginning the study.

The identity of the centre and the teacher participants will be protected through the use of pseudonyms. However, the use of photographs for the thesis documentation and dissemination may result in possible identification of the centre and teacher participants by those who have visited the environment, or know children who attend the centre. It is hoped that through a careful selection process the photos chosen will minimise this risk and a separate consent will be required for any visual images that identify teacher participants, children or other adults in the environment. All data material collected will be confidential and the destroyed after 3 years. A copy of the photographs will also be kept by the centre for the use of documenting children's learning.

This research has been approved by the Victoria University, College of Education, Ethics Committee. The thesis will be submitted for marking to the School of Education and deposited in the University Library. It is intended that the findings will be used for publication in scholarly journals and academic conference presentations. Along with providing information for the wider early childhood community, I hope that as a result of the study the centre and participants will have had an opportunity to examine and reflect on their own science teaching and possibly develop current practices further or modify them.

Researcher/Student - Kayte Edwards

Ph: 4639667

kayte.edwards@vuw.ac/nz
Supervisor - Judith Loveridge

Ph: 4636028

judith.loveridge@vuw.ac/nz 


\section{Appendix G: Management Consent Form}

TE WHARE WĀNANGA O TE ÜPOKO O TE IKA A MĀUI

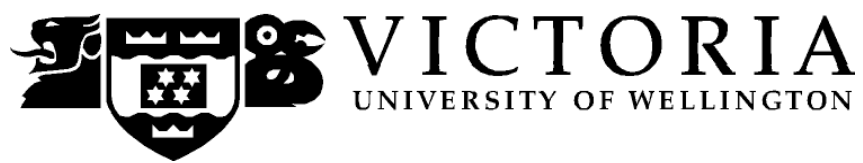

\section{Management Consent Form}

Title of project: The inside story: Early childhood practitioners' perceptions of teaching science.

We the management of have agreed for

the centre to be part of Kayte Edward's Masters Thesis research project. We have been given, and have understood an explanation of this research project and have had an opportunity to ask questions and have them answered to our satisfaction.

We understand the following:

That teacher research participants will give their personal consent to being part of the research and may withdraw themselves (or any information provided by them) from this project without having to give reasons or without penalty of any sort.

That any parents of children at the centre may withdraw their child/ren (or any information provided by them, or about their child) from this project without having to give reasons or without penalty of any sort.

That the centre will receive a copy of all photographs taken during the research and that any person is able to use them when complying with the centre's policy on photographs.

That any written or taped information provided will be kept confidential to the researcher, the supervisor and the person who transcribes the interview tape recordings, and destroyed after 3 years.

That any published results will not use the centre's name or any of those people associated with the centre.

That a summary of the key findings will be presented to teacher participants and any other interested parties, such as parents, in an oral presentation. 
That all teacher participants, and parents of children attending the centre, will be entitled to a copy of the summary of the final report. All parents will be asked if they wish to receive a copy of all photos taken of their child during the study.

The centre management will receive a copy of the final thesis, and of any publications or conference presentations that arise from it.

Signed: $\quad$ (please print each signatories name alongside it)

Date:

Researcher/Student - Kayte Edwards Ph: 4639667

kayte.edwards@vuw.ac/nz
Supervisor - Judith Loveridge

$\mathrm{Ph}: 4636028$

judith.loveridge@vuw.ac/nz 


\section{Appendix H: Participant Information Sheet}

\section{The inside story: Early childhood practitioners' perceptions of teaching science}

As part of my Masters of Education thesis I wish to invite you and the trained teachers working in the centre, be part of a research project that intends to look at early childhood science teaching. I wish to specifically look at the teacher's perspective; how they feel about early childhood science, how they feel they support children's scientific learning, what they draw on to do this, and what factors they feel influences the way they teach science.

As you may imagine this requires research participants to be involved to a high degree as in order to gain a teacher perspective I intend to ask participants to help gather some of the data (primarily photos) as well as talk about what it means to them. It would be important that all trained teachers employed at the centre would be free to volunteer for the project as well as being able to withdraw up until the end of data collection.

I would like to conduct initial interviews with each participant looking into the teacher views of science. Teachers would then be asked to take photos and keep a teacher diary of science experiences in the centre over a specific period of time. I envisage that data collection may take up to a month. At the end of this time another interview would take place asking participants for their interpretations of the data they have gathered.

After initial analysis of the research data I intend to ask participants to comment on the research findings to date in a group discussion situation. This is intended to be a time for the findings to be assessed as a representation of the data you have gathered as well as an opportunity to discuss emerging concepts. I anticipate the participant's involvement in the study taking $2-3$ months and hopefully occurring toward the end of this year.

While I realise that the research will disrupt teaching practices in the centre during this time, I hope to minimise this by deciding on a specific process for data gathering with the participants before beginning the study.

Along with providing information for the wider early childhood community, I hope that as a result of the study the centre and participants will have had an opportunity to examine and reflect on their own science teaching and possibly develop current practices further or modify them. 
If you are interested in being part of this study, I would like to set up an initial meeting to discuss the research and your possible involvement in it further.

Researcher/Student - Kayte Edwards Ph 4639667

kayte.edwards@vuw.ac/nz
Supervisor - Judith Loveridge $\mathrm{Ph} ; 4636028$

judith.loveridge@vuw.ac/nz 


\section{Appendix I: Teacher Participant Consent and Request Forms}

\section{TE WHARE WĀNANGA O TE ŨPOKO O TE IKA A MĀUI

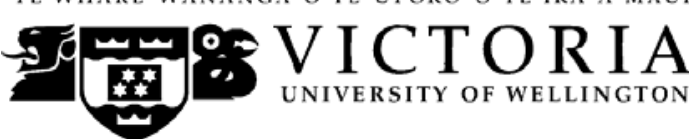 \\ Teacher Participant Consent Form}

Title of project: The inside story: Early childhood practitioners ' perceptions of teaching science.

I have agreed to be part of the research project to be held in the centre at which I am employed. I have been given and have understood an explanation of this research project and have had an opportunity to ask questions and have them answered to my satisfaction.

I understand the following;

That any information I provide will be kept confidential to the researcher, the supervisor and the person who transcribes the tape recordings of our interviews. The published results will not use my name, and that no opinions will be attributed to me in any way that will identify me.

I will also consent to be an active part of a focus group meeting to discuss my thoughts on the key research findings at a later date and keep confidential the contribution of other participants.

That the tape recording of interviews will be electronically wiped at the end of the project unless I indicate that I would like them returned to me in the accompanying form.

That I will have an opportunity to check the transcripts of the interview before publication.

I am able to request a summary of the results of this research when it is completed in the accompanying form.

Signed:

Date:

Name of participant (please print clearly):

Researcher/Student - Kayte Edwards

$\mathrm{Ph} 4639667$

kayte.edwards@vuw.ac/nz
Supervisor - Judith Loveridge

$\mathrm{Ph} ; 4636028$

judith.loveridge@vuw.ac/nz 


\section{Teacher Participant Request Form}

Can you please send to the address below;

(Please tick if required)

$\square$ A summary of the results of this research when it is completed.

$\square$ The original and only tape recording of individual interviews held between myself and the researcher.

Name:

Postal address:

Researcher/Student - Kayte Edwards

Ph 4639667

kayte.edwards@vuw.ac/nz
Supervisor - Judith Loveridge

$\mathrm{Ph} ; 4636028$

judith.loveridge@vuw.ac/nz 


\section{Appendix J: Participant Focus Group Information Sheet}

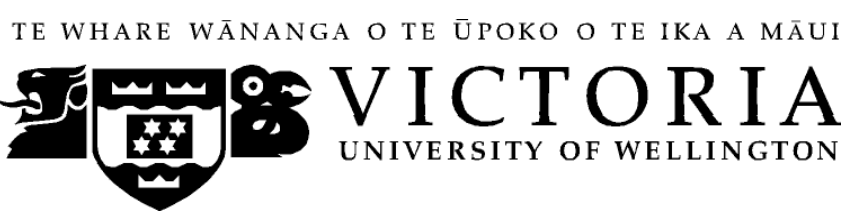

Title of project: The inside story: Early childhood practitioners 'perceptions of teaching science.

As part of the research I am conducting on early childhood science teaching I wish to hold a focus group interview with all participants present. This is to check that the key findings are inline with the data you have gathered, as well as providing an opportunity to discuss the emerging concepts further.

The focus group interview is for all teacher research participants only and would start with a presentation of 3 to 5 of the key themes emerging from my analysis of the taped, written or photographic data teacher research participants have provided me with, and then followed by a discussion about these.

A facilitator would guide the process of the focus group discussion in a neutral manner. They would be bound by a confidentiality agreement and would not be privy to personal teacher participant details. Although present I would not be a speaking group participant. My role would be to present the initial research findings, and then tape the following discussion about them, noting down any significant observations such as identifying a speaker. Elements of the interview would then be transcribed to enrich and provide rigour to the existing research data. Along with all other data the focus group records would remain confidential to the researcher, thesis supervisor and transcribers and destroyed after 3 years.

It is essential for the success of the focus group that each member of the group keeps group confidentiality by not disclosing any information about focus group discussions to non-group members, such as parents or other staff members. It is vital that group members feel secure that the views expressed within the focus group interview will not be repeated or disadvantage them in any way.

It is expected that the focus group discussion would proceed in an open, polite and orderly manner with the facilitator ensuring that each member is able to express their opinion about each key theme within the agreed time frame. If you wish to discuss any aspect of the focus group discussion, please do not hesitate to contact me.

Researcher/Student - Kayte Edwards

$\mathrm{Ph} 4639667$

kayte.edwards@vuw.ac/nz
Supervisor - Judith Loveridge

$\mathrm{Ph} ; 4636028$

judith.loveridge@vuw.ac/nz 


\section{Appendix K: Participant Consent and Request Forms - Focus Group Only}

TE Whare Wänanga o Te ŨPoko o te ika a mäUi

Participant Consent Form - Focus Group Only

Title of project: The inside story: Early childhood practitioners' perceptions of teaching science.

I have agreed to be part of the research project to be held in the centre at which I am employed. I have been given and have understood an explanation of this research project and have had an opportunity to ask questions and have them answered to my satisfaction.

I understand the following;

That any information I provide will be kept confidential to the researcher, the supervisor and the person who transcribes the tape recordings of our interviews. The published results will not use my name, and that no opinions will be attributed to me in any way that will identify me.

I will also consent to be an active part of a focus group meeting to discuss my thoughts on the key research findings at a later date and keep confidential the contribution of other participants.

That the tape recording of interviews will be electronically wiped at the end of the project unless I indicate that I would like them returned to me in the accompanying form.

That I will have an opportunity to check the transcripts of the interview before publication.

I am able to request a summary of the results of this research when it is completed in the accompanying form.

Signed:

Date:

Name of participant (please print clearly):

Researcher/Student - Kayte Edwards

Ph 4639667

kayte.edwards@vuw.ac/nz
Supervisor - Judith Loveridge

$\mathrm{Ph} ; 4636028$

judith.loveridge@vuw.ac/nz 


\section{Teacher Participant Request Form}

Can you please send to the address below;

(Please tick if required)

A summary of the results of this research when it is completed.

The original and only tape recording of individual interviews held between myself and the researcher.

Name:

Postal address:

Researcher/Student - Kayte Edwards

Ph 4639667

kayte.edwards@vuw.ac/nz
Supervisor - Judith Loveridge

Ph; 4636028

judith.loveridge@vuw.ac/nz 


\section{Appendix L: Parent Information Sheet}

\section{TE WHARE WĀNANGA O TE ŨPOKO O TE IKA A MĀUI

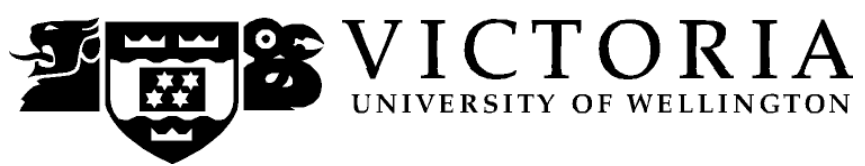

Title of project: The inside story: Early childhood practitioners' perceptions of teaching science.

As part of my Masters degree I am undertaking a research project looking at early childhood science teaching and intend to conduct it at the centre your child attends. While researching the teachers' views are the focus of this study, one of the research strategies involved will require the teachers to observe and photograph children involved in scientific exploration at the centre. Consequently I am seeking consent from you on your child's behalf to use any photos or observations of your child that teachers may make during the time of the research.

I have outlined the research process below and would appreciate you discussing this with your child, filling out the accompanying consent form and returning it in the reply paid envelope provided. I will also make visits the centre to talk with children about the research process and answer any questions they may have. Please feel free to contact me for any further questions or clarification of the process.

The research is designed to gather information on early childhood teachers' perceptions about supporting children's scientific learning. How teachers feel about early childhood science; how teachers feel they support children's scientific learning; what teacher's draw on to do this; and what factors teacher's feel influence the way they teach science.

As part of the research process teacher research participants will be asked to take photos and record their thoughts about children involved in scientific investigation (independently or with teachers) in the centre over a specific period of time. The teacher participants will then discuss their interpretations of the photos with the researcher. I anticipate the centre's involvement in data gathering will take for 4 to 6 weeks and will occur toward the end of this year.

The research report will not personally identify your child and a separate permission would be sought for any photographic data that could possibly identify your child. All data material collected will be kept confidential and the destroyed after 3 years. 
At the end of the process you will be able to request a copy of the findings as well as any photographs taken of your child. The centre will also retain a copy of all photographs taken for children's documentation of learning. Any subsequent use of photos would follow centre policies.

The thesis will be submitted for marking to the School of Education, V.U.W. and deposited in the University Library. It is intended that the findings will be used for publication in scholarly journals and academic conference presentations. This research has been approved by the Victoria University, College of Education, Ethics Committee.

If you have any concerns regarding the research please do not hesitate to contact me. Otherwise please sign the accompanying forms and return in the self-addressed envelope within a week.

Researcher/Student - Kayte Edwards

$\mathrm{Ph} 4639667$

kayte.edwards@vuw.ac/nz
Supervisor - Judith Loveridge $\mathrm{Ph} ; 4636028$

judith.loveridge@vuw.ac/nz 


\section{Appendix M: Parent Consent and Request Forms}

TE WHARE WĀNANGA O TE ŪPOKO O TE IKA A MĀUI

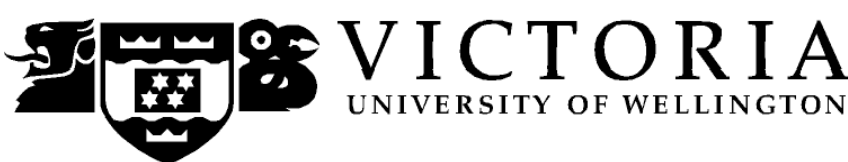

Title of project: The inside story: Early childhood practitioners' perceptions of teaching science.

I have agreed for my child to be part of the research project to be held in the centre they attend and have discussed this with my child. I have been given and have understood an explanation of this research project and have had an opportunity to ask questions and have them answered to my satisfaction.

I understand the following:

That I may withdraw my child (or any information I have provided) from this project without having to give reasons or without penalty of any sort.

That any photos or observations taken of my child will be used by the researcher for analysis, as well as the centre using them for usual assessment practices, complying with the centre's policy on photographs.

The published results will not use my child's name.

Separate consent will be sought at a later date for any photos used in the thesis or dissemination of the thesis that may specifically identify my child.

I am able to request copies of all photos taken of my child.

I am able to request a summary of the results of this research when it is completed.

Signed:

Date:

Name of child:

Name of parent:

(Please print clearly)

Researcher/Student - Kayte Edwards

Ph: 4639667

kayte.edwards@vuw.ac/nz
Supervisor - Judith Loveridge

Ph: 4636028

judith.loveridge@vuw.ac/nz 


\section{Parent Request Form}

Can you please send to the address below;

(Please tick if required)

A summary of the results of this research when it is completed.

A copy of all photos taken of my child.

Name of child:

Name of parent:

Postal address:

Researcher/Student - Kayte Edwards

Ph: 4639667

kayte.edwards@vuw.ac/nz
Supervisor - Judith Loveridge Ph: 4636028

judith.loveridge@vuw.ac/nz 


\section{Appendix N: Photo Dissemination Permission}

TE WHARE WĀNANGA O TE ÜPOKO O TE IKA A MĀUI

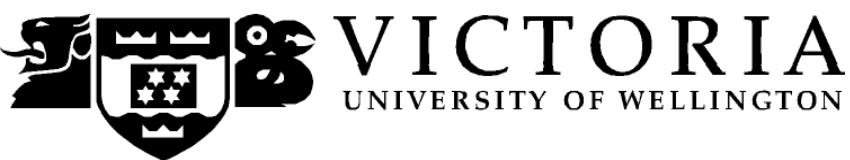

The inside story: Early childhood practitioners' perceptions of teaching science.

\section{Authority to use photographs in disseminating information about this study}

\section{This form will be held for a period of five (5) years}

During the data-gathering phase of the research, photograph/s of your child were taken of them while they were engaged in science investigation at the centre where the research took place. I am seeking your consent to use the photograph/s below in the dissemination of the findings to a wider education audience.

These photographs may appear in visual presentations (e.g. PowerPoint) and / or in written publications (journals).

All data including the photographs will be kept for a period of five years in a secured area.

I give permission for these photographs to be used in this way for up to a period of five years.

\section{Childs name:}

Signature:

Full name - printed

Relationship to the child:

Date: 
Appendix O: Analysis of Participants' Teaching Strategies

\begin{tabular}{|c|c|c|c|c|c|c|c|c|}
\hline \multirow{2}{*}{$\begin{array}{c}\text { Line } \\
1\end{array}$} & \multicolumn{2}{|c|}{ Behaviour encouraged in child by participant } & \multirow[b]{2}{*}{ Participant 1} & \multirow[b]{2}{*}{ Participant 2} & \multirow[b]{2}{*}{ Participant 3} & \multirow[b]{2}{*}{ Participant 4} & \multirow[b]{2}{*}{ Participant 5} & \multirow[b]{2}{*}{ Participant 6} \\
\hline & Skill-process & Total & & & & & & \\
\hline 2 & Theory development & 2 of 6 & 1 & & & & & 1 \\
\hline 3 & Observation & 1 of 6 & & & 1 & & 1 & \\
\hline 4 & Ask questions & 2 of 6 & & & 1 & & & 1 \\
\hline 5 & Experiment -try things out & 5 of 6 & 1 & 1 & 1 & 1 & 1 & \\
\hline 6 & Find out - discover & 5 of 6 & 1 & 1 & 1 & & 1 & 1 \\
\hline 7 & Focument their findings & 1 of 6 & & & & & & 1 \\
\hline 8 & Find alternative solutions & 1 of 6 & & & 1 & & & \\
\hline 9 & Use of prior knowledge & 2 of 6 & & & 1 & & & 1 \\
\hline 10 & Re-visit \& reflect on experience & 1 of 6 & 1 & & & & 1 & \\
\hline 11 & Self learning & 4 of 6 & 1 & & 1 & 1 & & 1 \\
\hline 12 & \multicolumn{8}{|l|}{ Content knowledge } \\
\hline 13 & Increased understanding & 2 of 6 & & & & 1 & 1 & \\
\hline 14 & \multicolumn{8}{|l|}{ Attitude -disposition } \\
\hline 15 & Exploration & all & 1 & 1 & 1 & 1 & 1 & 1 \\
\hline 16 & Try something new & 1 of 6 & 1 & & & & & \\
\hline 17 & Finding answers to questions & 1 of 6 & & & 1 & & & \\
\hline 18 & \multicolumn{8}{|l|}{ Participant teaching behaviour } \\
\hline 19 & Drawing child's attention to a phenomena & 3 of 6 & plants & general & air movement & & & \\
\hline 20 & Invite child to engage & 2 of 6 & 1 & & 1 & & & \\
\hline 21 & Offer options to extend & 5 of 6 & 1 & 1 & 1 & e.g. given & & 1 \\
\hline 22 & Not 'over guide' & 2 of 6 & 1 & 1 & & & & \\
\hline 23 & Being there & 2 of 6 & 1 & & & 1 & & \\
\hline 24 & Ask open ended questions & all & 1 & e.g. given & e.g. given & 1 & e.g. given & e.g. given \\
\hline 25 & Support children's learning & all & assisting & guide & scaffold & facilitate & help & extend \\
\hline
\end{tabular}




\begin{tabular}{|c|c|c|c|c|c|c|c|c|}
\hline \multirow{2}{*}{$\frac{\text { Line }}{1}$} & \multicolumn{2}{|c|}{ Behaviour encouraged in child by participant } & \multirow[b]{2}{*}{ Participant 1} & \multirow[b]{2}{*}{ Participant 2} & \multirow[b]{2}{*}{ Participant 3} & \multirow[b]{2}{*}{ Participant 4} & \multirow[b]{2}{*}{ Participant 5} & \multirow[b]{2}{*}{ Participant 6} \\
\hline & Skill-process & Total & & & & & & \\
\hline 26 & Communicate content ideas & 4 of 6 & & with & 1 & & tell, talk to & talk to \\
\hline 27 & Encouarge dispostions & 2 of 6 & 1 & & 1 & & & \\
\hline 28 & Giving prompts & 3 of 6 & 1 & e.g. given & e.g. given & & & \\
\hline 29 & Provoke thinking & 5 of 6 & 1 & 1 & 1 & 1 & & 1 \\
\hline 30 & Recognise \& encourage working theories & all & e.g. given & 1 & 1 & e.g. given & e.g. given & e.g. given \\
\hline 31 & Revisit situtations observed & 1 of 6 & & & & & & 1 \\
\hline 32 & Engage in learning with the child & all & 1 & 1 & 1 & e.g. given & 1 & e.g. given \\
\hline 33 & Observe child & all & 1 & 1 & 1 & 1 & e.g. given & 1 \\
\hline 34 & Follow child's interest & all & 1 & 1 & 1 & 1 & e.g. given & e.g. given \\
\hline 35 & Finding out child's prior knowledge & 3 of 6 & & 1 & 1 & & 1 & \\
\hline 36 & Link to home experiences & 2 of 6 & & & 1 & & & 1 \\
\hline 37 & Link from centre experiences & 5 of 6 & art work & construction & parent talk & artwork & & documentaion \\
\hline 38 & Reflect on teachng incidents & all & 1 & 1 & 1 & 1 & 1 & 1 \\
\hline 39 & Provide new experiences & 2 of 6 & & 1 & & & & 1 \\
\hline 40 & Use resources & all & 1 & 1 & 1 & 1 & 1 & 1 \\
\hline 41 & Get additional resources & 5 of 6 & 1 & 1 & 1 & 1 & & 1 \\
\hline 42 & Specific teaching strategy & 5 of 6 & resources & role plays & questioning & & infant focus & group time \\
\hline 43 & Learning with or from the child & all & 1 & 1 & 1 & 1 & 1 & 1 \\
\hline 44 & Joint learning & 3 of 6 & 1 & & & & 1 & 1 \\
\hline 45 & Set up environment & 4 of 6 & 1 & & 1 & & 1 & 1 \\
\hline 46 & Planned activity & all & 1 & 1 & e.g. given & 1 & 1 & 1 \\
\hline 47 & Planned project & 3 of 6 & garden & garden & garden & & & \\
\hline 48 & Encourage peer learning & all & e.g. given & 1 & 1 & 1 & 1 & 1 \\
\hline 49 & Specific teaching point & 4 of 6 & e.g. given & 1 & e.g. given & e.g. given & & \\
\hline 50 & Document child's learning & all & 1 & 1 & 1 & 1 & 1 & 1 \\
\hline 51 & Flexible planning & 3 of 6 & 1 & & 1 & 1 & & \\
\hline
\end{tabular}




\begin{tabular}{|c|c|c|c|c|c|c|c|c|}
\hline \multirow{2}{*}{$\begin{array}{c}\text { Line } \\
1 \\
\end{array}$} & \multicolumn{2}{|c|}{ Behaviour encouraged in child by participant } & \multirow[b]{2}{*}{ Participant 1} & \multirow[b]{2}{*}{ Participant 2} & \multirow[b]{2}{*}{ Participant 3} & \multirow[b]{2}{*}{ Participant 4} & \multirow[b]{2}{*}{ Participant 5} & \multirow[b]{2}{*}{ Participant $\mathrm{f}$} \\
\hline & Skill-process & Total & & & & & & \\
\hline 52 & Provide environmental resources & 3 of 6 & planks & & windsocks & & & 1 \\
\hline 53 & \multicolumn{8}{|l|}{ Teacher attitude } \\
\hline 54 & Open to learning - interested & all & 1 & 1 & 1 & 1 & 1 & 1 \\
\hline 55 & Willing to engage in activity & 3 of 6 & 1 & 1 & 1 & & & \\
\hline 56 & Being excited - passionate & 2 of 6 & & & 1 & 1 & & \\
\hline 57 & Inclusion (ability \& age) & all & 1 & 1 & 1 & 1 & 1 & e.g. given \\
\hline 58 & \multicolumn{8}{|l|}{ Use of teaching knowledge } \\
\hline 59 & Having clear teaching intentions & 1 of 6 & & 1 & & & & \\
\hline 60 & Increase understanding of the concept & all & 1 & 1 & 1 & 1 & 1 & e.g. given \\
\hline 61 & Use of specific language & 3 of 6 & & 1 & 1 & & & 1 \\
\hline
\end{tabular}




\section{Appendix P: Participant information}

\begin{tabular}{|c|c|c|}
\hline Line & & Collated data \\
\hline 1 & Age bracket & $20-25 ; 25-30 ; 30-35(2) ; 35-40 ; 40-45$ \\
\hline 2 & Ethnicity & 4 NZ European, Maori, Indian \\
\hline 3 & Teaching qualification & Dip ECE (2); BEd ECE(2), BEd Prim (2), Grad dip (1) - all Wgtn \\
\hline 4 & Year of qualification & $1998 ;$ post $2000(5)$ \\
\hline 5 & Teaching experience & 2 yrs $(2), 4-5$ yrs $(2), 10-11$ yrs $(2)$ \\
\hline 6 & Location & All at centre except for relieving \\
\hline 7 & Secondary science level & 7th form science $(3)$,6 th form ; last school yr, not specialised \\
\hline 8 & Comments on secondary schooling & Positive (4), negative (2) \\
\hline 9 & Confidence level in teaching & See table page 2 Chapter 5 \\
\hline 10 & Knowledge acquisition -home & Growing up environment - all ( 1 negative $)$ \\
\hline 11 & Knowledge acquisition -Primary & Primary school -1 (1 negative) \\
\hline 12 & Knowledge acquisition -Secondary & Secondary school -6 (2 negative) \\
\hline 13 & Knowledge acquisition -T Coll. & Teacher training -3 (1 negative) \\
\hline 14 & Knowledge acquisition -World & Wider world -2 \\
\hline \multirow[t]{2}{*}{15} & Knowledge acquisition -Colleagues & Other teachers -1 \\
\hline & & Participant 1 \\
\hline 16 & Age bracket & $35-40$ \\
\hline 17 & Ethnicity & Maori \\
\hline 18 & Teaching qualification & Dip ECE Wgtn \\
\hline 19 & Year of qualification & 2005 \\
\hline 20 & Teaching experience & 4 yrs pre, 4 yrs in-training, 3 post $=11$ yrs \\
\hline 21 & Location & All at research centre \\
\hline 22 & Confidence level in teaching & 4 to $6 / 7$ \\
\hline 23 & Knowledge acquisition -home & It seems like I'm reliving my childhood years with the children \\
\hline 24 & Knowledge acquisition -Primary & \\
\hline
\end{tabular}




\begin{tabular}{|c|c|c|}
\hline Line & & Collated data \\
\hline 25 & Knowledge acquisition -Secondary & Too theoretical not aligned to hands-on approach preference \\
\hline 26 & Secondary science level & Not specialised in \\
\hline 27 & Knowledge acquisition -T Coll. & \\
\hline 28 & Knowledge acquisition -World & \\
\hline \multirow[t]{2}{*}{29} & Knowledge acquisition -Colleagues & \\
\hline & & Participant 2 \\
\hline 30 & Age bracket & $25-30$ \\
\hline 31 & Ethnicity & NZ European \\
\hline 32 & Teaching qualification & BEd(Primary) Grad Dip (ECE) Wgtn \\
\hline 33 & Year of qualification & 2006 \\
\hline 34 & Teaching experience & $1.5 \mathrm{yrs}$ pre-training, 2 yrs training, $1 \mathrm{yr}$ post training $=4.5 \mathrm{yrs}$ \\
\hline 35 & Location & All but Primary School tching, \& work in Britain at research centre \\
\hline 36 & Confidence level in teaching & Want to gain more confidence $-15 / 6$ to $6 / 7$ \\
\hline 37 & Knowledge acquisition -home & Astronomy a family interest \\
\hline 38 & Knowledge acquisition -Primary & \\
\hline 39 & Knowledge acquisition -Secondary & Anatomy learnt at school \\
\hline 40 & Secondary science level & 7th form biology, 4th form chemistry \\
\hline 41 & Knowledge acquisition -T Coll. & Use of T Coll. knowledge- recognition of science when you see it \\
\hline 42 & Knowledge acquisition -World & \\
\hline \multirow[t]{2}{*}{43} & Knowledge acquisition -Colleagues & \\
\hline & & Participant 3 \\
\hline 44 & Age bracket & $40-45$ \\
\hline 45 & Ethnicity & NZ European \\
\hline 46 & Teaching qualification & BEd ECE Wgtn \\
\hline 47 & Year of qualification & 2001 \\
\hline 48 & Teaching experience & $1 \mathrm{yr}$ pre, 3 yrs in-training, $6 \mathrm{yrs}$ post $=10 \mathrm{yrs}$ \\
\hline
\end{tabular}




\begin{tabular}{|c|c|c|}
\hline Line & & Collated data \\
\hline 49 & Location & All at research centre \\
\hline 50 & Confidence level in teaching & $9 / 10$ to $8 / 9$ \\
\hline 51 & Knowledge acquisition -home & Familyinto natural environment. Husband an engineer \\
\hline 52 & Knowledge acquisition -Primary & \\
\hline 53 & Knowledge acquisition -Secondary & Loved it \\
\hline 54 & Secondary science level & 6th form Biology \& Chemistry \\
\hline 55 & Knowledge acquisition -T Coll. & Not enough emphasis \\
\hline 56 & Knowledge acquisition -World & \\
\hline \multirow[t]{2}{*}{57} & Knowledge acquisition -Colleagues & \\
\hline & & Participant 4 \\
\hline 58 & Age bracket & $20-25$ \\
\hline 59 & Ethnicity & NZ European \\
\hline 60 & Teaching qualification & BEd Wgtn \\
\hline 61 & Year of qualification & 2005 \\
\hline 62 & Teaching experience & $2 \mathrm{yr}$ in-training, $2 \mathrm{yr}$ post $=4 \mathrm{yrs}$ \\
\hline 63 & Location & All at research centre \\
\hline 64 & Confidence level in teaching & 5-ish to $7 / 8$ \\
\hline 65 & Knowledge acquisition -home & Family seen as 'not scientific' \\
\hline 66 & Knowledge acquisition -Primary & Can't remember specifics of Primary school science \\
\hline 67 & Knowledge acquisition -Secondary & School 'didn't really work for me \\
\hline 68 & Secondary science level & 7th Form Biology \\
\hline 69 & Knowledge acquisition -T Coll. & Recall information on inclines \\
\hline 70 & Knowledge acquisition -World & \\
\hline \multirow[t]{2}{*}{71} & Knowledge acquisition -Colleagues & \\
\hline & & Participant 5 \\
\hline 72 & Age bracket & $35-40$ \\
\hline 73 & Ethnicity & Indian Hindu \\
\hline
\end{tabular}




\begin{tabular}{|c|c|c|}
\hline Line & & Collated data \\
\hline 74 & Teaching qualification & Dip Ed Wgtn \\
\hline 75 & Year of qualification & 2004 \\
\hline 76 & Teaching experience & Relief teacher $2 \mathrm{yrs}$, post-study $2 \mathrm{yrs}=2 \mathrm{yrs}+$ \\
\hline 77 & Location & All but relieving at research centre \\
\hline 78 & Confidence level in teaching & 5 to not confident yet - getting better \\
\hline 79 & Knowledge acquisition -home & Mother a nurse \\
\hline 80 & Knowledge acquisition -Primary & \\
\hline 81 & Knowledge acquisition -Secondary & NZ science schooling very different \\
\hline 83 & Secondary science level & Final year in India \\
\hline 84 & Knowledge acquisition -T Coll. & \\
\hline 85 & Knowledge acquisition -World & Reads books on science since arriving in NZ \\
\hline \multirow[t]{2}{*}{86} & Knowledge acquisition -Colleagues & Observing other teachers to learn \\
\hline & & Participant 6 \\
\hline 87 & Age bracket & $25-30$ \\
\hline 88 & Ethnicity & New Zealand European \\
\hline 89 & Teaching qualification & BEd Wgtn \\
\hline 90 & Year of qualification & 1998 \\
\hline 91 & Teaching experience & 2 ys + Primary \\
\hline 92 & Location & All at research centre \\
\hline 93 & Confidence level in teaching & 7 or 8 to 7 -fairly much the same \\
\hline 94 & Knowledge acquisition -home & Dad an electrician \\
\hline 95 & Knowledge acquisition -Primary & \\
\hline 96 & Knowledge acquisition -Secondary & Good, passionate teachers \\
\hline 97 & Secondary science level & 7th form chemistry \& biology \\
\hline 98 & Knowledge acquisition -T Coll. & \\
\hline 99 & Knowledge acquisition -World & I like looking things up \& finding out why \\
\hline 100 & Knowledge acquisition -Colleagues & \\
\hline
\end{tabular}




\section{Appendix Q: The story of viscosity: A narrative}

One of the research participants had a nephew at the case study childcare centre where she taught. He was almost four-years-old and did "little things at home with his dad" (Participant 6, Interview 1). On the day he came into the centre talking about viscosity everyone was surprised. "I mean, I don't think viscosity is a term I would use with a nearly 4 year-old but $\mathrm{H}$ has cottoned on to what it means" (Participant 6, Interview 1). Participant 3 recounts how he later asked her "What about the oil viscosity?" She replied "What makes it like that?" "Oh, it's slippery" he replied back (Participant 3, Interview 2). Participant 3 is confident in her knowledge of viscosity and attributes that to having married an engineer. She enjoys situations like this and utilises them as teaching opportunities for other children: "It's quite good cos it pulls other children in when you start talking about conversations and then getting things out to have a go. Getting the oil out from the cupboard and putting it on the plate and dipping your fingers in there and trying to move something through it" (Participant 3, Interview 2).

Half of the six participants in the case study referred to this incident and their reflections on it. Participant 6 (Focus group interview) talked about the capacity of a child's scientific learning when it was their interest. She wondered if teachers limit learning by having limited expectations of the child. Participant 3 (Focus group interview) wondered how to support further understanding of the concept and how this might be explained to younger children in the mixed age setting:

If we used H's example of viscosity as a 4 year old and you talked to an infant about viscosity then that linking ... the actual thought processes that child uses to try and understand those words are different. So you'd use things like slippery and you'd possibly change those words around to suit the child's age and or knowledge and ability of science.

While Participant 4 commented that viscosity was something she had previously not heard of and found the experience had also increased her personal scientific knowledge base.

In this narrative the home is the primary source of the child's interest. This may not only be from the child's father's scientific interest but also the non-fiction DVD Little Einstein. As the child's aunt, Participant 6, comments: "That comes from ... He watches Little Einstein. I always thought it was a cartoon but I think it must take 
quite a science-y turn sometimes and that really gets his attention" (Participant 6, Focus group interview). The narrative not only demonstrates teachers following a child's interest and learning from that child, but also raises questions for further thought.

- What would have happened if none of the participants had known about viscosity?

- In which case, how might the teachers have limited or enhanced the child's working theory of viscosity?

- How effective is the continuity of learning between the child's learning environments, of the home and the educational setting, when one environment lacks content knowledge in the child's learning interest?

- Do teachers, in these cases, rely on the home environment to solely support children's scientific learning? 


\section{Appendix R: The sandpit story: A narrative}

(an extract from Participant 6 Interview 2)

"He was just building a sand castle. He's built one just before this which didn't work because he was using dry sand. And he tried it again with dry sand and he was talking about using 'sugar'. Which is what they call dry sand. And so we talked about 'I'm patting it down."'

\section{Researcher: What scientific things do you think he was investigating?}

"Just the difference between wet and dry sand."

Researcher: Did he initiate it? "Yep. When the first one didn't work he said, 'I can't do it.' And then we used more wet sand but the whole sand pit was quite dry and so we were just talking about that and how they couldn't make anything properly because it wouldn't stick together. And so I'd asked what they'd needed to stick it together and they said 'water.' So that's the next photo and they're pouring it in to mix up the sand."

"They decided to make a river and so we moved right away from sand castles and they were talking about it following the path as well $\cos \mathrm{H}$ had dug a curved path from $\mathrm{M}$ to him. So he's just saying how it was going to M. And they talked about how it was mud now and not sand anymore because it was all sloppy. And how they needed to add more sand to make it less sloppy and more sticky. Except they used different words but I can't remember what the words are now, I was going to write it down. Harder they said something about making it harder."

\section{(Later in the interview)}

"After it got really sloppy they started talking about making wombat soup. And I said did they know what a wombat was and neither of them did. So we actually at the big group mattime we got the computer out and looked up the picture of a wombat. Yeah, so it kinda ended up taking a different feel. I
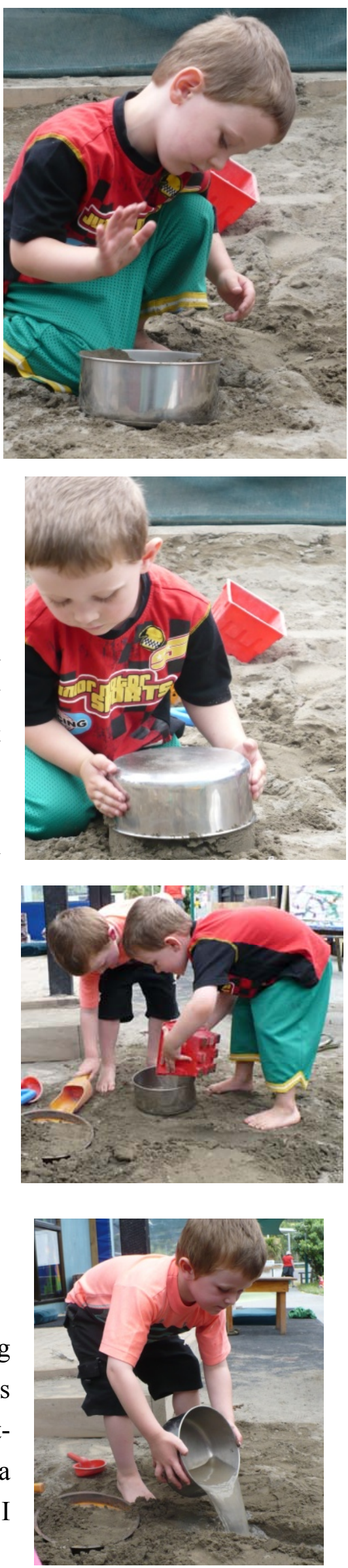
didn't talk through the sand cos I didn't know how to explain it about wet and dry and those sorts of, but then they were talking a lot and generating their own ideas. I just went off what I already knew, I guess."

This narrative not only demonstrates the rapidly changing nature of children's learning as an interest in mixing sand and water, it is followed by a focus on creating rivers, then one on making imaginary wombat stew, and finally investigating what wombats look like on the computer with other children. It also illustrates the integrated nature of early childhood learning as the teacher supported the children in the traditional

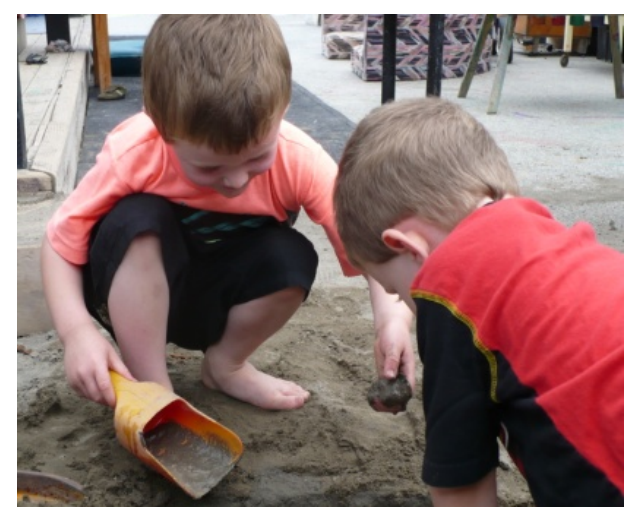
curriculum areas of science, technology, mathematics, literacy, drama, and physical development during the one situation. 


\section{Appendix S: Participant Teaching Strategies Comparison}

\begin{tabular}{|c|c|c|}
\hline Edwards, 2009 & Participant rate & Hipkins et. al., 2002 \\
\hline Drawing child's attention to a phenomena & 3 of 6 & Science content knowledge held by teacher \\
\hline Invite child to engage & 2 of 6 & Engaged in formative interactions to help students as they learnt \\
\hline Offer options to extend & 5 of 6 & Engaged in formative interactions to help students as they learnt \\
\hline Not 'over guide' & 2 of 6 & Teachers modelled and scaffolded conversations \& investigative skills \\
\hline Being there & 2 of 6 & Teachers modelled and scaffolded conversations \& investigative skills \\
\hline Ask open ended questions & all & The purpose of the learning was made clear \\
\hline Support children's learning & all & Science content knowledge held by teacher \\
\hline Communicate content ideas & 4 of 6 & Science content knowledge held by teacher \\
\hline Encourage dispositions & 2 of 6 & Teachers modelled and scaffolded conversations \& investigative skills \\
\hline Giving prompts & 3 of 6 & Science content knowledge held by teacher \\
\hline Provoke thinking & 5 of 6 & Students were engaged in thinking about their own thinking \\
\hline Recognise \& encourage working theories & all & Science content knowledge held by teacher \\
\hline Revisit situations observed & 1 of 6 & The purpose of the learning was made clear \\
\hline Engage in learning with the child & all & Engaged in formative interactions to help students as they learnt \\
\hline Observe child & all & Science content knowledge held by teacher \\
\hline Follow child's interest & all & The purpose of the learning was made clear \\
\hline Finding out child's prior knowledge & 3 of 6 & Learners existing ideas and beliefs incorporated \\
\hline Link to home experiences & 2 of 6 & Learners existing ideas and beliefs incorporated \\
\hline Link from centre experiences & 5 of 6 & Learners existing ideas and beliefs incorporated \\
\hline Reflect on teaching incidents & all & \\
\hline Provide new experiences & 2 of 6 & Science content knowledge held by teacher \\
\hline Use resources & all & Science content knowledge held by teacher \\
\hline Get additional resources & 5 of 6 & Science content knowledge held by teacher \\
\hline Specific teaching strategy & 5 of 6 & Teachers modelled and scaffolded conversations \& investigative skills \\
\hline Learning with or from the child & all & Engaged in formative interactions to help students as they learnt \\
\hline Joint learning & 3 of 6 & Engaged in formative interactions to help students as they learnt \\
\hline Set up environment & 4 of 6 & Science content knowledge held by teacher \\
\hline Planned activity & all & Science content knowledge held by teacher \\
\hline
\end{tabular}




\begin{tabular}{|c|c|c|}
\hline Edwards, 2009 & Participant rate & Hipkins et. al., 2002 \\
\hline Planned project & 3 of 6 & Science content knowledge held by teacher \\
\hline Encourage peer learning & all & Engaged in formative interactions to help students as they learnt \\
\hline Specific teaching point & 4 of 6 & Science content knowledge held by teacher \\
\hline Document child's learning & all & The purpose of the learning was made clear \\
\hline Flexible planning & 3 of 6 & Science content knowledge held by teacher \\
\hline \multirow[t]{2}{*}{ Provide environmental resources } & 3 of 6 & Science content knowledge held by teacher \\
\hline & None & Conceptual \& procedural knowledge \& NOS developed together \\
\hline
\end{tabular}

